
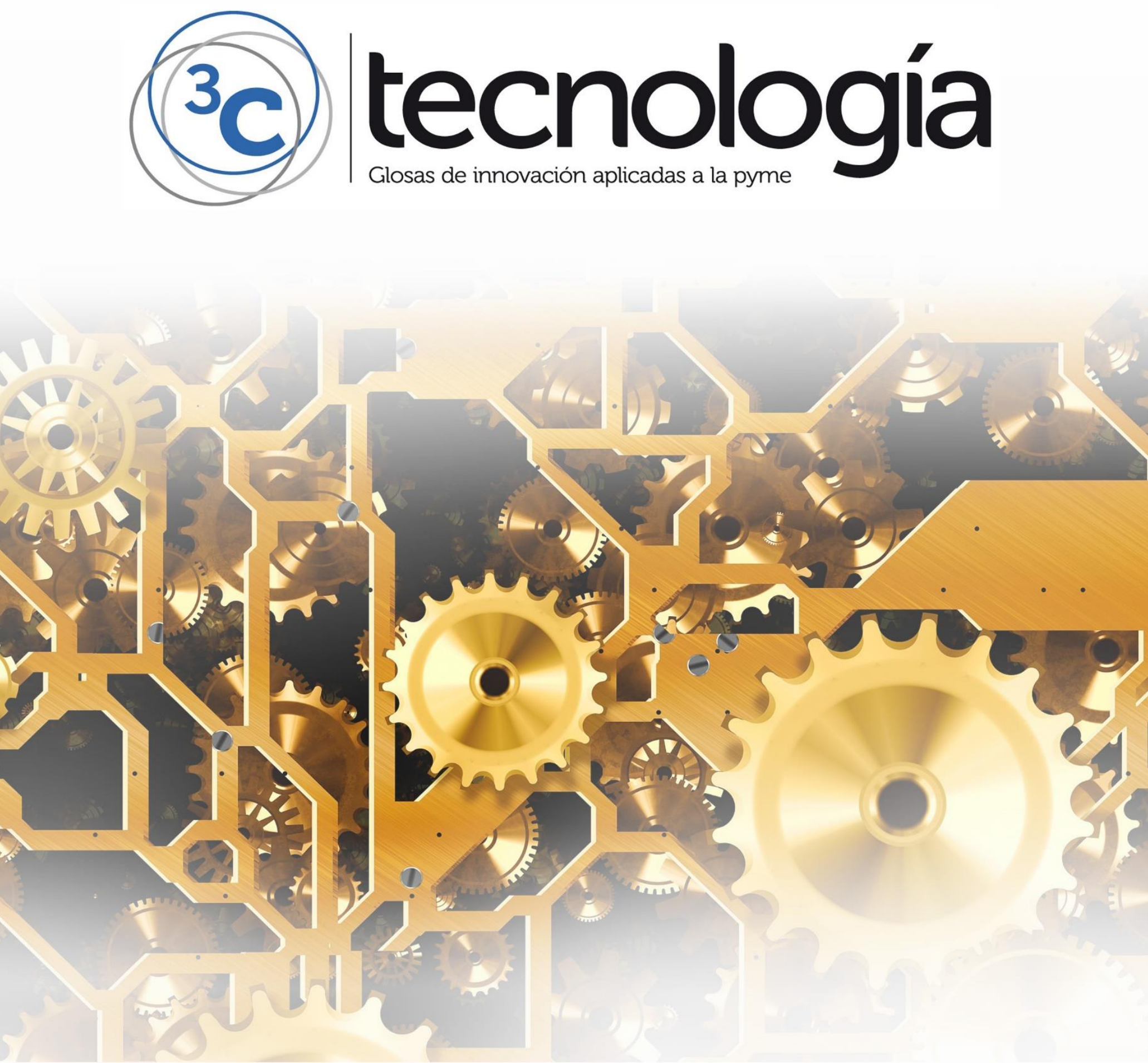

$$
\begin{aligned}
& \text { Edición } 23 \\
& \text { Vol. } 6 \text { № } 3 \text { (2017) } \\
& \text { Septiembre - diciembre'17 } \\
& \text { ISSN: } 2254 \text { - } 4143 \\
& \text { Publicación trimestral }
\end{aligned}
$$

Depósito legal: A299-2012 Área de Innovación y Desarrollo, S.L 


\section{INDIZADO POR/ INDEXED BY}

PLATAFORMA DE EVALUACIÓN DE REVISTAS

\begin{tabular}{|c|c|c|}
\hline Matriu d'Informació \\
per a 'Avaluació de Revistes
\end{tabular}




\section{OBJETIVO EDITORIAL}

La Editorial científica 3Ciencias pretende transmitir a la sociedad ideas y proyectos innovadores, plasmados, o bien en artículos originales sometidos a revisión por expertos, o bien en los libros publicados con la más alta calidad científica y técnica.

\section{NUESTRO PÚBLICO}

- Personal investigador.

- Doctorandos.

- Profesores de universidad.

- Oficinas de transferencia de resultados de investigación (OTRI).

- Empresas que desarrollan labor investigadora y quieran publicar alguno de sus estudios.

\section{COBERTURA TEMÁTICA}

La Revista 3C Tecnología es una revista de carácter científico-social donde se difunden trabajos originales de investigación que abarcan diferentes temáticas relacionadas con la ingeniería y la tecnología.

\section{INFORMACIÓN PARA AUTORES}

Toda la información sobre el envío de originales se puede encontrar en el siguiente enlace: http://www.3ciencias.com/normas-de-publicacion/instrucciones-para-el-envio-dearticulos/.

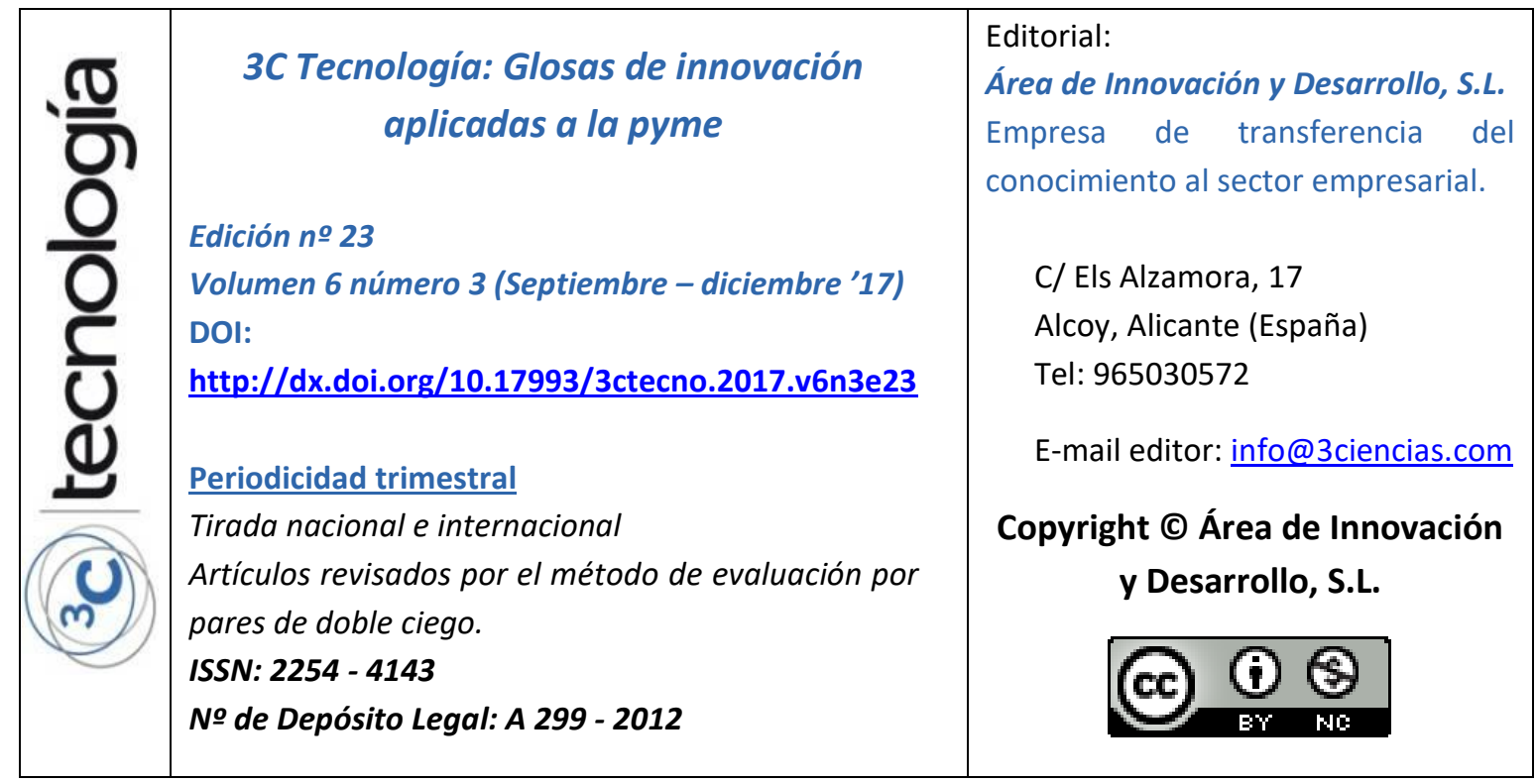




\section{PUBLISHING GOAL}

3 Ciencias wants to transmit to society innovative projects and ideas. This goal is reached thought the publication of original articles which are subdue to peer review or thorough the publication of scientific books.

\section{OUR PUBLIC}

- Research staff.

- PhD students.

- Professors.

- Research Results Transfer Office.

- Companies that develop research and want to publish some of their works.

\section{TEMATIC COVERAGE}

3C Tecnología journal is a scientific-social journal, where original works are disseminated. These works cover different themes related to engineering and technology.

\section{INSTRUCTIONS FOR AUTHORS}

All information about sending originals can be found at the following link: http://www.3ciencias.com/normas-de-publicacion/instrucciones-para-el-envio-dearticulos/ 
UN MÉTODO EMPÍRICO PARA LA SELECCIÓN DE MODELOS DE GESTIÓN DE TESORERÍA

AN EMPIRICAL METHOD TO SELECT CASH MANAGEMENT MODELS

Francisco Salas-Molina

ESTÁNDARES CRIPTOGRÁFICOS APLICADOS A LA INFRAESTRUCTURA DE CLAVE PÚBLICA DE AMÉRICA DEL SUR

CRYPTOGRAPHIC STANDARDS APPLIED TO THE PUBLIC KEY INFRAESTRUCTURE IN SOUTH AMERICA.

Aida D. Ormaza Vintimilla, José A.Carrillo Zenteno y Francisco J. Bolaños Burgos

IMPORTANCIA DE LOS ENTORNOS MOOCS PARA LA DIVULGACIÓN DE CONOCIMIENTOS ACADÉMICOS EN ENTORNOS UNIVERSITARIOS

IMPORTANCE OF THE MOOCS ENVIRONMENTS FOR THE DISSEMINATION OF ACADEMIC KNOWLEDGE IN UNIVERSITY ENVIRONMENTS

Roberto W. Acuña Caicedo, Christian R. Caicedo Plúa, Antonieta C. Rodríguez Gonzalez y Grace L. Figueroa Morán

ANÁLISIS DOCUMENTAL DE LOS INCONVENIENTES DE LA IMPRESIÓN 3D 48 DOCUMENTARY ANALYSIS OF THE DISADVANTAGES OF 3D PRINTING Leydy Gómez Reyes

ESTADO DEL ARTE: METODOLOGÍAS DE DESARROLLO EN APLICACIONES WEB 54 STATE OF ART: DEVELOPMENT METHODOLOGIES IN WEB APPLICATIONS Jimmy R. Molina Ríos, Mariuxi P. Zea Ordónez, María J. Contento y Fabricio G. García Zerda 


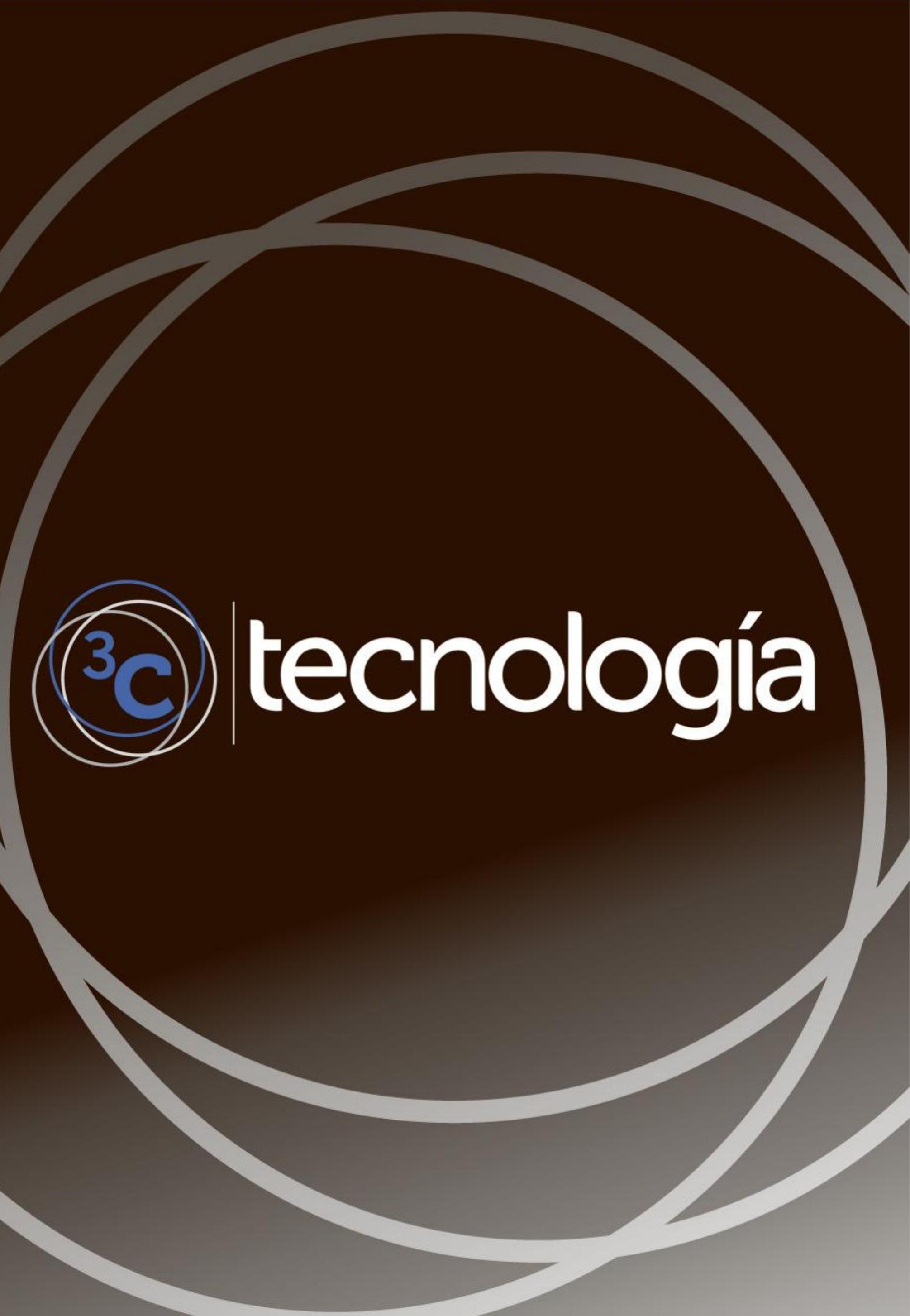




\section{UN MÉTODO EMPÍRICO PARA LA SELECCIÓN DE MODELOS DE GESTIÓN DE TESORERÍA}

\section{AN EMPIRICAL METHOD TO SELECT CASH MANAGEMENT MODELS}

Francisco Salas-Molina ${ }^{1}$

1. Ingeniero de Organización Industrial y Master en Creación de Empresas de Base Tecnológica. Director de I+D y Sistemas de Información en Hilaturas Ferre, S.A., Banyeres de Mariola, Alicante, (España). E-Mail: francisco.salas.molina@gmail.com

Citación sugerida:

Salas-Molina, F. (2017). Un método empírico para la selección de modelos de gestión de tesorería. $3 C$ Tecnología: glosas de innovación aplicadas a la pyme, 6(3). 1-13. DOI: $<$ http://dx.doi.org/10.17993/3ctecno.2017.v6n3e23.1-13/>. 


\section{RESUMEN}

La creciente posibilidad de acceder a grandes bases de datos transaccionales ha potenciado enormemente las finanzas corporativas empíricas. En este trabajo, proponemos explotar la dimensión empírica de la gestión de tesorería. Para ello, aplicaremos técnicas de (big) data sobre flujos de caja empíricos que son cruciales para la selección y ajuste de modelos de gestión de tesorería.

\section{ABSTRACT}

The increasing possibility to access big transactional data bases has boosted empirical corporate finance. In this work, we propose to exploit the empirical dimension of cash management. To this end, we apply (big) data techniques to empirical cash flows that are crucial to the selection and setting of cash management models.

\section{PALABRAS CLAVE}

Big data, finanzas, gestión de tesorería, previsión, control.

\section{KEY WORDS}

Big data, finance, cash management, forecasting, control. 


\section{INTRODUCCIÓN}

La gestión de tesorería se ocupa de la planificación y el control de los recursos financieros de la empresa a corto plazo. Desde un punto de vista cuantitativo, el objetivo básico es decidir qué cantidad de recursos se mantienen en caja por motivos operacionales, de precaución o incluso de especulación (Ross, 2002). Implícitamente, esta decisión supone invertir a corto plazo los recursos excedentes para obtener un ingreso financiero.

La investigación sobre la gestión de tesorería ha seguido un camino central caracterizado por modelos de gestión de tesorería basados en límites de control a partir del modelo de Miller (1966). Desde los años 60 del pasado siglo, los investigadores han propuesto un buen número de modelos alternativos que trataban de resolver alguna limitación de los anteriores o de considerar algún aspecto que no había sido tenido en cuenta (da Costa Moraes, 2015).

Desde un punto de vista práctico, el tesorero de una empresa se enfrenta a tarea cuya resolución no es en modo alguno trivial: decidir qué modelo debe aplicar su empresa y por qué razón. Comprender la metodología que hay detrás de decenas de propuestas y, sobre todo, verificar si se cumplen las asunciones de partida de estas propuestas en cada caso concreto es una tarea cuanto menos compleja.

Las negativas consecuencias que se podrían derivar de tomar decisiones sin un completo análisis de cada situación, justifican la dedicación de los esfuerzos necesarios para mejorar la gestión de una disciplina financiera habitualmente poco automatizada. De hecho, cualquier empresa con beneficios puede cesar su actividad si no es capaz de mantener un nivel mínimo de tesorería para sus operaciones habituales.

En la actualidad, uno de los recursos al alcance de cualquier tesorero es la gran cantidad de datos que continuamente se va generando en su empresa. Desgraciadamente, la dimensión empírica de las finanzas no se ha desarrollado a la misma velocidad que su dimensión teórica. Esta circunstancia representa un obstáculo a la hora de trasladar a la práctica diaria los resultados de la investigación en el ámbito de las finanzas.

Por todo ello, este trabajo pretende mejorar la toma de decisiones basadas en datos en el ámbito de la gestión de tesorería basado en tres aspectos básicos como se muestra en el Gráfico 2. En primer lugar, los datos constituyen la materia prima fundamental con la que ajustar y validar un modelo de gestión de tesorería. El estudio empírico de los datos facilita la comprensión de los modelos más avanzados de gestión de tesorería. Finalmente, estos modelos permiten una toma de decisiones más eficiente $y$, hasta cierto punto, automatizada 


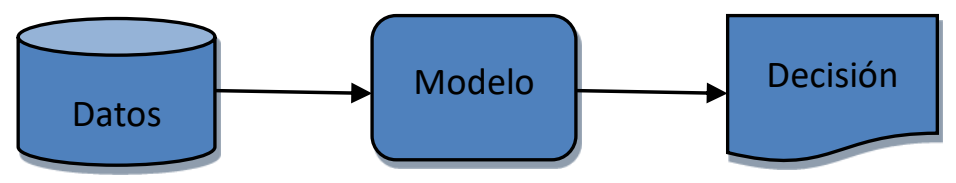

Gráfico 1. Decisiones basadas en datos.

Fuente: elaboración propia.

A continuación, tras analizar las principales dimensiones del problema de gestión de tesorería, se ofrecen directrices para el análisis empírico de los flujos de caja de una empresa. Las conclusiones de este análisis son cruciales para la selección de alguno de los modelos propuestos en la literatura. Adicionalmente, se propone un método para la validación empírica del modelo a partir de técnicas de (big) data. Como resultado final, se describe un método para seleccionar el modelo de gestión de tesorería más adecuado para una empresa a partir de datos empíricos.

\section{SELECCIÓN EMPÍRICA DE MODELOS DE GESTIÓN DE TESORERÍA}

La gestión de tesorería tiene como objetivo principal hacer un uso eficiente de los recursos financieros a corto plazo de una empresa. Para ello, el enfoque habitual propuesto en la literatura plantea el problema de gestión de tesorería desde una perspectiva de control. Básicamente, el tesorero dispone en cada momento de cierto nivel de efectivo cuyo nivel tiene que controlar para mantenerlo entre ciertos niveles que se consideran adecuados para evitar tanto saldos negativos como saldos excesivos que podrían estar generando un determinado ingreso financiero.

A continuación analizamos las principales dimensiones del problema de gestión de tesorería como marco de trabajo para nuestra posterior propuesta metodológica.

\subsection{DIMENSIONES DEL PROBLEMA DE GESTIÓN DE TESORERÍA}

De la literatura sobre gestión de tesorería es posible extraer una serie de aspectos o dimensiones del problema de gestión de tesorería que habitualmente son analizados para conseguir una mejor comprensión del problema. Estas dimensiones se recogen en el Gráfico 2. 


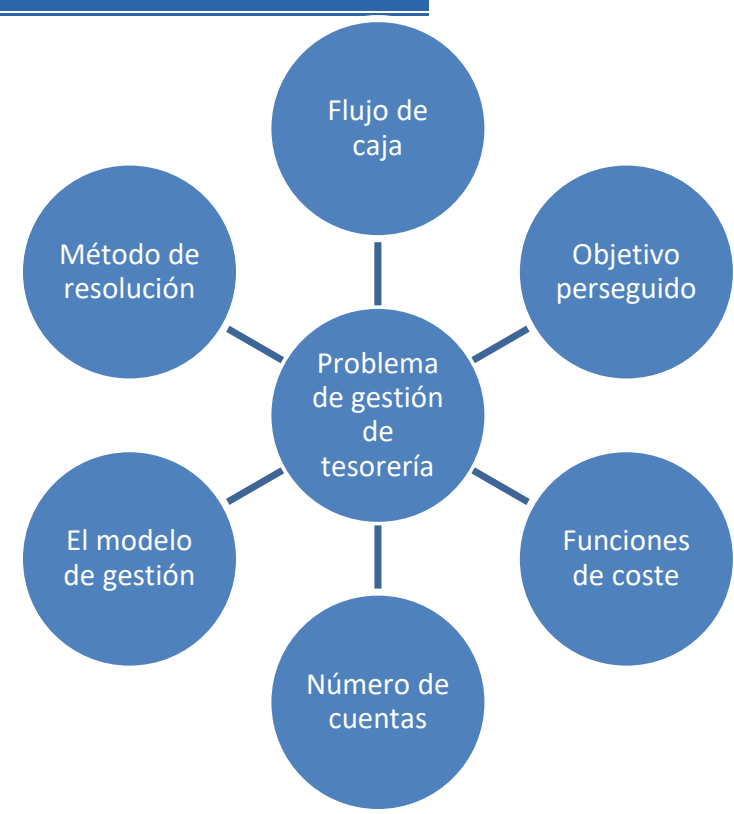

Gráfico 2. Las dimensiones del problema de gestión de tesorería.

Fuente: elaboración propia.

Aunque no es necesario seguir un orden estricto para abordar las diferentes dimensiones del problema de gestión de tesorería, sí que conviene seguir cierto orden lógico ya que las decisiones que se tomen en una dimensión pueden afectar al resto de dimensiones. Debido a su importancia, en este trabajo proponemos que el análisis comience en el flujo de caja y se desarrolle en sentido horario según el Gráfico 2.

El flujo de caja y sus principales propiedades estadísticas constituyen la dimensión clave de la gestión de tesorería. De hecho, la propuesta metodológica que se describe en este trabajo está basada en el análisis empírico de los flujos de caja. Sin embargo, a pesar de que la hipótesis más extendida en la literatura acerca de la distribución estadística de los flujos de caja es la de normalidad, hay pocas evidencias empíricas en este sentido sino más bien al contrario (Pindado, 1996). Esta circunstancia marca necesariamente la selección del modelo tal como se argumenta a continuación.

El objetivo perseguido por el decisor es principalmente la minimización de costes. Sin embargo, recientemente están apareciendo nuevas propuestas de optimización multiobjetivo en las que tanto el coste como el riesgo son tenidos en cuenta para obtener las mejores estrategias (Salas-Molina et al., 2016).

La definición de las funciones de coste que formarán parte de la función objetivo a optimizar es la siguiente dimensión del problema de gestión de tesorería. Tal como se muestra en el Gráfico 3, los costes considerados habitualmente en la gestión de tesorería son los de mantenimiento (por tener un saldo de caja improductivo) y los de transacción (por transferir parte del saldo a determinadas inversiones financieras temporales). 


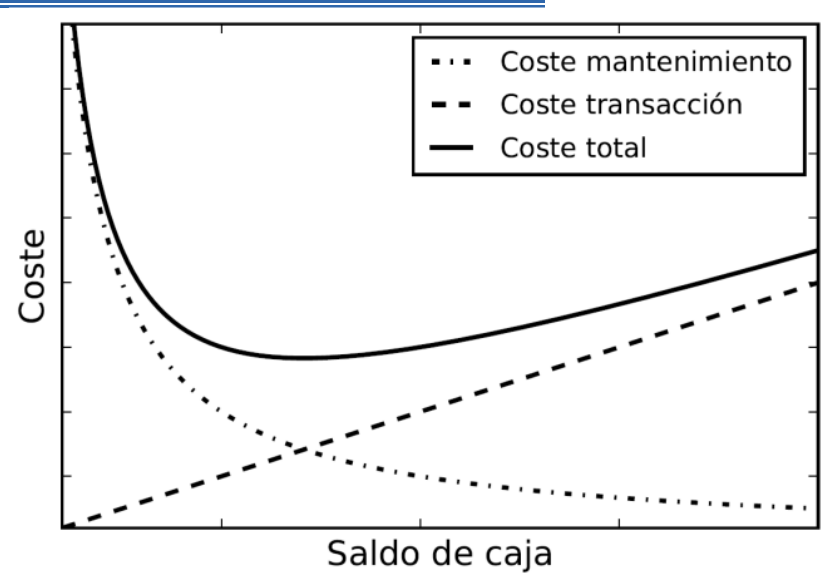

Gráfico 3. Costes de la gestión de tesorería. Fuente: elaboración propia.

Por otro lado, el marco de análisis habitual en la gestión de tesorería contempla dos tipos de activos: una cuenta de efectivo y una cuenta de inversión. En ambos casos, estas cuentas agregan los saldos disponibles en las posibles distintas cuentas de efectivo y de inversión con las que se trabaje.

Otro de los aspectos críticos en la gestión de tesorería es el modelo utilizado para definir las acciones de control necesarias para mantener el saldo entre los niveles deseados al tiempo que se minimizan las funciones de coste establecidas. En este caso, el abanico de disponibilidad es lo suficientemente grande como para plantear ciertas dudas que tratamos de resolver en este trabajo. Uno de los más relevantes es el modelo de Miller y Orr (1966) que está basado en tres niveles de manera que cuando el saldo alcanza el nivel superior ( $h$ ) o el inferior (I), la acción de control lleva el saldo de nuevo al nivel medio (z), tal como se muestra en el Gráfico 4.

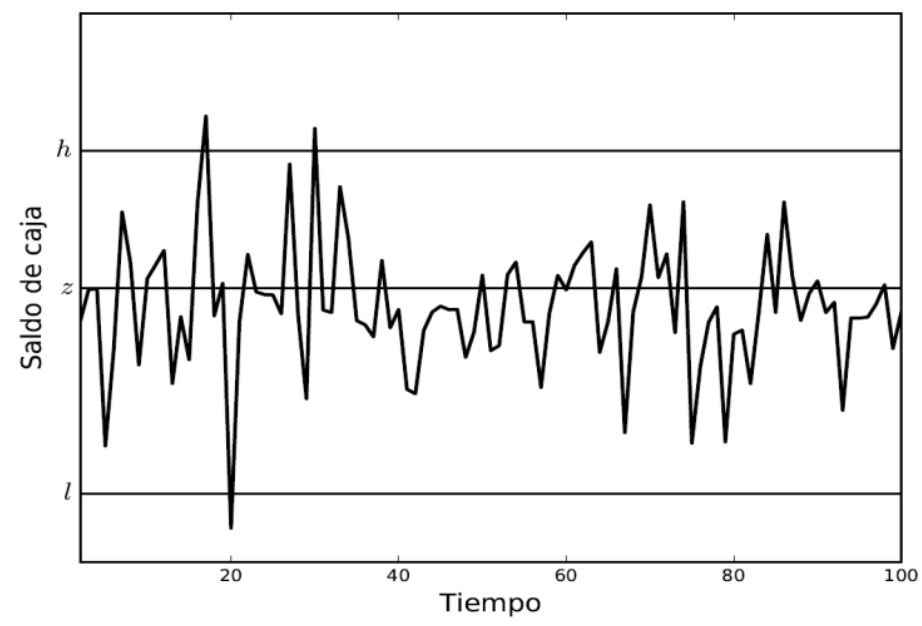

Gráfico 4. El modelo de Miller y Orr.

Fuente: elaboración propia. 
La última de las dimensiones está íntimamente relacionada con la selección del modelo gestión de tesorería. No solamente hay que seleccionar un modelo sino también hay que ajustar los parámetros de control inherentes al modelo. Por ejemplo, en el modelo de MillerOrr habría que determinar los parámetros $h, z$, y I. En este aspecto, también existe una gran variedad de métodos de resolución con complejidad variable desde la aplicación de una fórmula matemática (Miller y Orr, 1966) a la utilización de algoritmos genéticos (Gormley y Meade, 2007).

Una vez que ya conocemos las principales dimensiones de la gestión de tesorería, podemos plantearnos cómo un análisis empírico puede despejar algunas de las dudas a la hora seleccionar un modelo de gestión.

\subsection{ANÁLISIS EMPÍRICO DE LOS FLUJOS DE CAJA}

La primera cuestión que debemos hacernos al abordar el problema de gestión de tesorería es con qué materia prima vamos a trabajar o, en otras palabras, con qué tipo de flujos de caja contamos. No todos los flujos de caja son iguales. Los hay mayores y menores, ciertos e inciertos. Los flujos de caja mayores son todos aquellos de los que se conoce con exactitud tanto el importe como la fecha en la que se producirán. Algunos ejemplos son los vencimientos de préstamos, los pagos de impuestos, nóminas o dividendos. Los flujos de caja menores son todos aquellos sobre los que existe cierta incertidumbre tanto sobre el importe como en la fecha en que se producirán. El ejemplo más claro de flujo de caja menor son los cobros de clientes. Aunque exista un importe y una fecha de pago acordada, es bastante habitual que ni el primero ni la segunda acaben cumpliéndose.

La separación de los flujos de caja por tipo puede hacerse aún más detallada si somos capaces de identificar cuáles son sus componentes más importantes. Los componentes más evidentes del flujo de caja son los cobros y los pagos, pero podemos ir un poco más allá y realizar una separación por naturaleza, por origen o por destino, o por cualquier otro criterio. Por ejemplo, pagos a proveedores de materia prima, pagos a proveedores de financiación, pagos a proveedores de servicios de electricidad, de agua, de gas, de material de oficina. La separación puede ser todo lo minuciosa que nos interese. Esta separación puede resultar de gran utilidad debido a que es probable cada componente tenga unas características diferentes.

De la división de flujos de caja entre mayores o menores se deriva una primera consecuencia importante. Los flujos de caja mayores se conocen con exactitud y, por tanto, son fácilmente predecibles. Diremos de ellos que forman la parte determinista de nuestros flujos de caja totales. La parte restante, que llamaremos estocástica, merece un análisis estadístico en profundidad.

Las asunciones más comunes en la literatura sobre las propiedades estadísticas suponen que los flujos de caja son: 
- Normales: cuando las observaciones se distribuyen simétricamente alrededor de un valor medio y con una varianza finita según la curva de Gauss.

- Independientes: cuando las observaciones actuales no están correlacionadas con observaciones pasadas.

- Estacionarios: cuando la media y la varianza de las observaciones no varían con el tiempo.

Sin embargo, existe poca evidencia empírica sobre el cumplimiento de estas condiciones cuando se analizan datos reales. La forma más habitual de comprobar el cumplimiento de estas condiciones es mediante la utilización de un test estadístico. Por ejemplo, el test de Kolmogorov-Smirnov para normalidad o el test de Ljung-Box test para independencia, o el test de Dickey-Fuller para estacionariedad. Otros métodos más intuitivos son el cálculo de los coeficientes de asimetría y curtosis para comprobar la normalidad, los mapas de Poincaré para independencia, o los gráficos de medias y varianzas móviles para estacionariedad.

En este punto, es importante recordar que calificar de estocásticos los flujos de caja no significa que sean impredecibles. De hecho, la estacionalidad y la existencia de posibles patrones ocultos en los datos es una cuestión ampliamente estudiada y que puede ser utilizada en beneficio de la reducción de costes (Salas-Molina et al., 2017). En este sentido, la aplicación de técnicas de (big) data para la previsión de los flujos de caja a partir de un conjunto de variables explicativas constituye un elemento crucial en la selección empírica del modelo de gestión de tesorería más adecuado para cada empresa.

\subsection{SELECCIÓN DEL MODELO BASADA EN DATOS}

Para abordar la selección de modelos de gestión de tesorería consideremos la siguiente situación que puede darse con frecuencia. Un tesorero desea empezar a controlar el saldo de sus cuentas mediante un modelo de gestión de tesorería. A priori, un modelo sencillo con tres niveles de control como el de Miller y Orr (1966) representado en el Gráfico 3, no le parece complicado de implementar. Para determinar estos niveles de control, nuestro tesorero descubre con alivio que simplemente tiene que aplicar unas fórmulas sencillas que dependen de la desviación típica de los flujos de caja y de los costes de mantenimiento y transacción. Finalmente se da cuenta de que estas fórmulas sólo son óptimas cuando los flujos de caja son normales, independientes y estacionarios (NIE). Tras realizar un análisis empírico de sus datos de flujo de caja tal como se describe en la sección anterior, los resultados muestran que estas condiciones no se cumplen.

Del análisis de este tipo de situaciones se derivan dos cuestiones centrales para la gestión de tesorería:

1. ¿Qué modelo elegir? (Dimensión modelo)

2. ¿Cómo ajustar y validar el modelo elegido? (Dimensión método de resolución) 
En esta sección abordaremos la primera de estas cuestiones y dejaremos la segunda para la siguiente sección. Para la selección inicial del modelo, nos basaremos principalmente en los resultados del análisis empírico: primero, en las hipótesis NIE; segundo, en la posibilidad de predecir los flujos de caja. Por tanto, se asume que disponemos de un conjunto de datos de flujos de caja históricos sobre los que trabajar.

Supongamos que tras el estudio empírico, se cumplen las NIE. En este caso, planteamos (por simplicidad) dos opciones: el modelo de Miller y Orr (1966) con tres niveles cuando los costes variables de transacción son nulos, y el modelo de Eppen y Fama (1968) con cuatro niveles cuando se soportan costes de transacción fijos y variables.

En el caso de que alguna de las NIE no se cumpla, es posible plantear alguna técnica de transformación de datos como la de Box-Cox para conseguir normalidad, o el cálculo de diferencias entre períodos consecutivos para conseguir independencia. Si aun así, no es posible cumplir las NIE podemos considerar modelos alternativos.

Supongamos ahora que tras aplicar alguna de las técnicas de previsión de series temporales (Salas-Molina et al., 2017), somos capaces de predecir con cierta precisión los flujos de caja que se van producir en los próximos días. En este caso planteamos dos nuevos modelos: el modelo de Stone (1972) basado en cinco niveles de control; y el modelo de Gormley y Meade (2007) basado en cuatro niveles. Ambos modelos utilizan previsiones de los flujos de caja futuros para decidir las acciones de control a establecer. El modelo de Stone acumula las previsiones de los próximos períodos con el objetivo de reducir el número de transacciones mientras que el modelo de Gormley y Meade plantea una acción de control para cada período de tiempo. En este caso, no hay una razón clara para decantarse por uno u otro. La selección definitiva dependerá en última instancia de un aspecto adicional que ya hemos apuntado: el ajuste y la validación del modelo.

\subsection{AJUSTE Y VALIDACIÓN DEL MODELO}

Por ajuste del modelo, nos referimos a la selección de los parámetros o niveles de control necesarios para realizar las transacciones oportunas. Por validación del modelo, nos referimos a algún procedimiento basado en datos que permita comparar el modelo con otros modelos alternativos o incluso con una estrategia trivial, por ejemplo, si no aplicáramos ninguna acción de control.

Para la determinación de los niveles de control, los autores de los modelos propuestos propusieron distintos métodos. Mientras que Eppen y Fama utilizó programación dinámica, Stone simplemente sugería la simulación cómo método para calcular los niveles. Más recientemente, Gormley y Meade recomienda el uso de algoritmos genéticos. La gran variedad de métodos propuestos hacen del ajuste del modelo una tarea complicada cuando se barajan distintas opciones.

Con el objetivo de resolver esta limitación, en este trabajo proponemos realizar el ajuste de cualquier modelo basado en niveles mediante simulación Monte Carlo tal como se describe 
en Salas-Molina et al. (2016). Las técnicas de simulación Monte Carlo se basan en la realización de un número elevado de experimentos que posteriormente son evaluados de acuerdo con una función objetivo dada. La ley de los grandes números asegura que las estimaciones derivadas de este análisis convergen a los valores reales a medida que el número de experimentos aumenta. Este tipo de técnicas son especialmente útiles cuando existe un número finito de posibles combinaciones a evaluar como es el caso de la selección de niveles de control discretos entre un valor mínimo y un valor máximo.

El paso final de nuestra propuesta de selección de modelos de gestión de tesorería, es una validación empírica basada en un concepto ampliamente utilizado en el ámbito del (big) data: la validación cruzada. La idea básica de la validación cruzada es separar el conjunto de datos disponibles en dos partes: la primera parte se utilizará para ajustar el modelo (training set); y la segunda se utilizará para validar el modelo (test set). Por ejemplo, podemos utilizar el $80 \%$ de los datos de flujo de caja más antiguos para calcular los mejores límites de control del modelo. Posteriormente, utilizaremos el $20 \%$ restante para evaluar el comportamiento del modelo con datos que no han sido utilizados para ajustar el modelo. En la medida en que el desempeño del modelo en ambos conjuntos de datos sea similar se puede decir que el modelo generaliza bien y, por tanto, queda validado por los datos disponibles.

Tanto el método de ajuste de modelos de gestión de tesorería basado en técnicas de Monte Carlo como la validación cruzada son métodos generales que permiten contemplar un elevado número de modelos. Este hecho facilita la comparación entre modelos de manera que puedan disiparse empíricamente las dudas sobre la utilización de un modelo u otro. Esta comparación debe realizarse no sólo entre modelos propuestos en la literatura sino también con respecto a modelos triviales basados en reglas sencillas. Este ejercicio garantiza que los esfuerzos realizados en la mejora de la toma de decisiones en la gestión de tesorería tienen sentido. 


\section{RESULTADOS}

Como resultado final de la metodología propuesta en este trabajo, el Gráfico 5 presenta un resumen visual de los pasos a seguir para la selección empírica de modelos de gestión de tesorería.

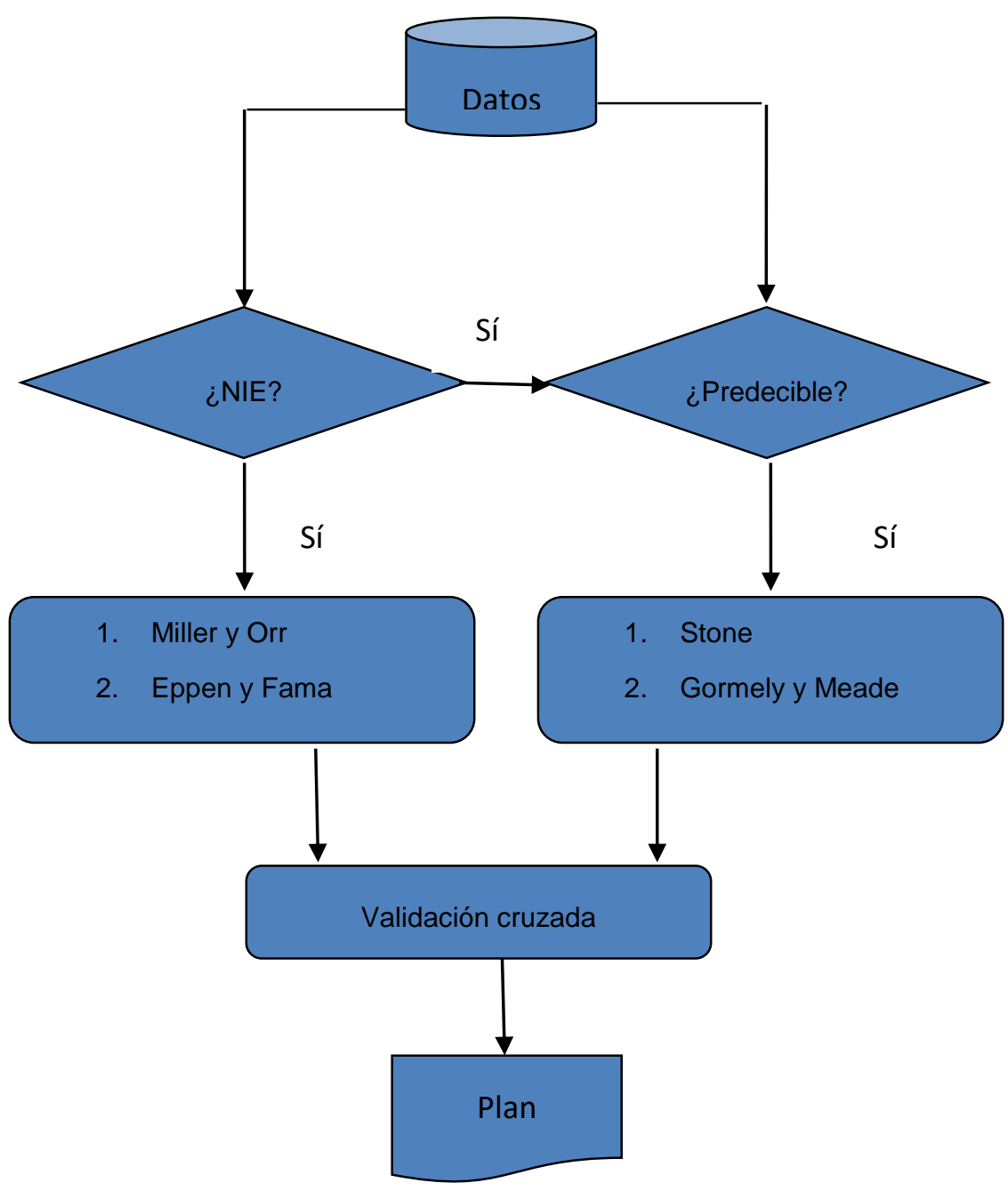

Gráfico 5. Selección empírica de modelos de gestión de tesorería.

Fuente: elaboración propia.

Como no puede ser de otra manera, la condición inicial para iniciar el proceso es la disponibilidad de una base de datos con los que trabajar. En este sentido, es importante destacar que no sólo es conveniente disponer de los flujos de caja sino de cualquier otro tipo de dato que pueda ser relevante para la extracción de patrones de comportamiento del flujo de caja. Además, si se pretende hacer una separación entre flujos de caja mayores y menores, será necesario disponer de los datos necesarios para la identificación de tales flujos.

Conviene recordar que la metodología descrita en el Gráfico 4 hace referencia a los flujos de caja menores ya que aquellos flujos de caja que se conocen con exactitud quedan fuera del 
análisis empírico. En la práctica, estos flujos de caja mayores serán considerados como datos de partida ciertos en la aplicación del modelo finalmente seleccionado.

El análisis empírico de los flujos de caja pretende responder dos preguntas cruciales para la selección del modelo. La primera es si se cumplen las hipótesis NIE. La segunda es si es posible obtener previsiones de los flujos caja que puedan utilizarse como entrada al modelo. La respuesta a estas cuestiones determinará el tipo de modelo que conviene elegir. Aunque ambas cuestiones no son incompatibles, obviamente la utilización de modelos que utilicen previsiones solo es posible si se utiliza algún modelo de previsión.

El paso previo a la utilización del modelo es la validación cruzada mediante la utilización de un training set y de un test set. Aunque por coherencia se omite en el Gráfico 4, en el caso de que la respuesta a las dos preguntas sea negativa no existe ninguna razón para descartar la posibilidad de realizar una validación cruzada de un modelo sin previsiones y evaluar su desempeño.

Finalmente, el modelo de gestión de tesorería que ha sido validado por los datos disponibles, puede empezar a utilizarse para planificar la toma de decisiones basadas en datos tal como se proponía en el Gráfico 1.

\section{CONCLUSIONES}

Parece evidente que la cantidad de datos disponible en las empresas para la toma de decisiones va a continuar creciendo de manera notable en los próximos años. Estos datos están ahí para quien los necesite, para quien quiera obtener un provecho de ellos. Desaprovechar este importante recurso para la toma de decisiones es equivalente a dejar el grifo de agua abierto malgastando un bien muy valioso.

En el ámbito de la gestión de tesorería, la utilización de modelos de gestión de tesorería puede contribuir a la mejora de la calidad de las decisiones financieras a corto plazo. La tesorería es el sistema circulatorio de la empresa y debe mantenerse en perfecto estado para evitar problemas indeseados. Sin embargo, la selección de uno de estos modelos no es una tarea sencilla. Para solucionar este problema, en este trabajo se ha propuesto una metodología empírica que partiendo de los datos disponibles en la empresa pretende seleccionar el modelo de gestión de tesorería más adecuado para cada empresa.

El análisis empírico de las características de los flujos de caja de una empresa constituye una primera contribución a la gestión de tesorería. Conocer qué tipo de componentes configuran el flujo de caja habitual de una empresa y qué propiedades estadísticas tienen ya aporta valor por sí mismo. Además, si la selección de modelos de gestión de tesorería está basada en este análisis empírico, la toma de decisiones estará mejor fundamentada.

Por último, el uso de técnicas de (big) data como las previsiones y la validación cruzada de modelos de gestión de tesorería son herramientas de gran utilidad para una toma de decisiones basada en datos en el ámbito de la gestión financiera a corto plazo. 


\section{REFERENCIAS BIBLIOGRÁFICAS}

da Costa Moraes, M. B., Nagano, M. S., \& Sobreiro, V. A. (2015). Stochastic cash flow management models: A literature review since the 1980s. Decision Models in Engineering and Management, 11-28.

Eppen, G. D., \& Fama, E. F. (1968). Solutions for cash-balance and simple dynamic-portfolio problems. The Journal of Business, 41(1), 94-112.

Gormley, F. M. and Meade, N. (2007). The utility of cash flow forecasts in the management of corporate cash balances. European journal of operational research, 182(2), 923-935.

Miller, M. H., \& Orr, D. (1966). A Model of the Demand for Money by Firms. The Quarterly journal of economics, 80(3), 413-435.

Pindado, J. and Vico, J. (1996). Evidencia empírica sobre los flujos de caja. Un nuevo enfoque en su tratamiento. Revista Española de Financiación y Contabilidad, 25(87), 497-517.

Ross, S. A., Westerfield, R., \& Jordan, B. D. (2002). Fundamentals of corporate finance (6th ed.). McGraw-Hill.

Salas-Molina, F., Pla-Santamaria, D., and Rodriguez-Aguilar, J. A. (2016). A multi-objective approach to the cash management problem. Annals of Operations Research. doi:10.1007/s10479-016-2359-1

Salas-Molina, F., Martin, F. J., Rodríguez-Aguilar, J. A., Serrà, J., and Arcos, J. L. (2017). Empowering cash managers to achieve cost savings by improving predictive accuracy. International Journal of Forecasting, 33(2), 403-415.

Stone, B. K. (1972). The use of forecasts and smoothing in control-limit models for cash management. Financial Management, 1(1), 72-84. 


\section{ESTÁNDARES}

\section{CRYPTOGRAPHIC STANDARDS APPLIED TO THE PUBLIC KEY INFRAESTRUCTURE IN SOUTH AMERICA}

Aida Diana Ormaza Vintimilla ${ }^{1}$ José Antonio Carrillo Zenteno ${ }^{2}$ Francisco Joseph Bolaños Burgos ${ }^{3}$

1. Analista e Ingeniero en Sistemas, Magister en Auditoría de Tecnologías de la Información, Universidad Espíritu Santo, (Ecuador). E-mail: aidaormaza@uees.edu.ec

2. Catedrático y Coordinador del Departamento de Investigación de la Universidad Católica de Cuenca, extensión Cañar. Analista e Ingeniero de Sistemas, Magister en Sistemas de la Información Gerencial, (Ecuador).E-mail: jacarrilloz@ucacue.edu.ec

3. Ingeniero en Computación, Especialización Sistemas de Información, Universidad Espíritu Santo, (Ecuador). E-mail: fcobolanos@uees.edu.ec

\section{Citación sugerida:}

Carrillo Zenteno, J.A., Ormaza Vintimilla, A.D. y Bolaños Burgos, F.J. (2017). Estándares criptográficos aplicados a la infraestructura de clave pública de América del Sur. 3C Tecnología: glosas de innovación aplicadas a la pyme, 6(3), 14-32. DOI: <http://dx.doi.org/10.17993/3ctecno.2017.v6n3e23.14-32/>. 


\section{RESUMEN}

Una de las principales aplicaciones de la criptografía es la protección de la información, asegurando la autenticación, confidencialidad, la integridad de los datos, y el no repudio, utilidad que ha sido aprovechada para dotar a firmas y certificados digitales de seguridad, siendo necesario el empleo de la Infraestructura de Clave Pública como un modelo de confianza.

\section{ABSTRACT}

One of the main applications of cryptography is the protection of information, which ensures authentication, confidentiality, data integrity, and non-repudiation. This useful application has been used to provide security to signatures and digital certificates, being necessary the employment of Public-Key infrastructure as a reliable model.

\section{PALABRAS CLAVE}

Estándares criptográficos, FIPS 140-2, Common Criteria, PKCS, América del Sur.

\section{KEY WORDS}

Cryptographic standards, FIPS 140-2, Common Criteria, PKCS, South America. 


\section{INTRODUCCIÓN}

Para Wollinger, Guajardo, \& Paar (2003) la criptografía proporciona a los datos servicios de autenticación, confidencialidad, integridad y no repudio. Dichos servicios son procurados mediante diversos algoritmos criptográficos, siendo uno de ellos el de clave pública. Además, al ser la clave pública el algoritmo utilizado en las firmas digitales es fundamental que la distribución de claves públicas y certificados hagan uso de la Infraestructura de Clave Pública (ICP), con el propósito de generar confianza y certeza en los datos y mensajes transmitidos, así como también el contar con normas y estándares internacionales aceptados que brinden mayor seguridad.

Es así que el empleo de normativas y estándares internacionales proveen de los elementos suficientes para que la Infraestructura de Clave Pública sea segura, por lo que muchos países han adoptado diferentes estándares para firmas y certificados digitales. A pesar de conocer que los mismos son aplicados y requeridos para certificar la integridad de los datos, no se cuenta con información sobre cuál de ellos es el más utilizado en América del Sur.

Por esta razón, el presente trabajo pretende analizar información sobre los estándares criptográficos aplicados a la Infraestructura de Clave Pública a fin de determinar cuáles han sido adoptados por los diferentes países de América del Sur. Se ha realizado una revisión bibliográfica partiendo de conceptos básicos sobre: criptografía y criptología, certificados firma electrónica, firma digital, firma digital avanzada infraestructura de clave pública; continuando con la exposición de información sobre los estándares como FIPS, Common Criteria y PKCS, y por último, presentando los estándares exigidos en los diferentes países.

\section{CRIPTOLOGÍA Y CRIPTOGRAFÍA}

La Criptología es la ciencia que trata sobre la seguridad en el intercambio de mensajes entre el emisor y el receptor, etimológicamente viene del griego krypto y logos que significa estudio de lo oculto (Fernández, 2004) y comprende conjuntamente el estudio de la criptografía y del criptoanálisis (Álvarez Sánchez, 2005). Por su parte, la criptografía es la ciencia de la escritura secreta con el objetivo de ocultar el significado de un mensaje (Paar \& Pelzl, 2010). Además, se encuentra relacionada con aspectos de seguridad de la información como: confidencialidad, integridad de datos, autenticidad y el no repudio (Castillo Rubí, M.A., Santana de la Cruz, Díaz Lobatón, Almanza Rodríguez, \& Castillo Rubí, F., 2011).

La criptografía se divide en: criptografía simétrica y criptografía asimétrica. En cuanto a la criptografía simétrica o de clave privada, esta se caracteriza por utilizar una clave para cifrar y descifrar. Los métodos empleados para el cifrado simétrico utilizan operaciones matemáticas que pueden ser programadas en algoritmos de computación sencillos y extremadamente rápidos (Whitman \& Mattord, 2012). Hay dos tipos de modos de cifrado de clave simétrica, uno es el cifrado de bloque y otro el cifrado de flujo; el primero funciona con grupos de bits llamados bloques, que son procesados varias veces, la clave aplicada es única en cada ronda y el segundo divide los datos tan pequeños como bits individuales, realizando el cifrado a continuación (Bisht \& Singh, 2015). 
Por otra parte, la criptografía asimétrica o de clave pública, utiliza dos claves diferentes, una pública que se distribuye libremente y que es empleada para cifrar y otra, denominada clave privada que es utilizada para descifrar (Marrero Travieso, 2003); de modo que cualquier mensaje (texto, archivos binarios o documentos) que es cifrado mediante la clave pública solo puede ser descifrado aplicando el mismo algoritmo, pero utilizando la clave privada coincidente (Rani \& Kaur, 2017).

\section{CERTIFICADOS}

Whitman \& Mattord (2012), indican que un certificado es un documento electrónico que contiene un valor clave e información de indentificación sobre la entidad que controla la clave y a menudo es emitido y certificado por un tercero denominado autoridad de certificación (AC). Así mismo y de acuerdo a lo expresado por Gentry (2003), además del usuario y la clave pública la AC incluye un número de serie SN, la fecha de emisión del certificado D1 y la fecha de vencimiento D2.

Un certificado permite enlazar de forma segura varias entidades, vincula a la persona o entidad (denominada entidad final) con su clave pública, una vez verificada que la entidad final posee realmente la clave pública particular la CA procede a asegurar el contenido del certificado a través de una firma digital a fin de evitar que éste sea alterado una vez emitido. Si un remitente quiere enviar un mensaje a un receptor, éste adjunta el certificado al mensaje, asegurándose de esta manera de la autenticidad de la clave pública (Balakrishnan, 2003).

\section{FIRMA ELECTRÓNICA}

Una firma electrónica es un mecanismo que permite identificar a una persona ante un sistema informático (Sistema Económico Latinoamericano y del Caribe, 2009). Son datos en forma electrónica depositados en un mensaje de datos, adjuntos o lógicamente asociados al mismo (Naciones Unidas, 2002), que puede acreditar quien es el firmante o emisor del mensaje (autenticación) y que además asegura que éste no ha sido manipulado o modificado por terceros en el transcurso de la comunicación (integridad) y da la seguridad de que el autor del mensaje no puede retractarse en el futuro de las acciones u opiniones dadas por él (Reyes, 2003).

\section{FIRMA DIGITAL}

Una firma digital es un análogo electrónico de una firma escrita (National Institute of Standards and Technology, 2013). Son datos consignados en un mensaje de forma electrónica o asociados al mismo, que pueden ser utilizados para identificar al firmante en relación con el mensaje de datos y que permiten determinar al firmante como dueño del mensaje (Naciones Unidas, 2002). Además, las firmas electrónicas generadas mediante criptografía asimétrica reciben el nombre de firma digital, por lo que la criptografía de clave pública o asimétrica es fundamental para proporcionar firmas electrónicas seguras (De Miguel Asensio, 2015), en el campo de las comunicaciones electrónicas (Velandia Ponce, 2011). Por lo tanto, el uso de la firma digital mediante el cifrado asimétrico, le provee al documento autenticación, satisfaciendo exigencias de autoría e integridad (Belloso Chacín, 2012). 


\section{FIRMA DIGITAL AVANZADA}

Firma digital avanzada es aquella que se crea en un dispositivo seguro de firmas y que además se basa en un certificado calificado (Chondrocoukis \& Lagou, s.f.). La tecnología de la firma digital avanzada utiliza un par de claves asimétrico: la clave privada y la clave pública. La clave privada debe permanecer en secreto mientras la clave pública es publicada y se utiliza para comprobar una firma digital y/o para enviar información confidencial en forma encriptada. Las claves privadas y públicas no pueden derivarse entre sí. Este par de claves es, en general, emitido por una autoridad de certificación que verifica y registra la identidad del firmante, pero también puede ser creada por el propio usuario. Al igual que el par de claves, el certificado digital puede ser creado por el propio remitente o por un intermediario autorizado como una autoridad de certificación que le proporciona un mayor grado de fiabilidad (Boudrez, 2005). Cabe mencionar que una firma digital avanzada debe cumplir con los siguientes requisitos: 1) Vinculada exclusivamente al signatario; 2) Capaz de identificar al firmante; 3) Creada utilizando medios que el firmante pueda tener bajo su control y 4) Estar vinculado a los datos de tal manera que cualquier cambio pueda ser detectado (Chondrocoukis \& Lagou, s.f.).

\section{INFRAESTRUCTURA DE CLAVE PÚBLICA}

La infraestructura de clave pública es un conjunto de componentes que proporcionan seguridad completa en las comunicaciones digitales a través de redes privadas o públicas y que permite a los usuarios intercambiar datos de forma segura (Sumalatha \& Sathyanarayana, 2015). Según Chaparro, Greenwood, \& Barán (2008), la infraestructura de clave pública es un medio que facilita el acceso a las claves públicas que asegura la correspondencia unívoca entre las claves públicas y sus respectivos usuarios. La ICP - PKI es necesaria para crear, manejar, almacenar, distribuir y revocar certificados digitales basados en criptografía asimétrica (Solinas et al., 2013). Además, proporciona seguridad y confianza, así como también el software, hardware, políticas y mecanismos de seguridad que garanticen las operaciones criptográficas como el cifrado, la firma digital y el no repudio (Boiero \& Tapia, 2014).

De acuerdo con RSA Data Security (1999), los tres componentes funcionales de la Infraestructura de Clave Pública son: 1) La Autoridad de Certificación AC, es la entidad que emite los certificados; 2) el Repositorio de Claves, Certificados y Listas de Revocación de Certificados LRC - CRL que suelen basarse en un protocolo de servicio de acceso a Directorio (LDAP); 3) Autoridad de Registro AR la misma que se dedica al registro de usuarios a través de un proceso de recolección de información y verificación de la identidad del mismo para registrar un usuario de acuerdo con una política y la aceptación de solicitudes de certificados; 4) Partes de confianza, que son los organizaciones y/o individuos que confían en el certificado para usar la clave pública dentro de ese certificado y 5) Repositorios que son las organizaciones y/o entidades que permiten publicar, almacenar y tener acceso a certificados y otra información relacionada con la ICP - PKI (American Bar Association, 2003). Por otro lado, la ICP -PKI tiene algunas funciones (ver tabla 1). 


\begin{tabular}{|c|c|}
\hline Funciones & Descripción \\
\hline Registro de usuarios & Recopila y verifica la información del usuario. \\
\hline $\begin{array}{l}\text { Emisión de } \\
\text { certificados }\end{array}$ & Crea certificados en respuesta a la solicitud de un usuario o administrador. \\
\hline $\begin{array}{l}\text { Revocación de } \\
\text { certificados }\end{array}$ & Crea y publica listas de revocación de certificados LRC \\
\hline $\begin{array}{l}\text { Almacenamiento y } \\
\text { recuperación }\end{array}$ & Elaborar certificados y LRCs para usuarios autorizados \\
\hline $\begin{array}{l}\text { Certificado basado } \\
\text { en }\end{array}$ & $\begin{array}{l}\text { Imponer restricciones basadas en políticas en la cadena de validación de rutas } \\
\text { de certificados y validar el cumplimiento de las restricciones. }\end{array}$ \\
\hline Sellar el certificado & $\begin{array}{l}\text { Establecer un tiempo de validez, combinando firmas digitales con sellos de } \\
\text { tiempo }\end{array}$ \\
\hline $\begin{array}{l}\text { Gestión de ciclo de } \\
\text { vida de la clave }\end{array}$ & Actualizar, archivar y restaurar claves \\
\hline
\end{tabular}

Tabla 1. Funciones de la ICP - PKI Fuente: Página RSA Security. Elaboración: adaptación de RSA Security.

\section{ESTÁNDARES CRIPTOGRÁFICOS}

En el ámbito de la criptografía, los estándares criptográficos se definen como modelos, normas o referencias que aseguran la transmisión de información privada. Esta estandarización se consigue por la revisión continua que realizan ciertos organismos y laboratorios a los diferentes algoritmos de cifrado, a la seguridad de las claves y a su durabilidad, con el objetivo de contar con procedimientos seguros, confiables y resistentes ante diferentes tipos de ataques. La certificación del sistema de cifrado debe estar otorgada por un Organismo de Certificación competente en materia de seguridad (Rodríguez Cabrero, 2007). Prueba de ello es el Instituto Nacional de Normas y Tecnologías (National Institute of Standars and Technology) ubicado en los Estados Unidos, que constantemente realiza un proceso de prueba y filtrado de los nuevos algoritmos, y los incorpora a una lista de nuevos métodos criptográficos aprobados.

\section{COMMON CRITERIA}

Según Eterovic \& Donadello (2014), Common Criteria (CC) define un criterio estándar que se usa como base para la evaluación de las propiedades y características de un determinado producto o sistema de Tecnologías de Información. American Bar Association (2003), señala que CC es un catálogo de requisitos de seguridad con dependencias indicadas. Se dan requisitos para las características de seguridad y para el aseguramiento de seguridad. Los requerimientos funcionales son proporcionados para las siguientes áreas: Auditoría, no repudio, características criptográficas generales, protección de datos de usuario, identificación y autenticación, gestión de la funcionalidad de seguridad, intimidad, protección de las funciones de seguridad y sus datos, uso de recursos, control de acceso al objetivo de evaluación (TOE), entre otros.

Por otro lado, en lo que se refiere a la ICP - PKI, CC no evalúa cuestiones de personal, procedimientos u otras cuestiones no técnicas. Su evaluación tiene tres actores principales: 1) Esquema, es el encargado de supervisar la evaluación, emitir la aprobación para que el evaluador realice la evaluación 
y confirmar los resultados de la misma; 2) Patrocinador, persona u organización que contrata el laboratorio de evaluación y 3) El laboratorio, aprobado por el sistema nacional que certifique que ésta cumple con un requisito identificado y se coloca en la lista nacional de productos evaluados (American Bar Association, 2003).

\subsection{ELEMENTOS COMMON CRITERIA}

\section{- PERFIL DE PROTECCIÓN - PP}

Documento formal que expresa un conjunto de requisitos a los que debe ajustarse un producto $\mathrm{TI}$ con la finalidad de asegurar que su funcionamiento es correcto y que cumple con las necesidades específicas de los clientes (INTECO, s.f.). Además, puede ser empleado como base para establecer requisitos encaminados a definir un Objetivo de Seguridad ST (Eterovic \& Donadello, 2014).

\section{- OBJETIVO DE SEGURIDAD - ST}

Es el seguimiento lógico de un PP, puede ser también el punto de partida para la captura de un diseño existente en la construcción CC. Proporciona una estructura común para expresar las capacidades de seguridad, mejorando la capacidad de la comunidad de usuarios para interpretar reclamos de proveedores. Provee de los mecanismos necesarios para para que los reclamos de los proveedores puedan ser fácilmente evaluados por terceros (American Bar Association, 2003).

\section{- REQUISITOS FUNCIONALES SE SEGURIDAD - SFR}

Los SFR forman una descripción clara, inequívoca y bien definida del comportamiento de seguridad esperado del objetivo de la evaluación TOE (Common Criteria, 2012). Los SFR se encuentran en un nivel de abstracción más detallado, en el que los objetivos de seguridad deben ser abordados completamente y ser independientes de cualquier solución técnica específica (Common Criteria, 2017). Los propósitos de SFR son: 1) describir el comportamiento de seguridad de un TOE; 2) alcanzar los objetivos de seguridad establecidos en el PP o en el ST; 3) anular las amenazas en el entorno del TOE; 4) cumplir las políticas de seguridad reconocidas por la organización y 5) especificar las propiedades de seguridad que los usuarios pueden detectar directamente o respondiendo a un estímulo (INTECO, s.f.).

\section{- OBjetivo de EVALUACIÓN - TOE}

Producto o sistema de tecnología de la información que se va a evaluar acompañado de las guías de uso, para el cual se especifican requisitos de seguridad en un perfil de protección o en un objetivo de seguridad (American Bar Association, 2003); es la implementación física del ST (INTECO, s.f.). 


\section{- REQUISITOS DE ASEGURAMIENTO DE LA CALIDAD - SAR}

Requisito de garantía que define como se evaluará TOE, PP y ST. Permite comparar dos ST dado que los diferentes autores del ST pueden utilizar una terminología diferente para describir la evaluación, el lenguaje estandarizado ya que se aplica la misma tecnología y conceptos; así mismo proporciona una descripción exacta de cómo se evaluará TOE (Common Criteria, 2017).

\section{- NIVEL DE ASEgURAMIENTO - EAL}

De acuerdo a Common Criteria (2012), el nivel de aseguramiento de evaluación NAE - EAL se utiliza para determinarla implementación de los requisitos de seguridad para un producto o grupo de productos específicos, tiene siete niveles ordenados jerárquicamente, descritos a continuación:

\section{○ EAL.1. PROBADO FUNCIONALMENTE}

Este nivel es aplicable cuando se requiere un nivel básico de aseguramiento, donde las amenazas a la seguridad no son consideradas como graves proporciona evidencia de que las funciones de Seguridad de los Objetivos de Evaluación (TOE Target of Evaluation) se encuentran implementadas de manera consistente y que propocionan una protección adecuada contra las amenazas.

\section{- EAL.2. PROBADO ESTRUCTURALMENTE}

Exige el cumplimiento de los requisitos del nivel anterior, siendo necesario haber realizado un análisis completo de los Requisitos Funcionales de Seguridad (SFR Security Funcional Requisites) en el objetivo de seguridad (ST Security Target). El análisis se apoya en pruebas independientes de la Evaluación de Tecnologías de Seguridad (TSF) evidencia de las especificaciones, confirmación independiente de esas pruebas y un análisis de vulnerabilidad que demuestre resistencia a ataques básicos. Es necesaria la cooperación del equipo de desarrollo para que se entregue la información sobre diseño y pruebas de testing.

\section{○ EAL.3. PROBADO Y COMPROBADO METODOLÓGICAMENTE}

Permite a los desarrolladores la máxima garantía de seguridad en la etapa de diseño, añade al nivel anterior el uso de controles de seguridad en el proceso de desarrollo para garantizar que el producto no ha sido manipulado y representa un aumento significativo con relación al nivel anterior.

\section{○ EAL. 4. DISEÑADO, PROBADO Y REVISADO METODOLÓGICAMENTE}

Permite a un desarrollador obtener la máxima garantía basado en las buenas prácticas de desarrollo comercial y no requiere un conocimiento especializado, habilidades y otros recursos. Necesita de un análisis de vulnerabilidades independiente, demostrando resistencia a intrusos con bajo potencial de ataque. Representa un aumento significativo en la garantía de EAL3.

\section{○ EAL.5. DISEÑADO Y PROBADO SEMIFORMALMENTE}

Es aplicable en aquellos casos en que los desarrolladores o usuarios requieren un alto nivel de seguridad. El análisis se apoya en pruebas independientes del TSF, evidencia de las pruebas basadas en la especificación funcional, diseño del TOE, confirmación selectiva independiente del resultado de las pruebas, análisis de vulnerabilidad independiente contra ataques moderados, proporciona garantía en el desarrollo de controles de medio ambiente y gestión de la configuración incluyendo 
automatización y evidencia de entrega de procedimientos de seguro. Representa un aumento significativo en la garantía de EAL4.

\section{○ EAL. 6. DISEÑADO, PROBADO Y VERIFICADO SEMIFORMALMENTE}

Permite a los desarrolladores obtener un alto grado de aseguramiento en un entorno de desarrollo riguroso con el fin de producir un TOE para protección de los activos de valor contra riesgos significativos, donde el valor de los bienes protegidos justifica los costes adicionales. Este nivel representa un avance importante en relación al nivel EAL 6, pues requiere un análisis más exhaustivo, una representación estructurada de la ejecución, mejor estructura arquitectónica, un análisis independiente de vulnerabilidades más amplio y mejorado, controles de gestión de la configuración y el entorno de desarrollo.

\section{○ EAL. 7. NIVEL DE GARANTÍA DE EVALUACIÓN VERIFICA Y PRUEBA FORMALMENTE EL DISEÑO}

Se aplica al desarrollo de TOE de seguridad para su adaptación en situaciones de alto riesgo y/o donde el valor de los activos justifica los costos altos. Necesita de un análisis más exhaustivo utilizando representaciones formales y pruebas completas.

\section{FIPS 140-2}

Estándar de Procesamiento de Información Federal es un conjunto de normas que especifican los requerimientos de seguridad para módulos criptográficos; el cual es aplicable a las agencias federales que utilizan sistemas de seguridad basados en criptografía para proteger la información sensible en los sistemas informáticos y de telecomunicaciones. De la misma forma, este estándar proporciona protección a la información asegurando la confidencialidad e integridad de los datos. FIPS 140-2 reemplazó a FIPS 140-1 debido a los cambios en lo que ha tecnología y prácticas se refiere (Kenworthy, 2002). Además, esta norma proporciona cuatro niveles de seguridad: Nivel 1, Nivel 2, Nivel 3 y Nivel 4; éstos incluyen la especificación de módulos criptográficos, puertos e interfaces de módulos criptográficos, funciones, servicios y autenticación, seguridad física y gestión de claves criptográficas. Los cuatro niveles de seguridad se especifican a continuación (National Institute of Standards and Technology, 2001).

\section{- NIVEL 1}

Es el nivel de menor exigencia, y en él se definen requisitos de seguridad básicos para un módulo criptográfico. No se requieren mecanismos específicos de seguridad física, por lo que esta implementación es apropiada cuando los niveles de seguridad física no existen o son inapropiados.

\section{- NIVEL 2}

Mejora mecanismos de seguridad física en un nivel criptográfico. Requiere autentificación basada en roles y el módulo criptográfico debe verificar la autorización de un operador para tener acceso a un conjunto específico de servicios. Por lo tanto, en este nivel los componentes de software y firmware de un sistema operativo deben haber sido evaluados con un nivel EAL2 o superior de Common Criteria. 


\section{- NIVEL 3}

Incorpora mecanismos de detección de intrusos, evitando el acceso no autorizado, uso o modificación de los módulos criptográficos. Además, se incluye protección criptográfica eficaz y administración de claves que se requieren para la autenticación. También, el software y firmware de un sistema operativo debe haber sido evaluado con un nivel EAL3 o superior.

\section{- NIVEL 4}

Contiene las mayores exigencias de seguridad y protección alrededor de un módulo criptográfico. Este nivel de seguridad es útil para el funcionamiento en entornos físicamente sin protección.

\section{ESTÁNDAR PKCS}

Son estándares de criptografía de clave pública, ofrecidos por los laboratorios de $\mathrm{RSA}^{1}$, cuyo objetivo es facilitar el uso de tecnologías de clave pública (Ortiz Figueroa, 2010). Según Wang (2012), este estándar tiene el propósito de acelerar el despliegue de la criptografía de clave pública. Además, PKCS define también una sintaxis de algoritmo independiente para firmas digitales, sobres digitales y certificados extendidos. La tabla 1 muestra el detalle del estándar criptográfico de clave pública (RSA Laboratories, 2015).

\begin{tabular}{|l|l|}
\hline Niveles & Características \\
\hline PKCS\#1 & $\begin{array}{l}\text { Define los mecanismos para la encriptación de datos y firma utilizando el } \\
\text { sistema de cifrado de clave pública RSA. }\end{array}$ \\
\hline PKCS\#3 & $\begin{array}{l}\text { Define un protocolo de acuerdo de claves Diffie-Hellman. } \\
\text { Describe un método para cifrar una cadena con una clave secreta derivada } \\
\text { de una contraseña. }\end{array}$ \\
\hline PKCS\#5 & $\begin{array}{l}\text { Se está eliminando a favor de la versión 3 de X.509. } \\
\text { Define una sintaxis general para los mensajes que incluyen } \\
\text { mejoras criptográficas, como las firmas digitales y cifrado. }\end{array}$ \\
\hline PKCS\#7 & $\begin{array}{l}\text { Describe un formato de información de clave privada. Esta información } \\
\text { incluye una clave privada para algún algoritmo de clave pública, y, } \\
\text { opcionalmente, un conjunto de atributos. }\end{array}$ \\
\hline PKCS\#8 & $\begin{array}{l}\text { Define seleccionado tipos de atributos para su uso en los otros estándares } \\
\text { PKCS. }\end{array}$ \\
\hline PKCS\#10 & $\begin{array}{l}\text { Describe la sintaxis para las solicitudes de certificación. } \\
\text { Define una interfaz de programación independiente de la tecnología, } \\
\text { llamada Cryptoki, para dispositivos criptográficos como tarjetas } \\
\text { inteligentes y tarjetas PCMCIA. }\end{array}$ \\
\hline PKCS\#11 & $\begin{array}{l}\text { Especifica un formato portátil para almacenar o transportar las claves de } \\
\text { un usuario privado, certificados, secretos diversos, etc. }\end{array}$ \\
\hline PKCS\#12
\end{tabular}




\begin{tabular}{|l|l|}
\hline \hline PKCS\#13 & $\begin{array}{l}\text { Tiene por objeto definir los mecanismos para el cifrado de datos y firma } \\
\text { utilizando criptografía de curva elíptica. }\end{array}$ \\
\hline PKCS\#14 & $\begin{array}{l}\text { Está actualmente en desarrollo y cubre la generación de números pseudo- } \\
\text { aleatorios. }\end{array}$ \\
\hline PKCS\#15 & $\begin{array}{l}\text { Es un complemento de PKCS \# } 11 \text { que da un estándar para el formato de } \\
\text { las credenciales criptográficas almacenadas en tokens criptográficos. }\end{array}$ \\
\hline
\end{tabular}

Tabla 2. Niveles del Estándar PKCS.

Fuente: Página RSA Laboratories.

Elaboración: los autores.

\section{ESTÁNDARES APLICADOS A MÓDULOS CRIPTOGRÁFICOS EN FIRMA Y CERTIFICADOS DIGITALES EN LOS PAISES DE AMÉRICA DEL SUR}

\subsection{ARGENTINA}

La firma digital en la República de Argentina se encuentra reglamentada en la ley 25.506 , sancionada el 14 de noviembre de 2001, promulgada el 11 de diciembre de 2011 y publicada el 14 de diciembre de ese mismo año (Ventura, s.f.). En la actualidad, la Firma Digital cuenta con una Entidad Certificante Raíz, administrada por la oficina de Tecnologías de Información. Así mismo, las firmas digitales al constituirse en una aplicación muy importante de la tecnología de claves públicas, deben apoyarse en estándares tecnológicos. Sus componentes son: 1) estándares para algoritmos de encriptación y algoritmos hash, 2) protocolos para facilitar el acceso de los usuarios a las claves públicas, 3) Estándares para la generación segura de pares de claves, entre otros (Rivolta, 2010).

En lo que se refiere a los estándares tecnológicos, la autoridad encargada es la Jefatura de Gabinete de Ministros, quienes pueden determinar los estándares internacionales que se utilizarán. El estándar reconocido es el X.509 versión 3, estándar que fue adoptado porque vincula la clave pública con los datos de identificación del titular (Ventura, s.f.).

Según Guini (2011), solo aquellas firmas aprobadas o licenciadas por Autoridad de Aplicación podrán demostrar la validez de la firma electrónica, el estándar criptográfico utilizado es FIPS 140-2 nivel 3 para dispositivos seguros en la creación de la firma y para dispositivos de almacenamiento de respaldo en un sitio de contingencia.

\subsection{BRASIL}

En Brasil la firma digital se promulgó en la Medida Provisória № 2.200-2, de 24 de Agosto de 2001 Institui a Infra-Estrutura de Chaves Públicas Brasileira - ICP-Brasil, e dá outras providências (Pario Communications Limited, 2013). Al mismo tiempo, la firma digital en Brasil se basa en la infraestructura de clave pública (ICP - Brasil), que debe ser emitida por autoridad certificada 
autorizada y de conformidad a los estándares y normas establecidos (Lopes Campos, Campos Zaghloul, \& Zanforlin Pereira, 2014).

Según Magioli Nuñez (2013), la autoridad responsable de la infraestructura de clave pública es el Instituto de tecnología de Brasil (ITI), que se constituye en la autoridad de certificación raíz, es la encargada de realizar las políticas y directrices de los certificados. En cuanto a los parámetros de generación de claves asimétricas, módulos criptográficos y parámetros de generación de claves, de acuerdo al documento de clave pública (DOC - ICP_01.01. Versão 2.6), en Brasil se adoptarán los estándares FIPS 140-1 o su equivalente, FIPS 140-1 nivel 2 (para la cadena de certificados V0); o FIPS 140-2 Nivel 2 (para la cadena V1 de acreditación); o FIPS 140-2 nivel 3 (para la cadena de certificados V2 y V3) utilizando el algoritmo ECDSA ${ }^{2}$ o RSA (Instituto Nacional de Tecnologia da Informação).

\subsection{BOLIVIA}

De acuerdo a Red Iberoamericana de Protección de datos (2013), en Bolivia la firma digital se encuentra reglamentada en la Ley Nro. 164 del 8 de agosto de 2011 que corresponde a la Ley general de Telecomunicaciones, Tecnologías de Información y Comunicación sobre desarrollo, contenidos y aplicaciones de tecnología de información y comunicación; en la que se establece la normativa que deberán cumplir las entidades certificadoras autorizadas para la emisión de certificados digitales, mismos que deberán responder a los formatos y estándares internacionales reconocidos por la Autoridad de Regulación y Fiscalización de Telecomunicaciones y Transportes (ATT). Las entidades certificadoras deberán establecer los formatos y procedimientos necesarios para la aplicación de la firma digital y los certificados digitales, los cuales se basarán en el estándar internacional RFC5280 en el cual se definen los formatos de certificados X.509 versión 3 (González Cruz, 2005) y los CRL (lista de certificados revocados) X.509 versión2. Además, el estándar FIPS 140-2 para el almacenamiento y custodio del certificado digital y su clave privada (Autoridad de regulación y fiscalización de telecomunicaciones y transportes, 2014).

\subsection{CHILE}

Según, Formentín Zayas (2013), la Ley 19.799 de 2002 corresponde a la Ley sobre Firma electrónica en Chile, promulgada el 26 de marzo de 2002. En cuanto a los tipos de firma electrónica, existen dos la simple y la avanzada (Quintanilla, Doren, \& Hernández, 2014). En Chile la firma digital avanzada es aquella que permite firmar documentos, otorgándoles validez legal, certificada por un prestador acreditado y que emplea la infraestructura de clave pública (PKI), diferenciándola de esta manera de la firma digital simple. Es así que, la firma digital avanzada cumple con exigentes estándares de seguridad, con la participación de entidades altamente tecnificadas y calificadas (Fernández Acevedo, 2004). Al mismo tiempo, la Subsecretaría de Economía cumple como entidad certificadora de modo que para que todos los certificados de los documentos firmados con firma electrónica avanzada sean válidos deberán pasar por el proceso de acreditación oficial de la Subsecretaría de Economía (Ministerio Secretaría General de la Presidencia. Proyecto Reforma y Modernización del Estado, 2013).

Según el Ministerio de Economía, Fomento y Turismo del Gobierno de Chile (2013), la certificación de la firma digital avanzada debe contar con el estándar internacional FIPS 140- 2 nivel 2 para la 
implementación o administración de llaves criptográficas y para verificar el nivel de seguridad del dispositivo seguro de los usuarios, el estándar FIPS 140-2 nivel 2 (o Common Criteria EAL 3).

\subsection{COLOMBIA}

Según Rojas López, Suarez Botero, \& Meneses Durango (2011), la ley sobre firma digital es la Ley 527 de 1999 que tomó como base la Ley modelo de la Comisión de las Naciones Unidas para el Derecho Mercantil Internacional CNUDMI promulgada por las Naciones Unidas y adaptada a la jurisprudencia colombiana, cuyo ámbito de aplicación es el uso de firmas digitales en los mensajes de datos. En Colombia, la supervisión de la infraestructura de clave pública está a cargo de la Superintendencia de Industria y Comercio, que concede la licencia para conformar entidades de certificación, las que para obtener licencia de funcionamiento deben estar alineados con la norma ISO o los estándares ITU reconocidos por el ende gubernamental (Salazar, 2009).

Por otro lado, la Organismo Nacional de Acreditación de Colombia establece criterios específicos para la acreditación de entidades de certificación digital de acuerdo a lo establecido en la Ley 527, Anexo F en lo que se refiere a Dispositivos Criptográficos, el cual especifica que los dispositivos criptográficos para el almacenamiento de certificados digitales y llave privada de los suscriptores debe cumplir con el certificado FIPS 140-2 nivel 3 o superior, o longitud de clave RSA 2048 o superior. Así también, los dispositivos criptográficos deberán cumplir con el certificado FIPS 140-2 nivel 3, RSA 2048 o superior, exigible 4096 cuando se declare inseguro RSA 2048 (Organismo Nacional de Acreditación de Colombia, 2014).

\subsection{ECUADOR}

En el Ecuador, la firma electrónica tuvo sus inicios en el año 2002 a través de la Ley de Comercio Electrónico, Firmas Electrónicas y Mensajes de Datos, teniendo igual validez que una firma manuscrita. La entidad de certificación de la firma electrónica es el Consejo Nacional de Telecomunicaciones ${ }^{3}$.

La generación del par de claves de las Autoridad de Certificación Raíz y Subordinada, se generan con módulos criptográficos Hardware Security Module PKCS\#11 y cumple con los requisitos establecidos para la protección de dispositivos seguros para la Autoridad de Certificación de acuerdo con Common Criteria y FIPS 140-2 nivel 3 o un nivel superior de seguridad. Para el almacenamiento de la clave en el token se utilizará FIPS 140-2 nivel 2 o nivel 3 y, para los certificados emitidos en dispositivos criptográficos se aplicará el estándar FIPS 1 nivel 2 o superior (Banco Central del Ecuador, 2013).

\subsection{PARAGUAY}

La firma digital en Paraguay fue reglamentada en la Ley Nro. 4017/10, de validez jurídica de la firma electrónica, la firma digital, los mensajes de datos y el expediente electrónico, a través del decreto Nro. 7.369 (Secretaría permanente del SELA, 2012). El Ministerio de Industrias y Comercio (MIC), por medio de la Subsecretaría de Estado de comercio es la autoridad de aplicación que tiene a su cargo la política de certificación, cuyo cumplimiento es de carácter obligatorio, los controles y medidas de seguridad tomados para proteger las claves criptográficas y datos de activación. Además, las claves 
privadas de las autoridades certificadoras de firma digital deben cumplir como mínimo con el estándar FIPS 140-2 nivel 3 para el caso de módulos criptográficos, certificados de persona jurídica para firma digital y generación de claves. Para certificados de personas físicas para firma digital se aplicará el estándar FIPS 140-2 nivel 2 (Ministerio de Industria y Comercio. Subsecretaría de Estado de Comercio de la República de Paraguay).

\subsection{PERÚ}

El 26 de mayo de 2000 se promulgó en Perú la Ley 27.269 de firmas y certificados digitales, cuyo principal objetivo es el de regular el uso de la firma electrónica en sus dos modalidades: electrónica y digital (Mendoza Navarro, 2007). De acuerdo a esta ley la firma digital es una firma electrónica que utiliza criptografía asimétrica, generada a partir de certificados digitales, emitidos por entidades de certificación aprobados (Ministerio de Justicia del Perú).

El Instituto Nacional de Defensa de la Competencia y la Protección de la Propiedad Intelectual, es la autoridad administrativa competente encargada de la regulación de la estructura de la firma digital. A través del documento de Lineamientos de la política de la Infraestructura Oficial de la Firma Digital (IOFD), establece que para los procesos criptográficos con dispositivos certificados se empleará como nivel mínimo el estándar FIPS 140-1 Nivel 3 o Common Criteria EAL4 u otro equivalente que facilite el reconocimiento trasnacional de los certificados (INDECOPI, 2006). Además, la entidad encargada para emitir certificados raíz para las entidades de certificación del estado Peruano y proponer las políticas y estándares para las entidades de certificación y entidades de registro y verificación es el Entidad de Certificación Nacional para el Estado Peruano (ECERNEP), que utiliza los siguientes estándares como parte de los controles del módulo ciptográfico: FIPS 140-2 Nivel 3 y Common Criteria EAL4+ (Registro Nacional de identifiación y estado civil, 2013).

\subsection{URUGUAY}

La firma electrónica en Uruguay está regulada por la Ley 18.600 aprobada el 21 de septiembre 2009 y publicada el 5 de noviembre del mismo año. En ésta se reconoce la validez de la firma electrónica y se instituye la diferencia entre la simple y la avanzada, estableciendo que la avanzada es creada con un dispositivo de creación de firmas y emitida por un prestador de servicios certificado acreditado. El lanzamiento de la infraestructura de claves públicas se realizó en el año 2011. La entidad certificadora es la Agencia para el Desarrollo del Gobierno de Gestión Electrónica y la Sociedad de la Información y el Conocimiento (AGESIC), que depende directamente de la Presidencia de la República (Bouvier Villa, Cami Soria, \& Ferreira Pina, 2012). Asimismo, se ha autorizado a la Administración Nacional de Correos (ANC) la generación de claves, generación y revocación de certificados y archivos de certificados emitidos. En cuanto a los estándares que se aplicarán a los módulos criptográficos y a la generación del par de claves éstos deben estar de acuerdo con la ITSEC ${ }^{4}$, FIPS 140-1, Nivel 3 o Common Criteria (Correo Uruguayo, 2011).

\subsection{VENEZUELA}


De acuerdo a Arias Ferrer (2008), la Ley sobre Mensajes de Datos y Firmas Electrónicas (LMDFE) fue publicado 28 de febrero de 2001, en el que una firma digital es aquella que utiliza un certificado emitido por un Proveedor de Servicios de Certificación. Según Arcila \& De la Barra (2009), la firma electrónica puede sustituir a una firma autógrafa siempre que ésta tenga el debido certificado de autenticidad, mismo que debe ser expedido por un proveedor registrado, que de acuerdo a la Ley sobre mensajes de Datos y Firmas Electrónicas, el ente que supervisa a los proveedores de servicios de certificación es la Superintendencia de Servicios de Certificación Electrónica.

De igual forma, la norma nro. 040, de la Guía de Estándares Tecnológicos y Lineamientos de seguridad para la Acreditación y revocación como proveedor de servicios de certificación o casos especiales, en la sección donde se referencia el plan de administración de claves públicas, señala que los estándares de evaluación que se aplicarán son ETSI TS $102042^{5}$ y FIPS 140-2 (SUSCERTE, 2012).

\section{CONCLUSIONES}

De acuerdo a la información recolectada durante el desarrollo de este trabajo se ha podido determinar que el estándar más utilizado para garantizar seguridad es el estándar FIPS 140-2 Nivel 1, Nivel 2 y Nivel 3.

Sin embargo, a pesar de que los estándares criptográficos han sido asumidos por los países de América del Sur, no se dispone de suficiente información procedente de otros autores que puedan ofrecer referencias sobre los estándares empleados en módulos y claves criptográficas.

Finalmente, sería importante realizar una revisión con mayor detalle sobre las características y el funcionamiento de FIPS 140-2, toda vez que éste estándar es el más utilizado para validar módulos criptográficos y que debido al objetivo de este trabajo no pudo ser abordado, dejando su desarrollo para trabajos futuros. 


\section{REFERENCIAS BIBLIOGRÁFICAS}

Álvarez Sánchez, R. I. (2005). Universidad de Alicante. Obtenido de http://rua.ua.es/dspace/bitstream/10045/13571/1/tesis_ralvarez.pdf

American Bar Association. (2003). Recuperado el 23 de Agosto de 2017, de https://www.americanbar.org/content/dam/aba/events/science_technology/2013/pki_guidelines.auth checkdam.pdf

Arcila, C., \& De la Barra, R. (2009). Aspectos legales del gobierno electrónico en Venezuela. Disertaciones, 238259.

Arias Ferrer, M. I. (2008). La Ley sobre Mensajes de Datos y Firma Electrónica. Comentarios a la Sentencia de fecha 12 de febrero de 2008. Scielo , 177-190.

Autoridad de regulación y fiscalización de telecomunicaciones y transportes. (11 de Julio de 2014). ATT. Obtenido de http://att.gob.bo/

Balakrishnan, T. (2003). Universidad de Leeds. Recuperado el 20 de Agosto de 2017, de https://minerva.leeds.ac.uk/

Banco Central del Ecuador. (Noviembre de 2013). Banco Central del Ecuador. Obtenido de https://www.eci.bce.ec

Barberán, C. F., Barberán, L. A., Bontempo, V., Lens, S. A., Pérez Williams, A., \& Scattolin, A. (s.f.). HfernandezdelPech. Recuperado el 21 de Octubre de 2015, de http://www.hfernandezdelpech.com.ar/PUBLICAtrabajosFirmaDigital.htm

Belloso Chacín, R. (2012). El documento electrónico, contratación electrónica y firma electrónica en el ordenamiento jurídico de la República Bolivariana de Venezuela. Revista Electrónica de Estudios Telemáticos, 33-49.

Bisht, N., \& Singh, S. (2015). A Comparative Study of Some Symmetric and Asymmetric Key Cryptography Algorithms. International Journal of Innovative Research in Science, Engineering and Technology, 10281031.

Boudrez, F. (2005). Recuperado el 2 de Septiembre de 2017, de http://www.edavid.be/docs/digitalsignatures.pdf

Boiero, F., \& Tapia, C. (2014). Fortalecimiendo de la seguridad de las comunicaciones mediante la implementación de una infraestructura de clave pública. Cytal, 339-344.

Bouvier Villa, E., Cami Soria, G., \& Ferreira Pina, J. (2012). Asociación de Escribanos de Uruguay. Obtenido de www.aeu.org.uy/andocasociado.aspx?2680,8152

Castillo Rubí, M. A., Santana de la Cruz, N., Díaz Lobatón, A. M., Almanza Rodríguez, G., \& Castillo Rubí, F. (2011). Teoría de números en criptografía y su debilidad ante la posible era de las computadoras cuánticas. Ciencia Ergo Sum, 264-273.

Chaparro , R., Greenwood, P., \& Barán, B. (2008). Alternativa de Infraestructura de Clave Pública Basada en el Uso de DNSSEC. Centro Latinoamericano de estdudios informáticos. Obtenido de http://clei.org/clei2004/HTML/PDFS/188.PDF

Common Criteria. (Septiembre de 2012). Common Criteria. Obtenido de https://www.commoncriteriaportal.org 
Common Criteria. (2017). Common Criteria. Recuperado el 01 de Septiembre de 2017, de http://www.commoncriteriaportal.org

Correo Uruguayo. (12 de Abril de 2011). Correo Uruguayo. Obtenido de www.correo.com.uy/correocert/cps.pd

Chondrocoukis, G., \& Lagou, P. (s.f. de s.f. de s.f.). semanticscholar. Recuperado el 2 de Septiembre de 2017, de https://pdfs.semanticscholar.org/4c5f/a8a560251f3aa4ab29a34fa904f2c5120669.pdf

De Miguel Asensio, P. A. (15 de Octubre de 2015). eprints.ucm.es. Obtenido de http://eprints.ucm.es/6867/1/Direitosocinffirmelectr19.03.03.pdf

Eterovic, J. E., \& Donadello, D. (15 de Enero de 2014). Ciencia y Técnica Administrativa. Obtenido de http://www.cyta.com.ar/ta1301/v13n1a4.htm

$\begin{array}{lllll}\text { Fernández } & \text { Acevedo, } & \text { (2004). } & \text { Obtenido de }\end{array}$ http://www.scielo.cl/scielo.php?script=sci_arttext\&pid=S0718-00122004000200005\&lang=en

Formentín Zayas, Y. M. (Enero de 2013). La firma electrónica, su recepción legal. Especial referencia a la ausencia legislativa en Cuba. Revista del Instituto de Ciencias Jurídicas de Puebla, 104-120.

Gentry, C. (13 de Mayo de 2003). Certificate-Based Encryption and the Certificate Revocation Problem. International Conference on the Theory and Applications of Cryptographic Techniques, (págs. 272-293).

González Cruz, R. (Agosto de 2005). Universidad San Francisco Javier. Obtenido de www.criptored.upm.es/guiateoria/gt_m115a.htm

Guini, L. (2011). Validez probatoria de firma electrónica emitida por un certificador no licenciado dentro de la infraestructura de firma digital en Argentina. Revista Digital ElDerecholnformático.

INDECOPI. (31 de Agosto de 2006). INDECOPI. Obtenido de http://www.iofesac.com/noticias/Implementaci\%C3\%B3n_IOFE_INDECOPI.pdf

Information Technology Laboratory National Institute of Standards and Technology. (25 de Mayo de 2001). National and Institute of Standards and Technology. Obtenido de http://csrc.nist.gov/

Instituto Nacional de Tecnologia da Informação. (s.f.). Instituto Nacional de Tecnologia da Informação. Obtenido de www.iti.gov.br

Kenworthy, T. (30 de Julio de 2002). SANS Institute. Obtenido de https://www.sans.org

Lopes Campos, R., Campos Zaghloul, B., \& Zanforlin Pereira, L. H. (25-27 de Marzo de 2014). VII Congresso CONSAD de gestão Pública . Governo Sem Papel: Desenvolvendo a cultura. Brasilia, Brasil. Obtenido de http://banco.consad.org.br/bitstream/123456789/1105/1/C7_PP_GOVERNO\%20SEM\%20PAPEL\%20DE SENVOLVENDO\%20A\%20CULTURA.pdf

Magioli Nuñez, C. A. (2013). Posibilidade Jurídica da Contestacao da assinatura digital. Revista da SJRJ, 13-38.

Marrero Travieso, Y. (2003). La Criptografía como elemento de la seguridad informática. Acimed, 0-0. Obtenido de eprints.rclis.org

Mendoza Navarro, A. L. (2007). El el Perú los archivos digitales no serán custodiados por los archiveros. Ciencias de la Información, 28-36.

Ministerio de Economía, Fomento y Turismo. Gobierno de Chile. (8 de Febrero de 2013). Ministerio de Economía, Fomento y Turismo. Obtenido de http://www.entidadacreditadora.gob.cl/ 
Ministerio de Industria y Comercio. Subsecretaría de Estado de Comercio de la República de Paraguay. (s.f.). $\begin{array}{llll}\text { Ministerio de Industria } \quad \text { Obtenido de } & \text { Comercio. }\end{array}$ http://www.mic.gov.py/v1/sites/172.30.9.105/files/VERSION\%20DEFINITIVA\%20AJUSTADA.pdf

Ministerio de Justicia del Perú. (s.f.). Ministerio de Justicia. Obtenido de www.minjus.gob.pe/wpcontent/uploads/2014/.../DS-052-2008-pcm.pd

Ministerio Secretaría General de la Presidencia. Proyecto Reforma y Modernización del Estado. (04 de Diciembre de 2013). Sistema Nacional de Información Ambiental SINIA - Chile. Obtenido de www.sinia.cl

Naciones Unidas. (2002). Ley Modelo de la CNUDMI sobre Firmas Electrónicas con la Guía para su incorporación al derecho interno 2001. Obtenido de Uncitral: www.uncitral.org/pdf/spanish/texts/electcom/mlelecsig-s.pd

National Institute of Standards and Technology. (25 de Mayo de 2001). NIST. Obtenido de http://csrc.nist.gov/publications/fips/fips140-2/fips1402.pdf

National Institute of Standards and Technology. (Julio de 2013). National Institute of Standards and Technology. Recuperado el 2 de Septiembre de 2017, de http://nvlpubs.nist.gov

Network Working Group. (Mayo de 2008). The Internet Engineering Task Force. Obtenido de http://tools.ietf.org/html/rfc5280\#section-3.2

Organismo Nacional de Acreditación de Colombia. (04 de Noviembre de 2014). ONAC. Obtenido de http://www.onac.org.co/anexos/documentos/CAMBIOSACTUALIZA/CEA-4\%201-10\%202015-08-13.pdf

Ortiz Figueroa, G. A. (10 de Junio de 2010). upcommons. Obtenido de http://upcommons.upc.edu/handle/2099.1/9750

Paar, C., \& Pelzl, J. (2010). Understanding Cryptography. New York: Springer.

Pario Communications Limited. (10 de Octubre de 2013). vlex. Obtenido de http://international.vlex.com/vid/table-electronic-signature-legislation-469369230

Quintanilla, J., Doren, C., \& Hernández, D. (2014). The Electronic Signature in Chile. Digital Evidence and Electronic Signature Law Review, 69-79.

Rani, S., \& Kaur, H. (2017). Technical Review on Symmetric and Asymmetric Cryptography Algorithms. International Journal of Advanced Research in Computer Science, 182 - 186.

Red Iberoamericana de Protección de datos. (13 de Noviembre de 2013). redip. Obtenido de http://www.redipd.es/legislacion/common/legislacion/Bolivia/DS_1793_Telecomunicaciones.pdf

Registro Nacional de identifiación y estado civil. (11 de Enero de 2013). RENIEC. Obtenido de www.reniec.gob.pe

Reyes, A. A. (2003). Biblioteca virtual Miguel de Cervantes. Recuperado el 21 de Agosto de 2017, de www.cervantesvirtual.com

Rivolta, M. (2010). Desarrollo de la Infraestructura de firma digital: resultado de encuesta a expertos. XV Congreso Internacional de CLAD sobre la reforma del Estado y de la Administración pública, (págs. 1-27). Santo Domingo.

Rodriguez Cabrero, J. (Julio de 2007). Revista Dintel. Obtenido de http://www.revistadintel.es/Revista1/DocsNum12/Tribuna/jrodriguez.pdf

Rojas López, M. D., Suarez Botero, D. M., \& Meneses Durango, C. N. (2011). Firma digital: Instrumento de transmisión de información a entidades financieras. Avances en Sistemas e Informática, 7-14. 
RSA Data Security. (1999). RSA security. Recuperado el 20 de Agosto de 2017, de http://storage.jakstik.ac.id/rsasecurity/understanding_pki.pdf

RSA Laboratories. (2015). RSA Laboratories. Obtenido de http://www.emc.com/emc-plus/rsa-labs/standardsinitiatives/pkcs.htm

Salazar, J. F. (2009). Situación normativa de la Sociedade de la Información en Colombia. Criterio Jur[idico, 89103.

Satizábal Echavarría, I. C. (Marzo de 2007). Tesis Doctorales en Xarxa. Obtenido de www.tdx.cat

Secretaría permanente del SELA. (Mayo de 2012). Red interamericanade ventanillas únicas de comercio exterior. Obtenido de www.redvuce.org/docs/ESP_Publication_Firma_Digital.pdf

Silva Dugarte, M. F. (2011). Certificación electrónica aplicada en Venezuela y su legislación: garantías y desventajas para negociaciones seguras. Visión Gerencial, 205-220.

Solinas, M., Castello, R. J., Tula, L., Gallo, C., Jorge, J., \& Bollo, D. (2013). Implementación de una infraestructura de clave pública con herramientas de software libre. 107 - 117.

SUSCERTE. (13 de Febrero de 2012). SUSCERTE. Obtenido de http://www.suscerte.gob.ve/normativas/

Sumalatha, P., \& Sathyanarayana, B. (2015). Enhanced Identity Based Cryptography for Efficient Group Key Management in WSN. International Journal of Application or Innovation in Engineering \& Management, 116-128.

Velandia Ponce, R. (Junio de 2011). Universidad Central de Venezuela. Obtenido de saber.ucv.ve

Ventura, G. (s.f.). Academia Nacional de Derecho y Ciencias Sociales de Córdoba. Obtenido de http://www.acaderc.org.ar/doctrina/firma-digital-analisis-exegetico-de-la-ley-25506-2001

Wang, Y. (Julio de 2012). UNC Charlotte. Obtenido de webpages.uncc.edu

Whitman, M., \& Mattord, H. (2012). Principles of Information Security. Boston.

Wollinger, T., Guajardo, J., \& Paar, C. (2003). Cryptography in Embedded Systems: An Overview. Proceedings of the Embedded World 2003 Exhibition and Conference, (págs. 735 - 744). Nuremberg. 


\title{
IMPORTANCIA DE LOS ENTORNOS MOOCS PARA LA DIVULGACIÓN DE CONOCIMIENTOS ACADÉMICOS EN ENTORNOS
}

\section{UNIVERSITARIOS}

\section{IMPORTANCE OF THE MOOCS ENVIRONMENTS FOR THE DISSEMINATION OF ACADEMIC KNOWLEDGE IN UNIVERSITY ENVIRONMENTS}

\author{
Roberto Wellington Acuña Caicedo ${ }^{1}$ \\ Christian Ruperto Caicedo Plúa ${ }^{2}$ \\ Antonieta Del Carmen Rodríguez Gonzalez ${ }^{3}$ \\ Grace Liliana Figueroa Morán ${ }^{4}$
}

1. Magister en Docencia Universitaria e Investigación Educativa, Master en Sistemas de Información Gerencial, Ingeniero en Sistemas, Analista En Sistemas, Docente Titular Principal de la Universidad Estatal del Sur de Manabí, Facultad Ciencias Técnicas, Carrera Ingeniería en Computación y Redes. (Ecuador). E-mail: roberec2000@ hotmail.com

2. Magister en Gerencia Educativa e Investigación, Ingeniero en Computación y Redes, Investigador Acreditado por la Senescyt REG-INV-16-01626, Docente Titular Principal de la Universidad Estatal del Sur de Manabí, Facultad Ciencias Técnicas, Carrera Ingeniería en Computación y Redes, Comisión Científica de la Carrera Ingeniería en Computación y Redes, Comisión Científica de Carrera. (Ecuador). E-mail: christiancaicedoplua@hotmail.com

3. Magister en enseñanza del idioma Ingles, Licenciada en Ciencia de la Educación mención Ingles, Tecnóloga en Computación Administrativa, Docente Titular Principal de la Universidad Estatal del Sur de Manabí, Carrera Ingeniería en Computación y Redes, Centro de Idiomas. (Ecuador). E-mail: antojipi2006@hotmail.com

4. Magister en Informática Empresarial, Magister en Docencia Universitaria e Investigación Educativa, Licenciada en Ciencias de la Educación Especialidad Informática, Docente Titular Principal de la Universidad Estatal del Sur de Manabí, Facultad Ciencias Técnicas, Carrera Ingeniería en Computación y Redes. (Ecuador). E-mail: gralifimo@hotmail.com

\section{Citación sugerida:}

Acuña Caicedo, R.W., Caicedo Plúa, C.R., Rodríguez González, A.C. y Figueroa Morán, G.L. (2017). Importancia de los entornos moocs para la divulgación de conocimientos académicos en entornos universitarios. $3 C$ Tecnología: glosas de innovación aplicadas a la pyme, 6(3), 33-47. DOI: <http://dx.doi.org/10.17993/3ctecno.2017.v6n3e23.33-47>. 


\section{RESUMEN}

El presente artículo tiene como objeto determinar la importancia de los entornos MOOCs en ambientes universitarios, a través del análisis de indicadores concernientes a la utilización del internet y sus beneficios para fines académicos, la identificación de tipos de plataformas de acceso abierto y el diseño de un modelo de plataforma de acuerdo a líneas curriculares y necesidades de capacitación del entorno. La metodología utilizada es de tipo investigación - acción, con una dimensión organizativa constructivista, ya que permitió indagar de manera introspectiva colectiva el hecho científico con el fin de mejorar la realidad educativa de las Instituciones. Se aplicó el modelo de Gértrudix Barrio, (2017) y (Carr, 1986 - 1987). Los resultados muestran la importancia de promover nuevas prácticas educativas a través del uso de las TIC, con el objeto de crear una red de intercambio de experiencias para mejorar la docencia e investigación en beneficio social.

\section{ABSTRACT}

The objective of this article is to determine the importance of $\mathrm{MOOC}$ environments in university environments, through the analysis of indicators concerning the use of the Internet and its benefits for academic purposes, the identification of open access platforms types and the design of a Platform model according to curricular lines and training needs of the environment. The methodology used is of research - action type, with a constructivist organizational dimension since it allowed to investigate in a collective introspective way the scientific fact in order to improve the educational reality of the Institutions. The model of Gértrudix Barrio, (2017) and (Carr, 1986 - 1987) was written. The results show the importance of promoting new educational practices through the use of ICTs, in order to create a network of exchange of experiences to improve teaching and research for social benefit.

\section{PALABRAS CLAVE}

Formación, autónoma, MOOC, educación superior, plataforma de enseñanza.

\section{KEY WORDS}

Training, autonomous, MOOC, higher education, teaching platform. 


\section{INTRODUCCIÓN}

Los MOOCs a nivel mundial se han considerado como una alternativa para la divulgación académica y científica en el área de la educación y tecnologías de la información y comunicación (Vázquez Cano, E., \& López Meneses, E., 2014). De igual manera, Cabero Almenara (2014) define que los MOOC son una iniciativa conjunta entre varias instituciones con un alcance de 4 a 5 años. Este tipo de entornos masivos abiertos tienen una característica específica y actualmente se utiliza a nivel mundial para el desarrollo de contenidos interactivos, además de ofrecer una formación gratuita, de calidad donde cualquier persona independientemente de su país puede acceder (Vázquez Cano, 2015). Actualmente vivimos en una época transcendental en la que se desarrollan una diversidad de cambios sociales a través del desarrollo de nuevas tecnologías (Michavila, 2010).

Según Ferro Soto, Martínez Senra, \& Otero Neira (2009), refieren que las Tic juegan un papel decisivo en el proceso de enseñanza / aprendizaje de las universidades Europeas a la hora de alcanzar los retos planteados en el proyecto de convergencia de los diferentes sistemas nacionales. Por otra parte, Durall Gazulla, (2012) en un análisis regional del informe Horizon del NMC y la UOC identifican y describen en forma sistemática las tecnologías emergentes que pueden tener un impacto significativo en la educación superior. En el mismo refleja doce tecnologías utilizadas en Iberoamérica donde se denotan a las aplicaciones móviles, computación en la nube, analíticas de aprendizaje - el aprendizaje basado en juegos, geolocalización y los entornos personales de aprendizaje.

Gracias a este enfoque las IES tienden a diversificar la oferta de asignaturas en forma virtual, esto equivale a una transformación gradual del concepto del rol de la universidad y del impacto que tiene que tener en la sociedad (Históricos, 2015). La aplicación de estrategias didácticas alternativas traslada al estudiante a un proceso de intercambio continuo, donde la inclusión de componentes tecnológicos fortalezca de manera directa el trabajo de tutela del docente a través del aprendizaje cooperativo y colaborativo (Rodriguez, 2012).

Dentro de esta realidad el uso de las estrategias tienen una perspectiva holística basada en la concepción de las preferencias del usuario y la representación de la realidad que este quiere alcanzar, lo que permitirá desarrollar un aprendizaje significativo que conlleva a modelar el comportamiento del estudiante Chandler, (2014). En este contexto los avances tecnológicos en relación con Massive Open Online Courses (MOOCs) están alcanzando actualmente una madurez técnica y pedagógica con el único fin de robustecer la formación a distancia apoyada en el uso y la aplicación de las Learning Management Systems. En este sentido, los MOOC establecen un nuevo modelo de enseñanza/aprendizaje sostenible y asistido bajo un paradigma educativo concreto (Kop, R., Fournier, H., \& Mak, J. S. F., 2011). De tal forma que las instituciones educativas del nivel superior deben alcanzar su transformación en base a la innovación de su nivel estructural cuya experimentación conllevará a potenciar la educación del futuro, ya que las IES tienen que tener un alcance global sustentado en base a las alianzas entre universidades y contenidos técnicos - científicos a compartir, donde no exista fronteras y sus estudiantes puedan completar sus créditos en cualquier parte del mundo (Plúa, C. R. C., Gonzalez, A. D. C. R., Castro, M. I. R., \& Rodríguez, E. L., 2016). 


\section{TECNOLOGÍAS Y SU IMPACTO EN LAS IES}

Con una población mundial estimada a enero del 2016 en 7.159.071.800 millones World \& Clock (2016), expresa que la urgencia de potenciar la comunicación es una necesidad imperiosa. Por ello, según Miniwatts Marketing Group (2015), en la actualidad existen 3.035.749.340 de internautas que representan el $42,55 \%$ de la población mundial quienes utilizan las Tecnologías de la Información y Comunicación, no solo para mantenerse comunicados, sino también para capacitarse en línea a través de plataformas informáticas disponibles en internet cuyas temáticas son auspiciadas por universidades o por empresas privadas, con el fin de permitirles alcanzar una preparación académica que conlleve a que cada vez sean más competitivos y exitosos en las actividades que desarrollen (Aguaded \& Gómez, 2013).

En Latinoamérica, la educación superior está pasando por procesos de trasformación, ya que se incorporan metodologías y nuevas tecnologías (TI) cuya tendencia fortalece la enseñanza aprendizaje dentro de las instituciones de educación. De tal forma que en el 2008 el término "MOOC" fue introducido en Canadá por Cormier, (2008), denominado curso en línea por Siemens, (2004) \& Downes, (2007). Es importante recalcar que estos escenarios podrían considerarse la manifestación más reciente en la utilización de software libre con miras a potenciar la cultura digital es decir la expansión de conocimiento.

Los MOOC potencian de manera directa la interacción entre el docente y estudiante, de tal modo que el proceso de aprendizaje mejora a través del uso de diferentes herramientas integradoras (redes sociales, RSS). Así, el estudiante se convierte en generador de nuevos contenidos a través de estas estrategias de aprendizaje (Clarà, 2013).

De acuerdo a Durall Gazulla, Perspectivas tecnológicas, (2012), presenta un informe sobre las tecnologías actuales y su impacto en donde se muestra una tendencia que influye de manera directa en los procesos académicos y científicos dentro de las IES, de igual manera se señala que los usuarios pueden trabajar, aprender y estudiar en el tiempo que estimen además de existir una mayor movilidad. Por consiguiente, es importante tener en cuenta que la aplicación de éstas en la educación conlleva a fortalecer el papel como docentes (garantizar la calidad de la docencia) y a potenciar los procesos académicos (en la creación de contenidos online, asesoramiento y acreditación).

\section{HORIZONTE DE IMPLANTACIÓN: UN AÑO O MENOS}

Aplicaciones móviles, computación en nube, contenido abierto entornos colaborativos

Computación en nube, Aplicaciones móviles, Lecturas sociales, Tabletas

\section{HORIZONTE DE IMPLANTACIÓN: DE DOS A TRES AÑOS}

Analíticas de aprendizaje, aplicaciones semánticas, cursos masivos abiertos en línea, realidad aumentada

Entornos adaptativos, Realidad aumentada, Aprendizaje basado en juegos, Analíticas de aprendizaje

HORIZONTE DE IMPLANTACIÓN: DE CUATRO A CINCO AÑOS

Aprendizaje basado en juegos, tabletas, entornos personales de aprendizaje, geolocalización
Interfaces naturales, Internet de los objetos, Computación basada en gestos

Fuente: (Durall Gazulla, 2012). 
En sí, los nuevos escenarios formativos de las IES se están alineando hacia la concepción de un nuevo modelo de formación masiva / gratuita por medio de una metodología denominada video -simulación como instrumento cooperativo y colaborativo dentro del aula virtual de clase (Margaryan, A., Bianco, M., \& Littlejohn, A., 2015).

Por lo tanto los cursos abiertos - online se presentan bajo una combinación de organización y diseño que exhiben contenidos específicos, procesos, normas que debe seguir el alumno en el desarrollo de cada curso y evaluación del mismo. Desde esta representación, Creed-Dikeogu, (2013), establece diferentes categorías de MOOC definida en siete tipos: 1) TransferMOOCs (Cursos existentes en las Universidades de E-Learning y transferirlos a una plataforma MOOC), 2) MadeMOOCs (agregan compendios de vídeo, eficacia de la creación de tareas que deben ejecutar los alumnos, fomentan el trabajo entre docente / alumno y la coevaluación), 3) SynchMOOCs (los cursos presentan fechas específicas de comienzo y de finalización, así como de realización de las evaluaciones), 4) AsynchMOOCs (sin fechas límites), 5) AdaptiveMOOCs (utilizan algoritmos adaptativos para presentar experiencias de aprendizaje personalizadas, basadas en la evaluación dinámica y la recopilación de datos del curso), 6) GroupMOOCs (elaborados para grupos específicos), 7) ConnectivistMOOCS (los propuestos por Siemens) y 8) MiniMOOCSs (de cortos números de contenidos y plazos de desarrollo).

Según Ferreira, J. M. M., (2016) para operativizar la transmisión de conocimientos a través de la vinculación con la comunidad de manera global se han formado redes de universidades internacionales, mismas que a través de plataformas online ofrecen cursos en línea masivos y abiertos conocidos como MOOC (Massive Online Open Courses) en diferentes áreas del conocimiento. Esto representa un cambio cultural puesto que esto ha permitido pasar de plataformas educativas cerradas a entornos de aprendizajes abiertos, y ha supuesto la posibilidad de que miles de personas de todo el mundo sigan diferentes iniciativas educativas: Entre las plataformas universitarias más importantes a nivel mundial que ofrecen cursos MOOC gratuitos se tiene a:

EDX.- Esta plataforma aglutina a las principales universidades del mundo de habla inglesa como son Massachusetts Institute of Technology, Harvard University, Berkeley University of california, The University of Texas System, Australian National University, Boston University, Georgetown University, Sorbonne University, entre otras (Oliver Riera, 2014).

MIRIADAX.- Esta plataforma engloba a las principales universidades hispanoamericanas como son Universidad Politécnica de Valencia, Universidad Rey Juan Carlos, Universidad Politécnica de Madrid, Universidad de Málaga, Universidad de Palermo, Universidad Carlos III de Madrid, Universidad de Zaragoza, Universidad Complutense de Madrid, Universidad de Cataluña, Pontificia Universidad Católica de Rio Grande do Soul, Universidad de Nova de Lisboa, Universidad Politécnica de Cartagena, Universidad Nacional de Quilmes, Universidad de Santiago de Chile entre otras (Ruiz Martín, 2013).

COURSERA.- Esta plataforma aglutina a universidades de diferentes partes del mundo con cursos en diferentes idiomas muchos de los cuales no son gratuitos (Bates, 2012).

Además de las plataformas universitarias, se encuentran plataformas académica dirigidas por empresas privadas, que a diferencias de las plataformas antes indicadas ofrecen un servicio a cambio de un pago. Entre las plataformas informáticas privadas más conocidas a nivel mundial tenemos a Open english, que ofrece un aprendizaje especializado en inglés. 


\section{MATERIALES Y MÉTODOS}

La metodología utilizada es de tipo investigación - acción, con una dimensión organizativa constructivista, ya que permitió indagar de manera introspectiva colectiva el hecho científico con el fin de mejorar la realidad educativa de las Instituciones. Se plico el modelo de Gértrudix Barrio, (2017) y métodos de producción para el desarrollo de contenidos audiovisuales y multimedia para MOOC y la metodologia eficiente para la práctica educativa definida por (Carr, 1986 - 1987).

Se aplicación encuestas a 140 usuarios entre estudiantes y docentes de las carreras de Ingeniería en Sistemas de la Universidad Técnica de Manabí y Carrera de Ingeniería en Computación y Redes de la Universidad Estatal del Sur de Manabí, y estas permitieron obtener información pertinente respecto al hecho científico y su solución.

\section{RESULTADOS Y DISCUSIÓN}

Para conocer la importancia que dan los estudiantes Universitarios Manabitas a su auto preparación académica, se realizó una encuesta en la que participaron 140 estudiantes y docentes de las Carreras de Ingeniería en Computación y Redes de la Universidad Estatal del Sur de Manabí e Ingeniería en Sistemas de la Universidad Técnica de Manabí, de los cuales 105 son de sexo masculino que representan un porcentaje del $75 \%$ y 35 de sexo femenino que representan un porcentaje del $25 \%$, de los cuales se obtuvo la siguiente información:

\section{1. ¿Desde qué lugares tienes acceso a internet?}

Tabla 2. Desde que lugares tienes acceso a internet.

\begin{tabular}{|c|c|c|}
\hline Alternativa & Encuestados & Porcentaje \\
\hline Hogar & 80 & $57,1 \%$ \\
\hline Trabajo & 15 & $10,7 \%$ \\
\hline Centro de estudios & 20 & $14,3 \%$ \\
\hline Lugar de acceso público & 25 & $17,9 \%$ \\
\hline Ninguno & 0 & $0 \%$ \\
\hline Total & 140 & $100 \%$ \\
\hline
\end{tabular}

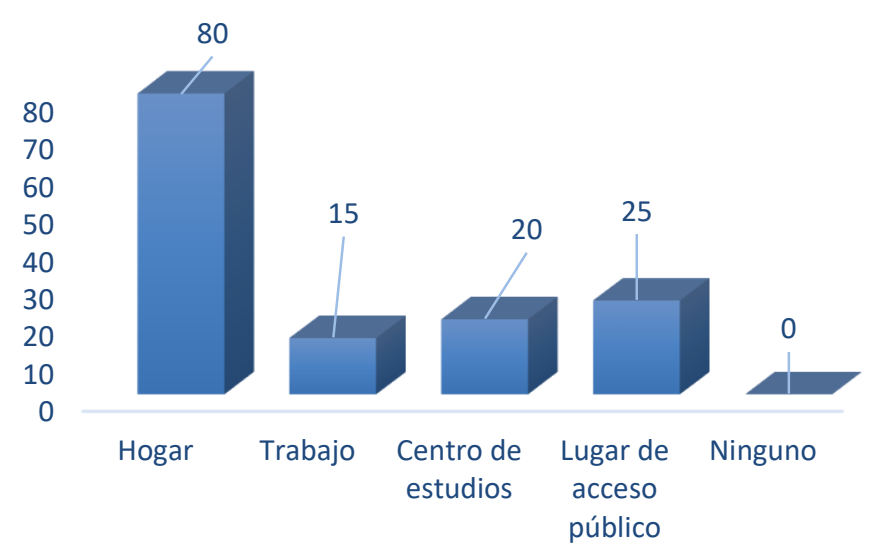

Ilustración 1. Porcentaje de lugares desde donde tienes acceso a internet. Fuente: trabajo de Campo. Encuesta realizada dentro de la UNESUM y UTM. 
De los resultados obtenidos se determina que 80 usuarios que representan el $57,1 \%$ respondieron que se conectan desde el hogar, 15 usuarios que representan el 10,7\% que se conectan desde el trabajo, 20 usuarios que representan el 14,3\% respondieron que se conectan desde el centro de estudios, 25 usuarios que representan el 17,9\% respondieron que se conectan desde lugar de acceso público y el $0 \%$ ninguno. Por lo tanto se establece que un gran porcentaje de usuarios se conecta desde el hogar, por lo que sería idóneo el implementar políticas para que los estudiantes y docentes realicen cursos virtuales interactivos para mejorar competencias específicas en horas extra - curriculares.

\section{2. ¿Con qué tipo de equipos se conecta a internet?}

Tabla 3. Equipos con los cuales se conecta a internet.

\begin{tabular}{|c|c|c|}
\hline Alternativa & Encuestados & Porcentaje \\
\hline Computador & 80 & $57,1 \%$ \\
\hline Smartphone & 40 & $28,6 \%$ \\
\hline Tablet & 16 & $11,4 \%$ \\
\hline Otro dispositivo & 4 & $2,9 \%$ \\
\hline Ninguno & 0 & $0 \%$ \\
\hline Total & 140 & $100 \%$ \\
\hline
\end{tabular}

80

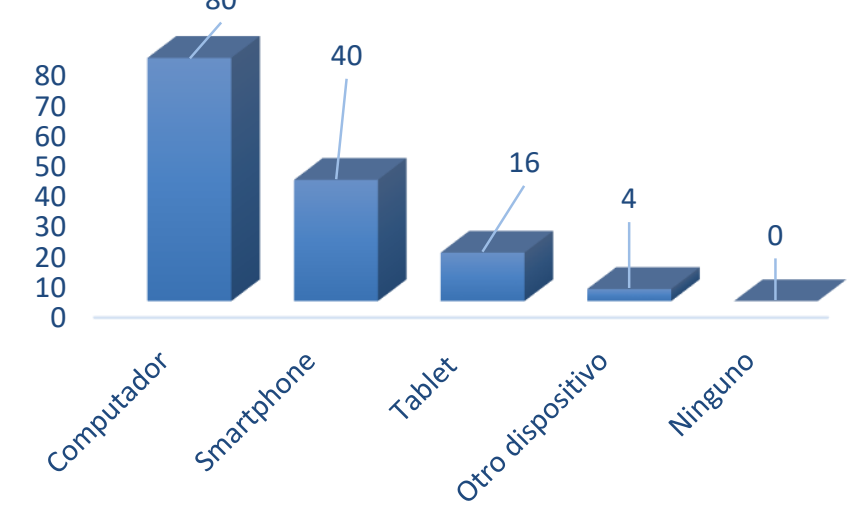

Ilustración 2. Equipos con los cuales se conecta a Internet.

Fuente: trabajo de Campo. Encuesta realizada dentro de la UNESUM y UTM.

De los resultados obtenidos se determina que 80 usuarios que representan el 57,1\% expresaron que se conectan a través de un computador personal, 40 usuarios que representan el $28,6 \%$ que se conectan a través de un Smartphone, 16 usuarios que representan el $11,4 \%$ se conectan desde tablet, 4 usuarios que representan el $2,9 \%$ indicaron que se conectan por medio de otros dispositivos y el $0 \%$ ninguno.

Por lo tanto, se puede evidenciar el uso de equipos tecnológicos para realizar diferentes actividades a través del Internet. 
3. ¿Cuántas horas dedica diariamente a estar conectado al internet?

Tabla 4. Horas que dedicas diariamente a estar conectado a Internet.

\begin{tabular}{|c|c|c|}
\hline Alternativa & Encuestados & Porcentaje \\
\hline De 1 a 2 horas & 40 & $28,6 \%$ \\
\hline De 2 a 3 horas & 45 & $32,1 \%$ \\
\hline De 3 a 4 horas & 27 & $19,3 \%$ \\
\hline Más de 5 horas & 28 & $20 \%$ \\
\hline Ninguna & 0 & $0 \%$ \\
\hline Total & 140 & $100 \%$ \\
\hline
\end{tabular}

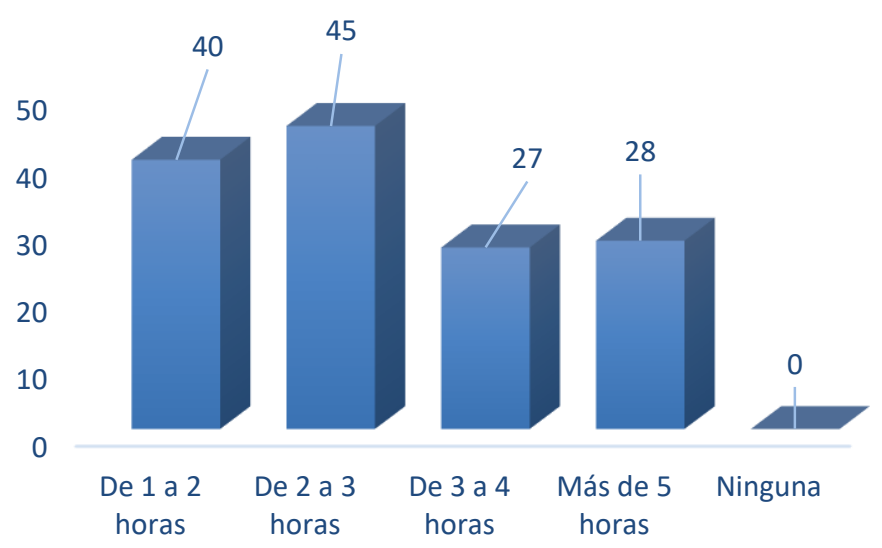

Ilustración 3. Horas que dedicas diariamente a estar conectado a Internet. Fuente: trabajo de Campo. Encuesta realizada dentro de la UNESUM y UTM.

De los resultados obtenidos se determina que 40 usuarios que representan el $28,6 \%$ se conectan a internet entre 1 a 2 horas, 45 usuarios que representan el 32,1\% entre 2 a 3 horas, 27 usuarios que representan el 19,3\% 3 a 4 horas, y 28 usuarios que representan el $20 \%$ más de 5 horas.

Por lo tanto, se observa que los usuarios encuestados se conectan a internet en un rango significativo cuyo tiempo bien distribuido podría beneficiar la preparación del mismo a través de cursos MOOCs.

\section{4. ¿Para qué servicios/actividades utiliza internet?}

Tabla 5. Servicios/actividades utiliza Internet.

\begin{tabular}{|c|c|c|}
\hline Alternativa & Encuestados & Porcentaje \\
\hline Obtener información (producto, servicios, etc.) & 20 & $14,3 \%$ \\
\hline Comunicación en general & 18 & $12,9 \%$ \\
\hline Educación y aprendizaje & 60 & $42,9 \%$ \\
\hline Actividades de entretenimiento (videos, descarga de juegos, entre otros) & 25 & $17,9 \%$ \\
\hline Por razones de trabajo & 10 & $7,1 \%$ \\
\hline Otro & 7 & $5,0 \%$ \\
\hline Ninguno & 0 & $0 \%$ \\
\hline Total & 140 & $100 \%$ \\
\hline
\end{tabular}




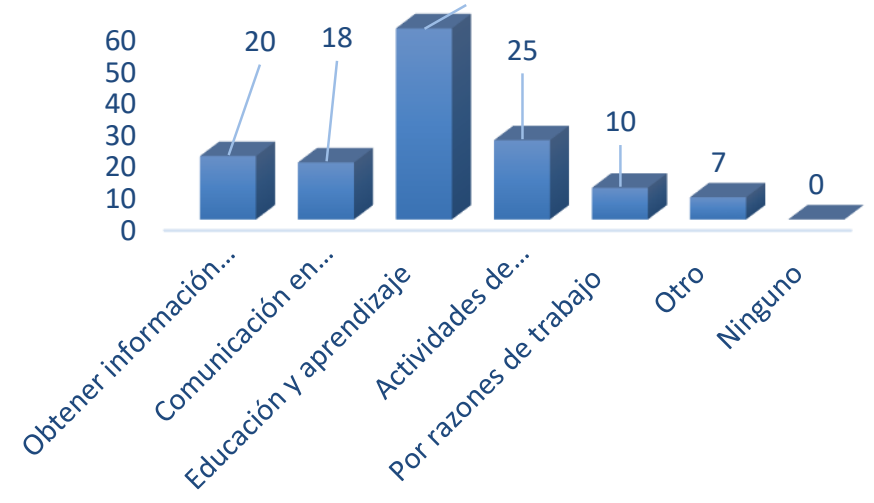

llustración 4. Servicios/actividades utiliza Internet.

Fuente: trabajo de Campo. Encuesta realizada dentro de la UNESUM y UTM.

De los resultados obtenidos se determina que 20 usuarios que representan el 14,3\% respondieron que utilizan el internet para obtener información, 18 usuarios que representan el 12,9\% respondieron comunicaciones en general, 60 usuarios que representan el 42,9\% respondieron educación y aprendizaje, 25 usuarios que representan el 17,9\% respondieron actividades de entretenimiento, 10 usuarios que representan el $7,1 \%$ expresaron que utilizan el internet por razones de trabajo y 7 usuarios que representan el $5 \%$ otros.

De tal forma que un gran porcentaje de usuarios utiliza el internet para la autoformación en áreas específicas de acuerdo a sus necesidades académicas y científicas.

\section{5. ¿Cuánto tiempo dedica semanalmente a su auto preparación académica?}

Tabla 6. Tiempo que dedica semanalmente a su auto preparación académica.

\begin{tabular}{|c|c|c|}
\hline Alternativa & Encuestados & Porcentaje \\
\hline De 1 a 3 & 41 & $29,3 \%$ \\
\hline De $\mathbf{3}$ a 5 & 38 & $27,1 \%$ \\
\hline De 5 a 7 & 30 & $21,4 \%$ \\
\hline De 7 a 9 & 7 & $5 \%$ \\
\hline Menos de 9 & 16 & $11,4 \%$ \\
\hline Ninguna & 8 & $5,7 \%$ \\
\hline Total & 140 & $100 \%$ \\
\hline
\end{tabular}

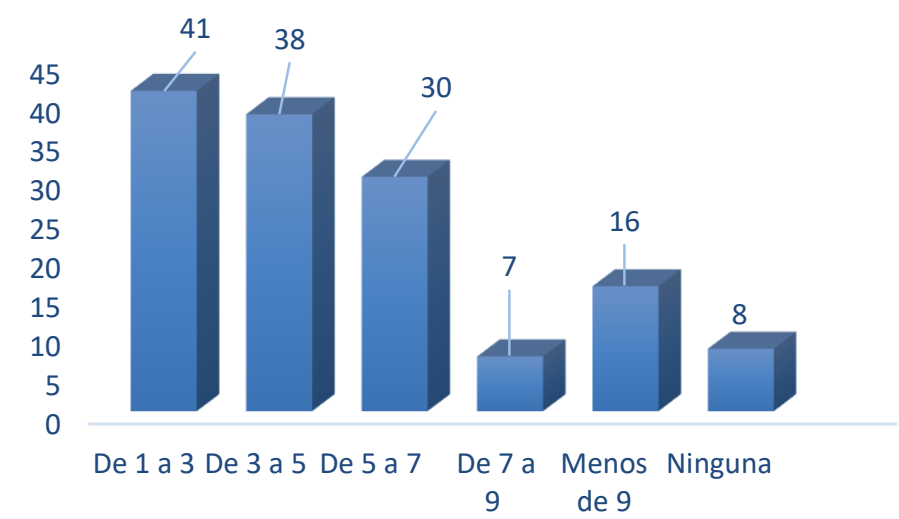

Ilustración 5. Tiempo que dedica semanalmente a su auto preparación académica. Fuente: trabajo de Campo. Encuesta realizada dentro de la UNESUM y UTM. 
De los resultados obtenidos se determina que 41 usuarios que representan 29,3\% expresaron que dedican entre 1 y 2 horas a su auto - preparación académica, 38 usuarios que representan el 27,1\% indicaron que dedican de 3 a 5 horas, 30musuarios que representan el 21,4\% indicaron de 5 a 7 horas, 7 usuarios que representan el $5 \%$ de 7 a 9 , y 8 usuarios que representan el $5,7 \%$ ninguno.

De tal forma que existe un alto porcentaje de usuarios que utilizan el internet para realizar un proceso de auto - preparación es decir fortalecer conocimientos técnicos, académicos y científicos.

\section{6. ¿Conoce usted sobre los beneficios que tiene el acceder un MOOCs para fortalecer conocimientos?}

Tabla 7. Acceder un MOOCs para fortalecer conocimientos.

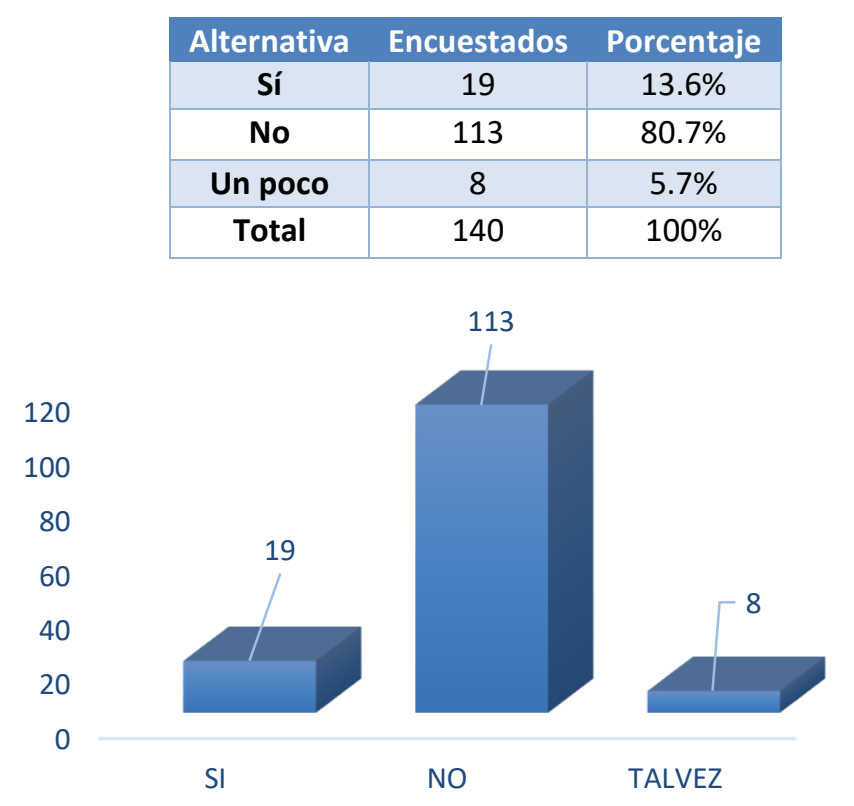

Ilustración 6. Beneficios que se tiene al acceder un MOOCs.

Fuente: Trabajo de Campo. Encuesta realizada dentro de la UNESUM y UTM.

De los resultados obtenidos se determina que 113 encuestados que representan el 80,7\% expresaron que no conocen los beneficios que tiene iniciar y terminar un curso MOOCs, 19 encuestados que representan el 13,6\% expresaron que si conocen y 8 encuestados que representan el 5,7\% expresaron que un poco. De tal forma resulta necesario incentivar mediante estrategias el uso de estas herramientas tecnológicas para fortalecer conocimientos tanto en la parte académica como científica.

\section{En cuál de las siguientes plataformas ha realizado cursos MOOC?}

Tabla 8. ¿En qué plataformas has realizado un MOOCs?

\begin{tabular}{|c|c|c|}
\hline Alternativa & Encuestados & Porcentaje \\
\hline Miríada X & 31 & $22,1 \%$ \\
\hline Edx & 1 & $0,7 \%$ \\
\hline Coursera & 4 & $2,9 \%$ \\
\hline Otra & 4 & $2,9 \%$ \\
\hline Ninguna & 100 & $71,4 \%$ \\
\hline Total & 140 & $100 \%$ \\
\hline
\end{tabular}




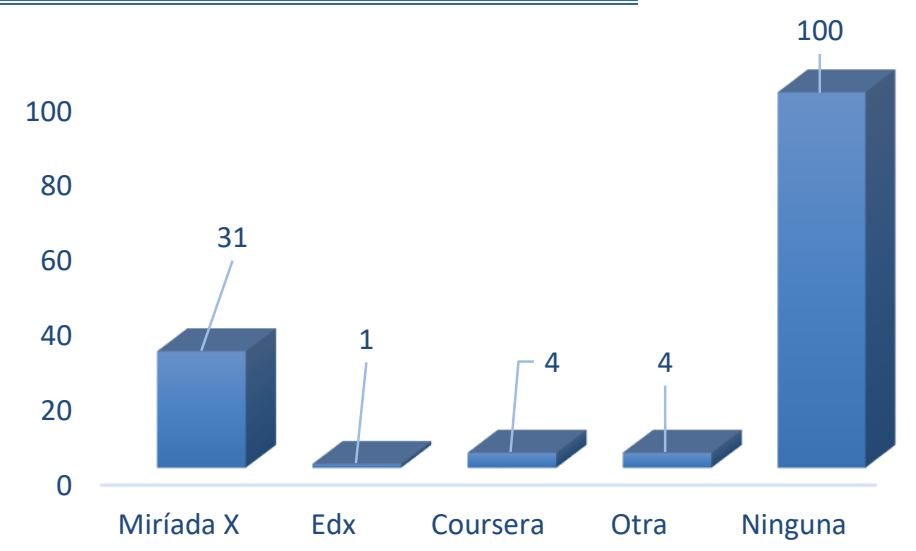

Ilustración 7. Uso de las Plataformas MOOCs.

Fuente: trabajo de Campo. Encuesta realizada dentro de la UNESUM y UTM.

De los resultados obtenidos se determina que 31 usuarios que representan el 22,11\% respondieron que han realizado un curso en la plataforma Miriadax, 1 usuario que representa el 0,7\% indicó que ha realizado un curso en $\mathrm{Edx}, 4$ usuarios que representan el 2,9\% indicó que ha trabajado con Coursera y 100 usuarios que representan el 71,4\% expresaron ninguno, es decir que no han trabajado con ninguna plataforma MOOCs.

De tal forma que resulta necesario aplicar estrategias para que los usuarios desarrollen cursos MOOCs de acuerdo a necesidades académicas propias y que las carreras de informática diseñen su propia plataforma para fortalecer la praxis constructivista a través de este enfoque interactivo colaborativo.

\section{8. ¿Cuántos cursos MOOCs ha concluido?}

Tabla 9. Cursos MOOCs terminado.

\begin{tabular}{|c|c|c|}
\hline Alternativa & Encuestados & Porcentaje \\
\hline De 1 a 2 & 24 & $17,1 \%$ \\
\hline De 2 a 3 & 3 & $2,1 \%$ \\
\hline De 3 a 4 & 3 & $2,1 \%$ \\
\hline Más de cinco & 2 & $1,4 \%$ \\
\hline Ninguno & 108 & $77,1 \%$ \\
\hline Total & 140 & $100 \%$ \\
\hline
\end{tabular}

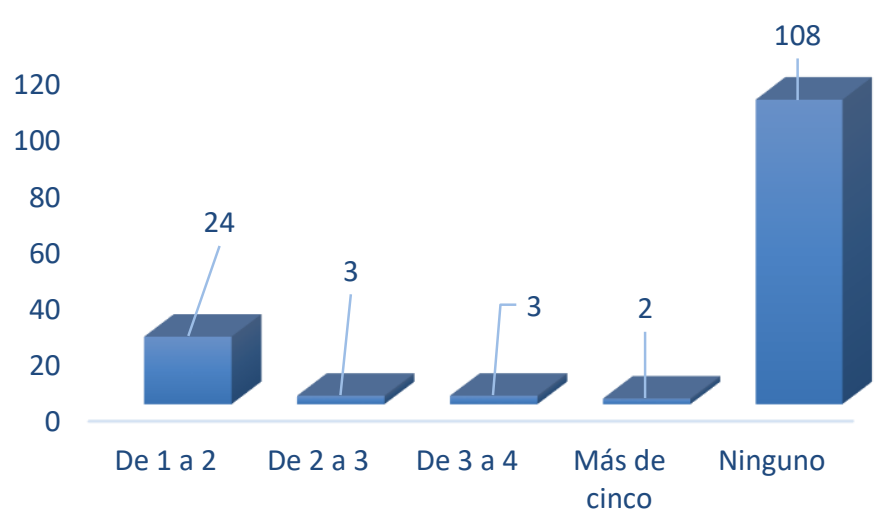

Ilustración 8. Porcentaje de cursos MOOCs terminados.

Fuente: trabajo de Campo. Encuesta realizada dentro de la UNESUM y UTM. 
De los resultados obtenidos se determina que 24 usuarios que representan el $17,1 \%$ afirman que ha terminado entre 1 y 2 cursos, 3 usuarios que representan el 2,1\% entre 2 y 3 cursos, 3 usuarios que representan el 2,1\% 3 a 4 cursos, 5 usuarios que representa 1,4\% expresó más de 5 y 108 usuarios que representan el $77,1 \%$ expresó que ninguno.

Por lo tanto, se observa un alto porcentaje de usuarios que no conocen los beneficios de poder acceder a estos cursos. Es necesario cambiar el esquema mental de la comunidad y que esta interactúe en ambientes internacionales virtuales y así abrir el espectro cognitivo para el desarrollo de la matriz de conocimiento de acuerdo a experiencias en áreas específicas.

\section{MODELO PARA LA CREACIÓN DE UN MOOC EN LA UNESUM}

La presente propuesta tiene como objeto principal el diseño de un modelo de MOOC que proporcione acceso libre de materiales pedagógicos de las unidades curriculares en las diversas carreras de la Universidad Estatal del Sur de Manabí a docentes, alumnos, investigadores y público en general que desee adquirir competencias técnicas para el desarrollo de sus actividades enfocados a potenciar el desarrollo local.

La idea general es aprovechar el conocimiento, compartirla y utilizarla para divulgar los productos intelectuales de los catedráticos realizando cursos masivos de contenido abierto a través del Internet donde los miembros de cada curso planifiquen su trayectoria de aprendizaje en base a las necesidades individuales de tiempo y espacio.

Esta propuesta está fundamentada en investigaciones realizadas por Cano, (2015), Cruz, (2017) y Gértrudix Barrio, (2017), que expresan el desarrollo de un MOOC sustentable y sostenible a traves de un proceso detallado de planificación, diseño y desarrollo que involucra a diversos catedraticos de diferentes áreas de trabajo, la aplicación de metodologias, estrategias y técnicas para el diseño de recursos educativos, audioviual, multimedia.

El mismo permitirá tanto a catedráticos y estudiantes apropiarse de conocimientos generados e integrar la praxis educativa para el desarrollo de la investigación y la catedra contribuyendo de manera inclusiva al acceso igualitario generando mayores y mejores oportunidades de formación.

La metodología a utilizar está compuesta por fases y etapas desde el 1) Diagnóstico, 2) Desarrollo, e 3) Implementación. La misma que tendrá una duración para su ejecución de 6 meses, los diversos cursos corresponderían a las unidades curriculares de la Carrera Ingeniería en Computación y Redes con la participación de los docentes titulares de la Universidad Estatal del Sur de Manabí, y los mismos constan de: lecturas, materiales de apoyo, actividades, evaluaciones y certificaciones de participación y acreditación.

Líneas curriculares identificadas: Telecomunicaciones, robótica, electrónica y programación. De acuerdo a la estructura de la propuesta se determinó el siguiente orden:

1) Diagnóstico.- En esta fase se tiene como objetivo realizar un análisis situacional sobre necesidades de capacitación técnica específica, la definición de elementos técnicos, pedagógicos y didácticos para la elaboración del curso virtual en la UNESUM. 
2) Desarrollo.- La determinación de elementos para el diseño, desarrollo, acceso evaluación y acreditación, la capacitación técnica, pedagógica y didáctica a docentes involucrados y el diseño del aula virtual y los diversos cursos en base a criterios técnicos y pedagógicos concretos. Además de la ampliación de cursos.

3) Implementación.- Se entrega el producto final y se evalúan los cursos previamente elaborados y se validan sus resultados. En esta etapa también se capacitan a nuevos docentes y se elaboran nuevos cursos virtuales de otras carreras y unidades curriculares.

En el área de formación general se pretende iniciar con los cursos: Metodología de la investigación, Ingles B2, electrónica, redes y ciudades digitales y Big - Data.

De acuerdo al desarrollo del MOOC se espera poder fortalecer el desarrollo de otros cursos necesarios de acuerdo al entorno, además tener información estadística sobre los resultados del impacto de los primeros cursos que permitan consolidar la calidad de los mismos.

\section{CONCLUSIONES}

El presente trabajo de investigación permitió determinar la importancia de los MOOCs en entornos universitarios para el fortalecimiento de la divulgación de conocimientos académicos y científicos. Se pudo realizar un análisis sobre indicadores concernientes a la utilización del Internet y sus beneficios para fines académicos, también se identificaron tipos de plataformas de código abierto gratuito para fortalecer actividades académicas y se procedió a proponer el desarrollo de un modelo de plataforma de acuerdo a líneas curriculares y necesidades de capacitación del entorno.

De acuerdo al análisis del estado del arte el diseño y desarrollo del MOOC requiere un fuerte apoyo institucional vinculándose de manera directa dentro de los objetivos educacionales de la IES, ya que éste exige estructuras definidas en la parte técnica, pedagógica y de recursos audiovisuales y multimedia. Como estrategia se puede considerar pertinente iniciar un programa de difusión de esta nueva forma de compartir conocimiento con el fin de que no solo los estudiantes universitarios las conozcan, sino que el público en general también las conozca y puedan hacer uso de ellas para auto - prepararse. 


\section{REFERENCIAS BIBLIOGRÁFICAS}

Bates, T. (2012). What's right and what's wrong about . Coursera-style MOOCs.

Blanco, Á. F. (2014). Educación en abierto: Integración de un MOOC con una asignatura académica. . Teoría de la Educación; Educación y Cultura en la Sociedad de la Información, 15(3), 233.

Cabero Almenara, J. L. (2014). Las tipologías de MOOC: su diseño e implicaciones educativas. digibug.ugr.es.

Cano, E. V.-M. (2015). Diseño y desarrollo del modelo pedagógico de la plataforma educativa "Quantum University Project". Campus virtuales, 2(1), 54-63.

Carr, W. \&. (1986 - 1987). Becoming critical Lewes. Falmer Press. Teaching for Learning, Bulletin of the American Association for Higher Education, 39, 3-7.

Chandler, P. (. (2014). Massive Open Online Courses (MOOCS). EEUU: School Librarian, 62(1), 18-19.

Cormier, D. (2008). Rhizomatic education: Community as curriculum. Innovate: . Journal of online education, 4(5), 2.

Creed-Dikeogu, G. \&. (2013). Are you MOOC-ing yet? A review for academic libraries. . Kansas Library Association College and University Libraries Section Proceedings, 3(1), 9-13.

Cruz, J. R. (2017). Integración de un curso MOOC y de un PLN-PLE en un curso presencial sobre fundamentos de la programación. . Revista de Educación a Distancia, (53).

Downes, S. (2007). Models for sustainable open educational resources. . Interdisciplinary journal of knowledge and learning objects, 3(1), 29-44.

Durall Gazulla, E. G. (2012). Perspectivas tecnológicas:. educación superior en Iberoamérica 20122017.

Durall Gazulla, E. G. (2012). Perspectivas tecnológicas: . Educación superior en Iberoamérica 20122017.

Ecuador, G. N. (2009). Plan nacional del buen vivir. Obtenido de Constituyendo un Estado Plurinacional e Intercultural:. http://issuu. com/publisenplades/docs/pnbv_2009-2013.

Ferreira, J. M. M. (2016). Massive Open Online Courses (MOOCs). In Cross-Border Higher Education and Quality Assurance (pp. 203-219). Palgrave Macmillan UK.

Gértrudix Barrio, M. R. (2017). Metodología de producción para el desarrollo de contenidos audiovisuales y multimedia para MOOC. RIED: . Revista Iberoamericana de Educación a Distancia, 20(1), 183-203.

Históricos, P. (2015). Sistema de Información Científica Red de Revistas Científicas de América Latina, el Caribe, España y Portugal Proyecto académico sin fines de lucro, desarrollado bajo la iniciativa de acceso abierto. Procesos Históricos, (28), 1-2. 
Kop, R., Fournier, H., \& Mak, J. S. F. (2011). A pedagogy of abundance or a pedagogy to support human beings? Participant support on massive open online courses. The International Review Of Research In Open And Distributed Learning, 12(7), 74-93.

Margaryan, A., Bianco, M., \& Littlejohn, A. (2015). Instructional quality of massive open online courses (MOOCs). Computers \& Education, 80, 77-83.

Michavila, F. (2010). Situación actual e perspectivas de futuro da formación e innovación educativa nas universidades. . España: Vicerreitoría de Formación e Innovación Educativa, Universidade de Vigo.

Molina Villacis, M. G. (2016). Análisis de la utilización de calidad de servicio (QoS) en redes de nueva generación (NGN) en el Ecuador. (Master's thesis, Espol).

Oliver Riera, M. H. (2014). MOOCs en España. . Panorama actual de los Cursos Masivos Abiertos en Línea en las universidades españolas.

Plúa, C. R. C., Gonzalez, A. D. C. R., Castro, M. I. R., \& Rodríguez, E. L. (2016). LA UNIVERSIDAD EN EL DESARROLLO DEL EMPRENDIMIENTO A TRAVÉS DE UNA PLATAFORMA VIRTUAL EN EL CECADEL DE LA UNESUM-PAJAN. 3C Tecnología, 5(4), 36-55.

Pulido, A. (2009). El futuro de la Universidad. Un tema.

Rodriguez, C. O. (2012). MOOCs and the Al-Stanford like courses: Two successful and distinct course formats for massive open online courses. European Journal of Open, Distance and E-Learning, 15(2).

Ruiz Martín, P. (2013). Presente y futuro de los Massive Open Online Courses (MOOC): Análisis de la oferta completa de cursos de las plataformas Coursera, EdX, Miríada X y Udacity.

Siemens, G. \&. (2004). Conectivismo: . Una teoría de aprendizaje para la era digital. Recuperado el, 15.

Sitaraman, R. K. (2014). Overlay networks: An akamai perspective. Advanced Content Delivery, Streaming, and Cloud Services, 51(4), 305-328.

Vázquez Cano, E. \&. (2015). La filosofía educativa de los MOOC y la educación universitaria. RIED: . Revista Iberoamericana de Educación a Distancia, 18(2), 25-37.

Vázquez Cano, E., \& López Meneses, E. (2014). Los MOOC y la educación superior: la expansión del conocimiento. dide.minedu.gob.pe. 


\section{ANÁLISIS DOCUMENTAL DE LOS INCONVENIENTES DE LA IMPRESIÓN 3D}

1. Licenciada en Informática Administrativa. Universidad Autónoma del Estado de México. Centro Universitario Temascaltepec, (México). E-mail: gomrey 13@hotmail.com

\section{Citación sugerida:}

Gómez Reyes, L. (2017). Análisis documental de los inconvenientes de la impresión 3D. 3C Tecnología: glosas de innovación aplicadas a la pyme, 6(3), 48-53. DOI: <http://dx.doi.org/10.17993/3ctecno.2017.v6n3e23.48-53/>. 


\section{RESUMEN}

El trabajo presente es un análisis documental acerca de la impresión 3D, en el cual se presentan sus principales características y a la vez un análisis de los principales inconvenientes que genera el uso de la tecnología de impresión 3D, la cual en los últimos años ha sido una tecnología innovadora y de mucho impacto. Esta tecnología se dio a conocer por primera vez en 1986, pero fue hasta hace apenas un par de años que comenzó a tener un mayor uso e impacto en distintos sectores productivos. La impresión 3D consiste en reproducir mediante cierto proceso objetos en tres dimensiones que se obtienen a partir de un modelo informático. Esta tecnología tiene sus ventajas y desventajas y en este análisis se podrán apreciar cuales son los principales inconvenientes que tiene el uso de esta.

\section{ABSTRACT}

The present work is a documentary analysis about 3D printing, which presents a study of the main drawbacks generated by the use of 3D printing technology, which in recent years has been an innovative technology and a lot of impact. This technology first became known in 1986, but it was only a couple of years ago that it began to have greater use and impact in different productive sectors. $3 \mathrm{D}$ printing consists of reproducing through a certain process objects in three dimensions that are obtained from a computer model. This technology has its advantages and disadvantages and in this analysis will be able to appreciate what are the main inconveniences that has the use of this.

\section{PALABRAS CLAVE}

Impresión 3D, Inconvenientes, Análisis, Riesgo, Tecnología.

\section{KEY WORDS}

3D Printing, Disadvantages, Analysis, Risk, Technology. 


\section{INTRODUCCIÓN}

Hace más de 20 años fue inventado el primer método de impresión 3D, fue en 1983 cuando Chuck Hull tuvo la idea de crear el primer método de impresión 3D, desde entonces su uso y alcance ha crecido exponencialmente avanzando cada día más. Para 1984 Hull patento la primera máquina capaz de crear impresiones en 3D.

La impresión 3D ha sido revolucionaria, porque presenta una nueva manera de producir, modificando el cómo se inventan y elaboran diferentes productos. En el 2014 la impresión 3D se comenzó a utilizar de forma masiva para la manufactura instantánea de diversos objetos domésticos y para la generación de tejidos orgánicos a partir de bases celulares.

"La impresión 3D es un grupo de tecnologías de fabricación por adición donde un objeto tridimensional es creado mediante la superposición de capas sucesivas de material" (Noguera, 2014). Las impresoras 3D se basan en modelos 3D para definir qué se va a imprimir. Un modelo no es sino la representación digital de lo que vamos a imprimir mediante algún software de modelado.

Actualmente, el proceso de impresión 3D se puede llevar a cabo mediante el uso de muy variados materiales, con los cuales se pueden elaborar desde productos domésticos sencillos, hasta detalladas piezas para aviones o automóviles, así como órganos funcionales para los seres vivos.

Mediante este trabajo se pretende dar a conocer un poco más acerca de este tema del cual se ha analizado poco, echando de ver cuáles son sus principales características y los inconvenientes principales que se generan al usar esta tecnología en la vida cotidiana y en los procesos de fabricación de distintos sectores industriales.

\section{IMPRESIÓN 3D}

La impresión 3D surgió en 1983 cuando el inventor Chuck Hull ideó el primer método de la impresión 3D o estereolitografia, el cual es un proceso de fabricación por adición que emplea resina que cura mediante una luz ultravioleta en un tanque, y un láser ultravioleta para construir los objetos que se obtienen mediante la adición de finas capas impresas una encima de la otra.

Hoy en dia se puede definir a la impresión 3D como un grupo de tecnologías de fabricación por adición capaz de crear piezas volumetricas en tres dimensiones. Esta fabricación se genera desde un software de diseño 3D, los archivos se envian a la impresora 3D que funciona gracias a los polímeros que se usan en el proceso, estos actúan por diferentes medios que solidifican el materia capa a capa hasta completar la pieza tridimensional fabricada.

Los programas de diseño por computadora que generan los modelos se les conoce como sistema de diseño asistido por computadora (CAD) y los equipos que reciben dichos programas para controlar las tareas de fabricación se les llama sistema de fabricación asistido por computadora (CAM). Estas tecnologías combinadas (CAD/CAM) conforman la impresora 3D, que de acuerdo con cada técnica utilizada forman la manufactura aditiva y marca el comienzo de la llamada tercera revolución 
industrial. Los materiales con los que actualmente se puede imprimir son muy variados, ya que se pueden utilizar desde múltiples polímeros hasta metales y demás materiales más firmes.

Los procesos mas utilizados al presente para la impresión 3D son:

1. Por adición, inyecta polímeros que se agregan o suman por capas, método tambien denominado por polimerización.

2. Por compactación, formando una masa de polvo que se compacta por estratos.

3. Por estilográfica, este método utiliza una masa de resina fotosensible que se solidifica al ser expuesta a la luz ultravioleta.

4. Por sintonización láser, este método combina distintas capas de metal que son provistas por un suministrador que entrega el metal a un dispositivo láser que funde las capas y forma el objeto.

No son pocos los que ven en las impresoras 3D esos objetos maravillosos con los que soñaron en su infancia. No se puede negar el asombroso potencial de estos dispositivos para reproducir los juguetes favoritos de prácticamente cualquiera con suficiente tiempo y paciencia. Son herramientas asombrosas y benéficas, siempre y cuando estén en las manos correctas.

\section{INCONVENIENTES DE LA IMPRESIÓN 3D}

De acuerdo a un análisis realizado en trabajos de investigación ya desarrollados y artículos publicados en páginas como Euro residentes, Facultad de Ciencia y Tecnologías de la Universidad de Nuestra señora de la Asunción, Audiencia Electrónica y Revistas bolivianas, entre otras, se puede hacer mención de que los principales inconvenientes que genera el uso de la impresión 3D son los siguientes.

Consumo de energía. Según un estudio de la Universidad de Loughborough cuando las impresoras 3D derriten plástico con calor o láser, estas consumen alrededor de 50 a 100 veces más energía eléctrica que el tradicional moldeo por inyección empleado para hacer un artículo del mismo peso.

> Riesgos a la salud. El autor Lyndsey Gilpen indicó, haciendo mención de un estudio del Instituto de Tecnología de Illinois, EE.UU. que cuando una impresora 3D trabaja con algunos materiales emite varios millones de micro-partículas por minuto, que se depositan en los pulmones o el torrente sanguíneo y plantean riesgos para la salud.

> Contaminación. Las impresoras 3D usan principalmente 2 tipos de plásticos: el PLA es biodegradable, pero la mayoría utiliza filamentos ABS, que contaminan. Todos los restos de plástico producidos por la impresión van a parar a la basura.

$>$ Vulneración de los derechos de autor. La réplica de objetos con copyright es difícil de controlar pues los escáneres 3D permiten la réplica de cualquier objeto. "Esta potencial situación de piratería digital es comparable a la forma en que internet desafió los derechos 
de autor de las industrias del cine y la música, las marcas comerciales y las descargas ilegales", dijo Gilpen.

> Disminución de puestos de trabajo. La elaboración propia de los productos, y la disminución de maquinaria puede conllevar menos puestos de trabajo en la manufactura.

> Creación de objetos ilícitos. Lamentablemente, existe la posibilidad de crear objetos tales como armas de fuego o armas blancas y el peligro de generalizar este tipo de objetos.

> Falta de responsabilidad. Si algún elemento creado y vendido por algún fabricante de impresoras 3D fallara o causara la muerte a otra persona, aun no se tiene claridad sobre en quien recae la responsabilidad.

$>$ Narcotráfico. Se pueden crear estupefacientes y drogas sintéticas, controlar el tráfico de drogas desde cualquier hogar es tarea imposible para las autoridades.

D Seguridad. Prácticamente cualquier cosa puede ser creada, desde armas hasta bombas, y controlar esto sería imposible.

> Químicos en los materiales de producción. Algunos de los plásticos son tóxicos o venenosos, y si estos se utilizan para crear por ejemplo recipientes para comida o cubiertos, al tener contacto con la comida serian un arma letal, un veneno moderno.

> Imperfecciones en el objeto. Partes del objeto generado por una impresora 3D suelen tener un acabado superficial rugoso y estriado. Esta apariencia se debe a cuentas de plástico o partículas de polvo en grandes dimensiones que se apilan una encima de la otra, dando al producto final un aspecto inacabado.

Estos inconvenientes mencionados anteriormente nos hacen preguntarnos si la implementación de esta nueva tecnología a la sociedad ha sido benéfica o contraproducente.

\section{CONCLUSIONES}

Después de haber llevado a cabo este análisis es posible mencionar que la impresión 3D hoy en día tiene muchas y variadas aplicaciones, y puede crear, al parecer cualquier objeto que se pueda imaginar e implementar en el software de diseño, en los últimos años esta tecnología ha llamado mucho la atención y se ha dado a conocer de una forma más comercial.

A pesar de que la impresión 3D se utiliza en distintos sectores y nos proporciona bastantes beneficios, se están presentando los distintos inconvenientes que mencione anteriormente al llevar a cabo la aplicación de esta tecnología.

Los inconvenientes que genera su uso son bastante significativos, y es de suma importancia tomar medidas para reducir los daños colaterales que puede tener el uso de esta. En su mayoría estos inconvenientes pueden ser regulados con la creación de leyes que permitan evitar las situaciones en las que esta tecnología se usa de manera incorrecta o para hacer daño a alguna persona. 
Por último se puede mencionar que al llevar a cabo este análisis se llegó a la conclusión de que las impresoras 3D son una tecnología que ha llegado a beneficiar a la sociedad en general en cuanto a todo lo que se puede realizar con ellas, siempre y cuando nosotros mismos como sociedad no busquemos darle un mal uso a tan útil herramienta, y siendo también consientes de los riesgos que esta tiene para evitar accidente o daños a la sociedad.

\section{REFERENCIAS BIBLIOGRÁFICAS}

3D, F. M. (17 de 11 de 2015). Fundamentos de la Impresion 3D. Bogota, Colombia.

Conde, J. E. (11 de 03 de 2016). Intranet Bibliotecas. Obtenido de http://intranet.bibliotecasgc.bage.es/intranettmpl/prog/local_repository/documents/17854.pdf

Escobar, C. $(23$ de 03 de 2013). Impresoras 3D. Obtenido de https://impresoras3d.com/blogs/noticias/102825479-breve-historia-de-la-impresion-3d

Flores, H. J. (2014). Revistas Bolivianas. Obtenido de http://www.revistasbolivianas.org.bo/pdf/rtft/v12n18/v12n18_a06.pdf

Morrison, H. (29 de 03 de 2014). Audiencia Electronica. Obtenido de http://www.audienciaelectronica.net/2014/03/las-10-principales-desventajas-de-lasimpresoras-3d/

Noguera, J. (Septiembre de 2014). Impresoras 3D. Obtenido de http://jeuazarru.com/wpcontent/uploads/2014/11/Impresoras-3D-2014.pdf

Reyes, L. G. (02 de 2015). Analisis de las Ventajas y Desventajas de las Diferentes Tecnicas de Impresion de la Tecnologia 3D 2014. Estado de México, México.

Rodriguez,

M.

(2015).

Euroresidentes.

Obtenido

de

https://www.euroresidentes.com/tecnologia/avances-tecnologicos/la-revolucion-de-la-

impresion-3d 


\title{
ESTADO DEL ARTE: METODOLOGÍAS DE DESARROLLO EN APLICACIONES WEB
}

\section{STATE OF ART: DEVELOPMENT METHODOLOGIES IN WEB APPLICATIONS}

\author{
Jimmy Rolando Molina Ríos ${ }^{1}$ \\ Mariuxi Paola Zea Ordóñez ${ }^{2}$ \\ María José Contento Segarra ${ }^{3}$ \\ Fabricio Gustavo García Zerda ${ }^{4}$
}

1. Universidad Técnica de Machala. Grupo de Investigación de la carrera de Ingeniería de Sistemas (Ecuador). E-mail: jmolina@utmachala.edu.ec

2. Universidad Técnica de Machala. Grupo de Investigación de la carrera de Ingeniería de Sistemas (Ecuador). E-mail: mzea@utmachala.edu.ec

3. Universidad Técnica de Machala. Grupo de Investigación de la carrera de Ingeniería de Sistemas (Ecuador). E-mail: micontento est@tmachala.edu.ec

4. Universidad Técnica de Machala. Grupo de Investigación de la carrera de Ingeniería de Sistemas (Ecuador).E-mail: fggarciaz est@utmachala.edu.ec

\section{Citación sugerida:}

Molina Ríos, J.R., Zea Ordóñez, M.P., Contento Segarra, M.J. y García Zerda, F. G (2017). Estado del arte: Metodologías de desarrollo en aplicaciones web. 3C Tecnología: glosas de innovación aplicadas a la pyme, 6(3), 54-71. DOI: <http://dx.doi.org/10.17993/3ctecno.2017.v6n3e23.54-71/>. 


\section{RESUMEN}

Actualmente el Internet es un importante medio de comunicación, por ello han surgido aplicaciones Web como intermediario para propagar información, así como para ofrecer servicios a los usuarios. Debido a esto se han desarrollado una serie de metodologías para el modelado de aplicaciones Web que apuntan a resolver distintos problemas existentes en el desarrollo de este tipo de software. Tanto para los investigadores, como para desarrolladores de software no es fácil identificar y conocer las diferencias entre una y otra metodología por el gran número de propuestas existentes y la complejidad de ellas. En vista de esto se realizó una investigación exhaustiva para obtener información sobre las metodologías y cuáles de éstas según diversos autores provee características esenciales en el desarrollo Web, cabe resaltar que estas metodologías se han tomado a partir de los resultados de una comparación realizada por los autores mediante el cumplimiento de los criterios expuestos, lo que permitió analizar las características de cada tipo de propuesta. Con esta comparativa se pudo verificar que las metodologías más potentes tienden a abarcar distintos elementos de todas las clasificaciones de metodologías, pues así se toman en cuenta muchos más aspectos de la Web que otras propuestas que se centran en brindar solución a un tipo de problema específico. Con esto se observa la necesidad de investigar las metodologías e identificar las propuestas que detallan el proceso de desarrollo de sitios más seguros y versátiles, a partir de esto se plantea el objetivo de analizar las metodologías de desarrollo de software orientadas a las aplicaciones Web a través de la recolección de información bibliográfica, de campo y la realización del estado del arte, para la comprobación de una metodología que cumpla las características y subcaracterísticas optimas en el desarrollo de aplicaciones Web. El resultado obtenido del análisis, confirma que existen diferencias entre las metodologías utilizadas de manera global y según la evidencia bibliográfica la metodología OOHDM se adapta al desarrollo ágil y preciso para la creación de aplicaciones Web.

\section{ABSTRACT}

Currently, the Internet is an important means of communication, which is why web applications have emerged as an intermediary to propagate information, as well as to offer services to users. Due to this have developed a series of methodologies for modeling Web applications that aim to solve various problems in the development of this type of software. For both researchers and software developers, it is not easy to identify and know the differences between the two approaches because of the large number of existing proposals and the complexity of them. In view of this, an exhaustive investigation was carried out to obtain information about the methodologies and which of them according to diverse authors provides essential characteristics in the Web development, it should be emphasized that these methodologies have been taken from the results of a comparison made by the authors Through the fulfillment of the exposed criteria, which allowed to analyze the characteristics of each type of proposal. With these comparisons, it was possible to verify that the most powerful methodologies tend to cover different elements of all classifications of methodologies, since so many aspects of the Web are taken into account that other proposals 
that focus on providing solution to a specific type of problem. With this, it is necessary to investigate the methodologies and identify the proposals that detail the process of developing safer and more versatile sites. Based on this, the objective is to analyze software development methodologies oriented to Web applications through of the collection of bibliographical information, of field and the accomplishment of the state of the art, for the verification of a methodology that fulfills the characteristics and sub-characteristics optimal in the development of Web applications. The result obtained from the analysis confirms that there are differences between the methodologies used in a global way and according to the bibliographic evidence the OOHDM methodology is adapted to the agile and precise development for the creation of Web applications.

\section{PALABRAS CLAVE}

Metodología, Aplicaciones Web, Desarrollo Ágil, software.

\section{KEY WORDS}

Methodology, Web Applications, Agile Development, Software. 


\section{INTRODUCCIÓN}

Las metodologías de desarrollo de software son un marco de trabajo eficiente que surgió en la década de los años 70, pues ofrecían una respuesta a los problemas que surgían con los antiguos métodos de desarrollo. Estos se enfocaban en la creación de software sin el control apropiado de las actividades del grupo de trabajo, lo que provocaba un producto lleno de deficiencias y problemas resultando en la insatisfacción del cliente, pues se le ofrecía un software que no cumplía con sus necesidades.

Con la implementación de estas metodologías de desarrollo web se han logrado mejorar de manera significativa las aplicaciones web, debido a que proveen una guía compuesta por etapas y procesos efectivos que permiten obtener mejores resultados y de calidad.

Actualmente existen muchas metodologías para el desarrollo de software que son utilizadas dependiendo del sistema a crear, los cuales pueden dividirse en grupos comunes como son: escritorio, móvil y web, siendo este último de los que más impulso ha venido acumulando, pues la necesidad del cliente de ser reconocido por medio del Internet se ha intensificado.

En base a esta comparativa se puede verificar que las metodologías más utilizadas abarcan una mayor cantidad de criterios y/o elementos de casi todas las metodologías. Estas permiten concentrar sus esfuerzos en aspectos web a diferencia de las otras las cuales se centran en brindar soluciones a problemas de carácter específico. A partir del análisis de la información y comparación en el marco de desarrollo del estado de arte se obtuvo como resultados que la metodología OOHDM es la que cumple con casi todos los criterios que se plantearon en base a otras investigaciones donde se realizaron estudios similares, permitiendo determinar una metodología de desarrollo general que cumpla las características óptimas en la construcción de aplicaciones Web.

\section{ANTECEDENTES O ESTADO DEL ARTE}

\subsection{APLICACIONES WEB}

\begin{tabular}{|l|l|l|}
\hline Año & \multicolumn{1}{|c|}{ Título } & \multicolumn{1}{c|}{ Contenido } \\
& Aplicaciones Web 2.0 & "Las aplicaciones Web generan dinámicamente una serie de \\
& páginas en un formato estándar, como HTML sigla en inglés de \\
& HyperText Markup Language o XHTML siglas en ingles de \\
& Extensible HyperText Markup Language, que soportan los \\
& navegadores Web comunes “ (Caivano \& Villoria, 2009) \\
\hline $\mathbf{2 0 1 0}$ & Desarrollo Profesional de & "La característica común de todas las aplicaciones Web es el \\
& Aplicaciones Web & hecho de centralizar el software para facilitar las tareas de \\
& mantenimiento y actualización de grandes sistemas" (Berzal \& \\
& Cortijo, 2010) \\
\hline
\end{tabular}

Tabla 1. Software o aplicaciones Web. 
Según el análisis de la tabla 1 , se puede mencionar que las aplicaciones web son herramientas que permiten realizar operaciones desde un ordenador a través de la utilización del Internet logrando que se reduzca el tiempo empleado en cada actividad. Este es uno de los aspectos positivos que ha permitido la aceptación y usabilidad de este tipo de software por parte de los usuarios.

Las aplicaciones web usan el formato estándar HTML (HyperText Markup Language o Lenguaje de Hipertextos) para efectuar las peticiones que el usuario desea, y otra característica favorable de este software es que permite un acceso simultaneo a sus operaciones, es decir más de un usuario puede acceder a la vez al sistema, esto lo realiza mediante una combinación de procesos y comunicaciones internas con la base de datos.

\subsection{METODOLOGÍAS ORIENTADAS AL DESARROLLO WEB}

\begin{tabular}{|c|c|c|}
\hline Año & Título & Observaciones \\
\hline 2008 & $\begin{array}{l}\text { Design and Maintenance of } \\
\text { Data-Intensive Web Sites }\end{array}$ & $\begin{array}{l}\text { "Contiene las siguientes etapas: Diseño Conceptual: en esta sección se } \\
\text { abarca temas relaciones a la especificación del dominio del problema, a } \\
\text { través de su definición y las relaciones que contrae. } \\
\text { Diseño Navegacional: Como su nombre lo indica ese diseño está } \\
\text { enfocado en lo que respecta al acceso y forma en la que los datos son } \\
\text { visibles. Diseño de la presentación o diseño de interfaz: Parte } \\
\text { importante y primordial en lo que respecta al desarrollo de páginas } \\
\text { Web, Implantación: es la construcción del software a partir de los } \\
\text { artefactos" (Atzeni, Mecca, \& Merialdo, 2008) }\end{array}$ \\
\hline 2009 & $\begin{array}{l}\text { Metodologías de diseño } \\
\text { usadas en ingeniería Web, su } \\
\text { vinculación con las NTICS }\end{array}$ & $\begin{array}{l}\text { "Las actividades que forman parte de cualquier metodología de } \\
\text { desarrollo ágil son: } \\
\text { 1. La Formulación identifica objetivos y establece el alcance de la } \\
\text { primera entrega. } \\
\text { 2. La Planificación genera la estimación del coste general del proyecto, } \\
\text { 3. El Análisis especifica los requerimientos e identifica el contenido. } \\
\text { 4. La Modelización se compone de dos secuencias paralelas de tareas. } \\
\text { 5. En la Generación de Páginas se integra contenido, arquitectura, } \\
\text { navegación e interfaz para crear estática o dinámicamente el aspecto } \\
\text { más visible de la aplicación: las páginas. } \\
\text { 6. El Test busca errores a todos los niveles: contenido, funcional, } \\
\text { navegacional, rendimiento, etc. 7. Finalmente, el resultado es sometido } \\
\text { a la Evaluación del Cliente." (Del Valle Rodríguez, 2008) }\end{array}$ \\
\hline
\end{tabular}

Tabla 2. Metodologías orientadas al desarrollo web.

Como se puede apreciar en la tabla 2, las metodologías de desarrollo web, al igual que otras metodologías contemplan una serie de actividades y fases que permiten modelar la construcción de la aplicación, con el fin de entregar un producto de calidad, confiable, funcional y correctamente estructurado.

Es importante mencionar que las metodologías web centran sus esfuerzos en lo usuarios de la aplicación debido a que ellos son los principales actores y críticos. Por lo general, en las primeras 
etapas, es donde se buscan los perfiles o clases de usuarios que navegarán en la aplicación. Otro aspecto relevante que se trabaja es el diseño, pues este abarca criterios de usabilidad y accesibilidad los mismos que se enfocan en la manipulación del sistema, adaptación, aprendizaje, y tecnología. Entre las fases que se encuentran diseño conceptual, diseño navegacional, diseño de la interfaz, implantación, pruebas, evaluación del cliente entre otras.

A continuación, se presentan metodologías orientadas al desarrollo web.

\subsection{HYPERTEXT DESIGN MODEL (HDM)}

\begin{tabular}{|ccc|}
\hline Año & Título & \multicolumn{1}{c|}{ Observaciones } \\
\hline 2001 & $\begin{array}{c}\text { Sistemas de interacción } \\
\text { persona-computador }\end{array}$ & $\begin{array}{c}\text { "La arquitectura del HDM se basa en un sistema de objetos distribuidos que } \\
\text { provee diferentes tipos de procesos clientes y servidores que se corresponden } \\
\text { con los niveles de modelo de Dexter." (Ortega Cantero \& Bravo Rodríguez, } \\
2001)\end{array}$ \\
\hline $\mathbf{2 0 0 2}$ & Metodologías de & "HDM constituye un primer paso en la definición de un método descendente \\
& Concepción para & de concepción de aplicaciones hipertexto. Ha sido la fuente de inspiración de \\
& Aplicaciones Hipermedia: & los métodos RMM y OOHDM. El modelo HDM no se interesa en la concepción \\
Análisis crítico & del contenido de los nodos se centra únicamente en la concepción topológica \\
& de las aplicaciones." (Escalona, 2002)
\end{tabular}

Tabla 3. Metodología HDM.

De lo analizado en la tabla 3, se puede manifestar que HDM o Modelos de Diseño de Hipermedia, fue uno de los principales modelos que surgieron con el objetivo de definir la estructura y la navegación en las aplicaciones. HDM fue base para el desarrollo y construcción de otras metodologías como RMM y OOHDM como manifiestan (Ortega Cantero \& Bravo Rodríguez, 2001) y (Escalona, 2002) en sus investigaciones.

Escalona, expresa que HDM se basa en la aplicación de un modelo Entidad - Relación, donde se introduce nuevos elementos que permiten representar la arquitectura de la aplicación que se pretende desarrollar sin mayores especificaciones. Es importante destacar que en la actualidad HDM ya no es muy utilizada debido que el mercado se encuentra acaparado por otras metodologías orientadas a objetos o que se enfocan en este paradigma, y además que se preocupan por aspectos relacionados con la interfaz. 


\subsection{SCENARIO-BASED OBJECT-ORIENTED HIPERMEDIA DESIGN METHODOLOGY (SOHDM)}

\begin{tabular}{|c|c|c|}
\hline Año & Título & Observación \\
\hline 2011 & $\begin{array}{l}\text { Metodologías para el desarrollo de sistemas de } \\
\text { información global: análisis comparativo y propuesta }\end{array}$ & $\begin{array}{l}\text { "Sus fases son: } \\
\text { Fase 1- Análisis } \\
\text { Fase 2- Modelado de objetos } \\
\text { Fase 3- Diseño de vistas } \\
\text { Fase 4- Diseño Navegacional Fase 5- Diseño de la } \\
\text { implementación } \\
\text { Fase 6- Construcción" (Escalona Cuaresma, 2011) }\end{array}$ \\
\hline 2015 & $\begin{array}{l}\text { Framework, Methodologies, and Tools for Developing } \\
\text { Rich Internet Applications }\end{array}$ & $\begin{array}{l}\text { "Esta propuesta se compone de seis fases y se } \\
\text { parece bastante a otras metodologías como lo son } \\
\text { la RMM, OOHDM y EORM. Sin embargo, hay algo } \\
\text { que hace diferente a esta metodología de las } \\
\text { anteriores y es el hecho de que se basa en los } \\
\text { escenarios para el desarrollo del sistema." (Alor- } \\
\text { Hernández, 2015) }\end{array}$ \\
\hline
\end{tabular}

Tabla 4. Metodología SOHDM.

La información proporcionada por los autores en la taba 4 analiza el hecho de que la metodología SOHDM o también denominada Metodología de Diseño de Escenarios Orientado a Objetos en Hipermedia, tiene características parecidas a las RMM incorporando los escenarios. Esto favorece el desarrollo del proyecto de software debido a que cubre todas las fases y etapas del ciclo de vida tradicional.

Esta metodología es reciente y no ha tenido mucho uso por parte de los desarrolladores debido a que el mercado lo ocupa OOHDM, entre las ventajas la más importante que se puede mencionar es que brinda mayor importancia al tratamiento de los requisitos, y para ello utiliza los escenarios como medio de obtención y definición de ellos. En relación al proceso de gestión de desarrollo de software SOHDM presenta 6 fases las cuales se muestran en la ilustración. 
Ilustración 9. Fases de la metodología SOHDM.

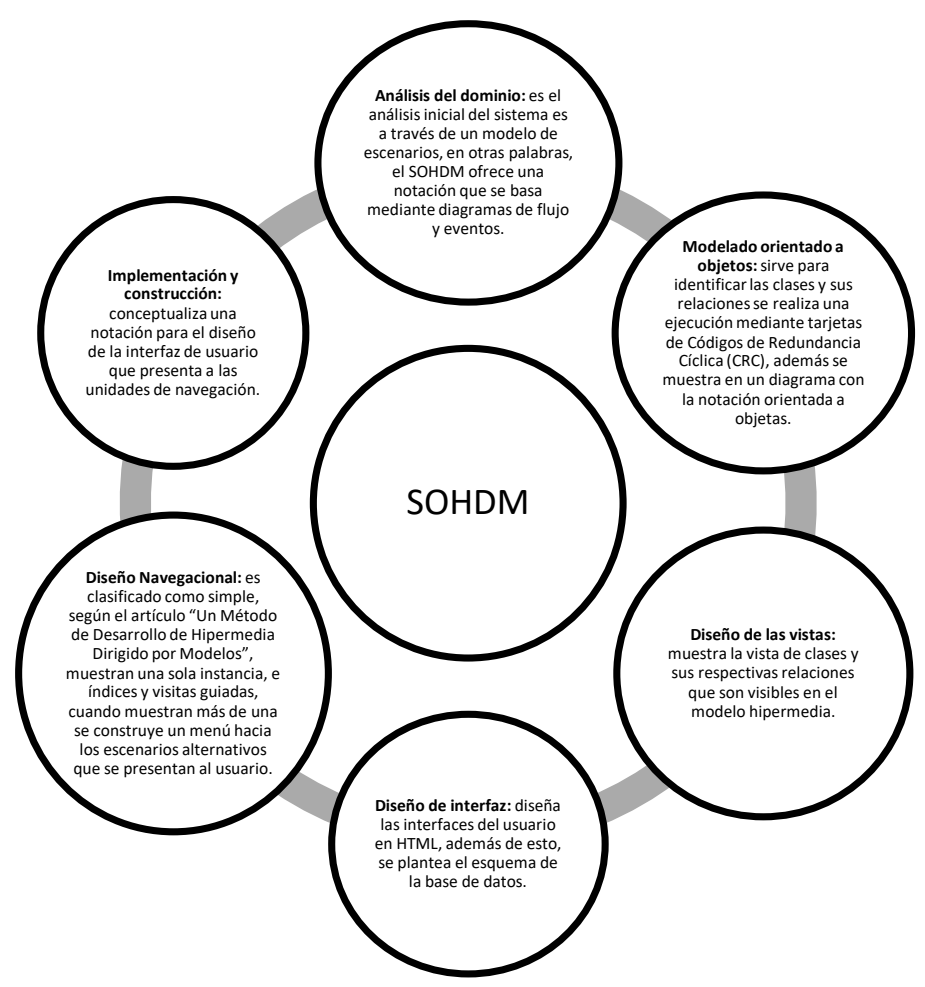

Fuente: (Escalona Cuaresma, 2011).

\subsection{WEB SITE DESIGN METHOD (WSDM)}

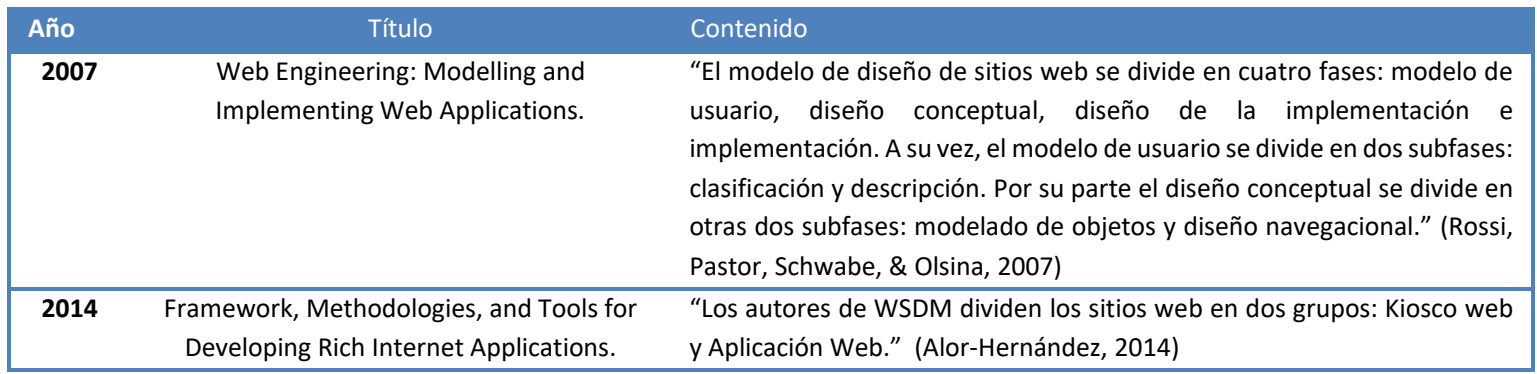

Tabla 5. Metodología o Método WSDM.

Con respecto a la tabla 5, se puede indicar que WSDM o Método de Diseño para Sitios web, es una propuesta que se enfoca en el usuario para el desarrollo del sitio web, y que además modela la aplicación en base a los requerimientos de cada grupo o clases que usuarios. Esta metodología contiene 4 fases las cuales se muestran en la ilustración 2. 
Ilustración 2. Fases de la metodología WSDM.

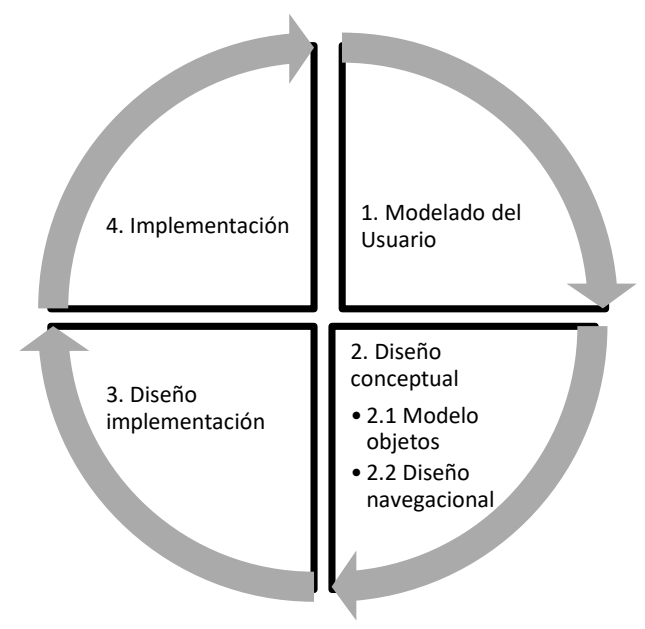

Fuente: (Rossi, Pastor, Schwabe, \& Olsina, 2007).

WSDM es una metodología que además de proporciona modelos primitivos que describen la construcción del sitio o aplicación web en diversos niveles de abstracción, también proporcionan una manera sistemática para el desarrollo de la aplicación.

\subsection{RELATIONSHIP MANAGEMENT METHODOLOGY (RMM)}

\begin{tabular}{|c|c|c|}
\hline Año & Título & Contenido \\
\hline 2008 & $\begin{array}{l}\text { Un Método de Desarrollo de Hipermedia } \\
\text { Dirigido por Modelos }\end{array}$ & $\begin{array}{l}\text { "Es una metodología para el desarrollo de aplicaciones de hipermedia que } \\
\text { tienen una estructura regular definida mediante entidades y relaciones" } \\
\text { (Solís Pineda, 2008) }\end{array}$ \\
\hline 2009 & $\begin{array}{l}\text { An Object-Oriented Design Approach for } \\
\text { Devloping } \\
\text { Hipermedia Information Systems }\end{array}$ & $\begin{array}{l}\text { “Las fases que realiza son: } \\
\text { Fase 1- Realizar el modelo E-R } \\
\text { Fase 2- Realizar los diseños de slice } \\
\text { Fase 3- Diseñar la navegación } \\
\text { Fase 4- Definir el protocolo de conversión } \\
\text { Fase 5- Diseñar la interfaz } \\
\text { Fase 6- Implementar la aplicación } \\
\text { Fase 7- Probar la aplicación” } \\
\text { (Lange, 2005) }\end{array}$ \\
\hline
\end{tabular}

Tabla 6. Metodología RMM.

En base a la tabla 6 se puede aseverar que la metodología RMM o Modelo de Datos de Administración de Relaciones surgió como una mejora de HDM en la que también hace uso del modelo Entidad-Relación como forma para representar la estructura general del sistema. Cuenta con 7 fases que facilitan el modelamiento y control de la aplicación Web, entre las ventajas más productivas de utilizar esta metodología está el hecho de que proporciona un medio que automatiza el desarrollo y construcción de las etapas del ciclo de vida del software. 
Las Rodajas-M y el Diagrama de Aplicación son las principales contribuciones aportadas por la nueva RMM. Los cimientos de RMM son el diagrama $E-R$, que es una técnica ya sólidamente establecida para el modelado de dominios relacionales.

\subsection{OBJECT-ORIENTED HYPERMEDIA DESIGN MODEL (OOHDM)}

\begin{tabular}{|c|c|c|}
\hline Año & Título & Contenido \\
\hline 2011 & $\begin{array}{l}\text { Metodología del análisis estructurado de } \\
\text { sistemas }\end{array}$ & $\begin{array}{l}\text { "OOHDM considera que el desarrollo de una aplicación hipermedial se da } \\
\text { en un proceso que posee cuatro actividades principales: Diseño } \\
\text { conceptual, navegacional y de interfaz abstracta, Implementación" } \\
\text { (Barranco de Areba, 2001). }\end{array}$ \\
\hline 2010 & $\begin{array}{l}\text { Modelo para la selección de la metodología } \\
\text { de desarrollo Web de una aplicación según } \\
\text { sus características funcionales }\end{array}$ & $\begin{array}{l}\text { "OOHDM Es una metodología basada en el paradigma OO la cual nos } \\
\text { muestra una descripción precisa de los elementos que la aplicación } \\
\text { poseerá" (Vilariño de Almeida, 2010). }\end{array}$ \\
\hline
\end{tabular}

Tabla 7. Metodología OOHDM.

Según los autores la metodología OOHDM cuyas siglas en español son Método de Diseño e Hipermedia Orientado a Objetos, tiene similitud en sus características con la HDM con la única diferencia de que tiene un proceso que indica las actividades a ejecutar y el producto o entregable que debe hacerse al finalizar una fase. Este método toma como punto de partida el modelo de clases obtenido durante la primera fase del desarrollo de software denominado modelo conceptual, además permite modelar aplicaciones de grandes tamaños o con grandes volúmenes de información y pueden ser usados en diversos tipos de aplicaciones navegables, sitios Web, sistemas de información o presentaciones multimedia.

OOHDM es una de las metodologías que más se utilizan hoy en día debido a que permiten reducir los tiempos de desarrollo, reutilizar diseño, simplificar la evolución y el mantenimiento de la aplicación. Las fases de esta metodología según los autores (Barranco de Areba, 2001) y (Vilariño de Almeida, 2010) se pueden apreciar en la ilustración 2.

Ilustración 10. Fases de la metodología OOHDM.

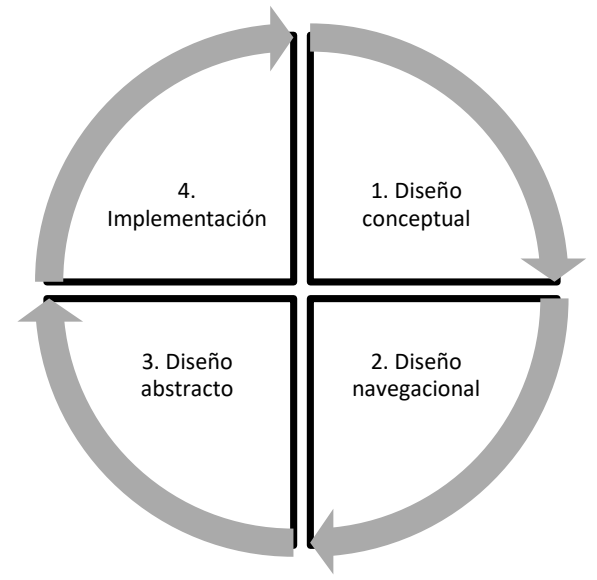

Fuente: (Vilariño de Almeida, 2010). 
Algo que propone esta metodología dentro de sus 4 fases establecidas es la posibilidad de añadir la representación del sistema en todos los aspectos propios de las aplicaciones Web, por lo cual ha tenido mucha aceptación y quizás la mayor usabilidad por parte de los desarrolladores al momento de comenzar su proyecto de desarrollo de software.

\subsection{WEB APPLICATION EXTENSION (WAE)}

\begin{tabular}{|lll|}
\hline Año & \multicolumn{1}{c}{ Título del libro } & $\begin{array}{c}\text { Contenido } \\
\text { WWM:A Practical Methodology for "WAE se centra principalmente en la semántica de elementos Web, no en la } \\
\text { Webspectiva orientada a objetos." (Kaewkasi \& Rivepiboon, 2002) }\end{array}$ \\
\hline $\mathbf{2 0 1 4}$ & $\begin{array}{l}\text { Modelo de navegación Web para } \\
\text { dispositivos móviles "WAE FOR } \\
\text { MOBILE DEVICES" }\end{array}$ & $\begin{array}{l}\text { "La notación WAE, brinda un estereotipo que muestra el momento en que una } \\
\text { aplicación Web que se desplegará sobre un dispositivo móvil" (Valencia, 2014) }\end{array}$ \\
\hline
\end{tabular}

Tabla 8. Metodología WAE.

Según José Escalona y Nora Koch, UWE (UML basado en Ingeniería Web) es una metodología que abarca todos los procesos de la construcción de las aplicaciones Web, sin embargo, se centra más en la recopilación y validación de requisitos (funcionales y no funcionales) dando como resultado un modelo de casos de uso y documentación acerca de los usuarios del sistema, casos de uso e interfaz.

\subsection{ENHANCED OBJECT RELATIONSHIP METHODOLOGY (EORM)}

\begin{tabular}{|c|c|c|}
\hline Año & Título del libro & Contenido \\
\hline 2003 & $\begin{array}{l}\text { Information Modeling for Internet } \\
\text { Applications. }\end{array}$ & $\begin{array}{l}\text { "EORM propone un proceso iterativo que consiste en enriquecer un } \\
\text { modelo de } \\
\text { objetos para representar las relaciones existentes entre objetos" (van } \\
\text { Bommel, 2003) }\end{array}$ \\
\hline 2015 & $\begin{array}{l}\text { Aplicación Web para la enseñanza del } \\
\text { Lenguaje de señas, Módulo Básico para Niños } \\
\text { del segundo año de Educación Básica de la } \\
\text { Unidad Educativa de Sordos del Gobierno } \\
\text { Provincial de Imbabura }\end{array}$ & $\begin{array}{l}\text { "Es una metodología de Relación entre Objetos de diseño de } \\
\text { aplicaciones multimedia, se define por un proceso iterativo que se } \\
\text { centra en el modelado orientado a objetos, por la representación de } \\
\text { relaciones entre los objetos (enlaces) como objetos, es por ello que fue } \\
\text { una de las primeras propuestas para la Web." (Sevilla, 2015) }\end{array}$ \\
\hline
\end{tabular}

Tabla 9. Metodología EORM.

En base a los datos de la tabla 9 en la que se menciona que la metodología EORM (Metodología de Relación de Objetos Mejorada) es sencilla con pocas fases y asume la orientación a Objetos como estructura para el desarrollo de sus aplicaciones. EORM es un método que separa la navegación de la parte conceptual, evitando así tiempo empleado en caso de fallos, es decir, no es necesario modificar ambas capas en caso de errores.

Es una de las primeras propuestas metodológicas que existieron en la que enmarcaban la orientación a objetos, y es adecuada si se trabaja con aplicaciones Web la cual contenga poca cantidad de información. Cabe recalcar que no ofrece nuevas técnicas o modelos que aseguren la calidad del software con referencias a las metodologías propuestas anteriormente. 


\subsection{ANÁLISIS ENTRE LAS DIFERENTES METODOLOGÍAS}

La tabla 12 muestra un análisis comparativo entre las diferentes metodologías, sus técnicas, la notación y sus herramientas de soporte. Se estableció abreviaturas en la tabla 10, con el fin de hacer más entendible los nombres de las metodologías:

Tabla 10. Abreviaturas de la tabla 11.

\begin{tabular}{|ll|}
\hline № & \multicolumn{1}{c|}{ Abreviaturas o Acrónimos } \\
\hline $\mathbf{1}$ & Entity - Relationship, Entidad - Relación \\
\hline $\mathbf{2}$ & Object Oriented, Orientado a Objetos \\
\hline $\mathbf{3}$ & $\begin{array}{l}\text { Relationship Management Data Model, Modelo de Datos de } \\
\text { Administración de Relaciones }\end{array}$ \\
\hline $\mathbf{5}$ & Graphical User Interface, Interfaz de Usuario Gráfica \\
\hline $\mathbf{6}$ & Object Modeling Technique, Técnica de Modelado de Objetos \\
\hline $\mathbf{7}$ & Unified Modeling Language, Lenguaje de Modelado Unificado \\
\hline
\end{tabular}

Fuente: Autores.

Tabla 11. Comparación de las metodologías en el desarrollo de aplicaciones Web.

\begin{tabular}{|c|c|c|c|c|}
\hline Metodología & $\begin{array}{l}\text { Técnica de } \\
\text { modelado }\end{array}$ & Representación gráfica & Notación & $\begin{array}{l}\text { Herramienta de } \\
\text { soporte }\end{array}$ \\
\hline HDM & $E-R$ & Diagrama E - R & $E-R$ & $\begin{array}{l}\text { No posee } \\
\text { herramienta de } \\
\text { soporte }\end{array}$ \\
\hline RMM & $E-R$ & $\begin{array}{l}\text { 1. Diagrama } \mathrm{E}-\mathrm{R} \\
\text { 2. Diagrama Slice } \\
\text { 3. Diagrama RMDM }\end{array}$ & $E-R$ & RMCase \\
\hline EORM & $\mathrm{OO}^{2}$ & $\begin{array}{l}\text { 1. Diagrama de clases } \\
\text { 2. Diseño GUI }\end{array}$ & OMT & ONTOS Studio \\
\hline OOHDM & $\mathrm{OO}$ & $\begin{array}{l}\text { 1. Diagrama de clases } \\
\text { 2. Diagrama navegacional, clase } \\
\text { + contexto } \\
\text { 3. Diagrama de configuración de } \\
\text { ADV }^{5} \text { y Diagrama ADV }\end{array}$ & $\begin{array}{c}1 . \\
\text { OMT/UML } \\
\text { 2. ADVs }\end{array}$ & OOHDM-Web \\
\hline SOHDM & $\begin{array}{l}\text { Escenarios } \\
\text { Vistas-OO }\end{array}$ & $\begin{array}{l}\text { 1. Diagramas de escenarios de } \\
\text { actividad } \\
\text { 2. Diagrama de estructura de } \\
\text { clase } \\
\text { 3. Vista } O O \\
\text { 4. Esquema de enlace } \\
\text { navegacional } \\
\text { 5. Esquema de páginas }\end{array}$ & Propio & $\begin{array}{l}\text { No posee } \\
\text { herramienta de } \\
\text { soporte }\end{array}$ \\
\hline WSDM & $\mathrm{E}-\mathrm{R} / \mathrm{OO}$ & $\begin{array}{l}\text { 1. Diagrama de } E-R \text { o clase } \\
\text { 2. Capas de navegación }\end{array}$ & $\begin{array}{l}\text { 1. E-R/ } \\
\text { OMT } \\
\text { 2. Propio }\end{array}$ & $\begin{array}{l}\text { No posee } \\
\text { herramienta de } \\
\text { soporte }\end{array}$ \\
\hline WAE & $\mathrm{OO}$ & Diagramas UML & UML & Rational Rose \\
\hline
\end{tabular}

Tabla tomada de: (Silva \& Mercerat, Construyendo aplicaciones web con una metdología de diseño orientada a objetos, 2010).

En base a la comparación realizada previamente y con fundamentos de la investigación realizada, se puede decir que la metodología más utilizada en el desarrollo de aplicaciones Web es OOHDM, teniendo en cuenta que este método ofrece procesos más seguros y enfocados a aspectos de 
métricas de calidad que verifican que las aplicaciones tengan mayor confiabilidad, consistencia y seguridad.

En la tabla 12 muestra una comparación de diseño basados en los tres niveles típicos del desarrollo Web: conceptual, estructural y visible.

Tabla 12. Comparación de conceptos de diseño de las metodologías de desarrollo Web.

\begin{tabular}{|c|c|c|c|}
\hline & Nivel concepto & Nivel estructura & Nivel visible \\
\hline 임 & $\begin{array}{l}\text { Entidad } \\
\text { Colección } \\
\text { Perspectiva } \\
\text { Relaciones }\end{array}$ & $\begin{array}{c}\text { Enlace: } \\
\text { - Estructural } \\
\text { - Aplicación } \\
\text { - Relaciones } \\
\text { Componente } \\
\text { Nodo } \\
\end{array}$ & $\begin{array}{l}\text { Ranura } \\
\text { Marco }\end{array}$ \\
\hline$\sum_{x}$ & $\begin{array}{c}\text { Entidad } \\
\text { Relación-OO- } \\
\text { generalizada-definida por } \\
\text { el usuario. }\end{array}$ & $\begin{array}{c}\text { Enlace: } \\
\text { - Unidireccional } \\
\text { - Bidireccional } \\
\text { Slices }\end{array}$ & Slices \\
\hline 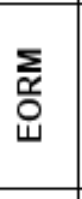 & $\begin{array}{l}\text { Clases } \\
\text { Perspectiva } \\
\text { Relación-OO }\end{array}$ & $\begin{array}{c}\text { Enlace: } \\
\text { - Simple } \\
\text { - Navegacional } \\
\text { - Nodo a Nodo } \\
\text { - Tramo a Nodo } \\
\end{array}$ & \\
\hline 옹 $\Sigma$ & $\begin{array}{l}\text { Clases } \\
\text { Perspectiva } \\
\text { Relación-OO }\end{array}$ & $\begin{array}{c}\text { Enlace } \\
\text { Clase navegacional } \\
\text { Contexto navegacional }\end{array}$ & $\begin{array}{c}\text { ADV } \\
\text { En contexto }\end{array}$ \\
\hline 촘 & $\begin{array}{c}\text { Escenarios: } \\
\text {-Evento } \\
\text {-Actividad } \\
\text { Flujo de actividad } \\
\end{array}$ & $\begin{array}{c}\text { Enlace navegacional } \\
\text { Visita-OO: } \\
\text { - Base } \\
\text { - Asociación }\end{array}$ & $\begin{array}{c}\text { Componente UI: } \\
\text { - Elección } \\
\text { - Texto de entrada de } \\
\text { búsqueda } \\
\text { - Botón }\end{array}$ \\
\hline $\begin{array}{l}\sum \\
\text { ถે } \\
3\end{array}$ & $\begin{array}{l}\text { Objeto } \\
\text { Perspectiva } \\
\text { Relación }\end{array}$ & $\begin{array}{c}\text { Enlace } \\
\text { Componente } \\
\text { - Navegación } \\
\text { - Información } \\
\text { - Externo } \\
\text { Camino navegacional }\end{array}$ & \\
\hline 岸 & $\begin{array}{c}\text { CASE } \\
\text { Relación-OO }\end{array}$ & $\begin{array}{c}\text { Enlace } \\
\text { Enlace dirigido } \\
\text { Redirigir } \\
\text { Construir } \\
\text { Enviar } \\
\end{array}$ & $\begin{array}{c}\text { Conjunto de marcos } \\
\text { Formulario }\end{array}$ \\
\hline
\end{tabular}

Tabla tomada de: (Silva \& Mercerat, Construyendo aplicaciones web con una metdología de diseño orientada a objetos, 2010). 


\section{METODOLOGÍA}

La investigación es de tipo heurística, hermenéutica y descriptiva, cuyo fin de escoger de las unidades de análisis del material documental, los datos pertinentes y someterlos a un proceso de revisión, reseña y descripción (Londoño, Maldonado, \& Calderón, 2014). Para realizar el siguiente trabajo se han denominado diferentes etapas que se centrarán en la evaluación de calidad de las metodologías en aplicaciones Web, las cuales son:

1. Investigación bibliográfica de trabajos que correspondan con estudios similares desarrollados en el mismo campo (metodologías en aplicaciones Web).

2. Determinación y procesamiento de datos recopilados de las diferentes normas estándares y métodos hallados.

3. Análisis comparativo de los datos obtenidos y verificación de los mismos.

4. Elaboración de los resultados y la conclusión sobre metodologías en aplicaciones Web.

\section{RESULTADOS}

El desarrollo de la tecnología digital por medio del uso de internet ha permitido que las aplicaciones Web se hayan incrementado de forma imparable, y con ello múltiples metodologías de desarrollo han surgido para ofrecer un producto final de calidad. Entre estas metodologías se destacan los grupos de las tradicionales y las ágiles, las cuales ofrecen grandes beneficios para el grupo de trabajo, siendo la ágil la más óptima para adoptarla en las empresas de desarrollo Web, pues reduce el tiempo y esfuerzo que se emplea, como se aprecia en la investigación. Otro factor importante que resalta la elección de las metodologías ágiles es la flexibilidad en su proceso de desarrollo, la generación de documentación eficiente y una serie de tareas reducidas. Aunque esto se pudo comprobar, no es posible descartar que la metodología tradicional no sea utilizada por numerosas empresas de desarrollo y que la eficiencia tanto como la calidad del producto sea menor al ofrecido en la utilización del método ágil. El proceso ágil es una metodología que se adapta a los cambios de las necesidades del cliente, por ello consigue mejorar el proceso de desarrollo de software al contrario de la metodología tradicional, además de ser más comprensible para el grupo de desarrollo lo cual la convierte en el tipo de metodología en la más adaptable al proceso de desarrollo Web. 
Tabla 13. Referencias de las investigaciones por autor.

\begin{tabular}{|c|c|c|c|}
\hline $\begin{array}{l}\text { Documento } \\
\mathrm{N}^{\circ}\end{array}$ & Autor/es & Titulo & Lugar \\
\hline DOC1 & $\begin{array}{l}\text { Villarroel Acevedo, Rodolfo; } \\
\text { Rioseco Reinoso, Cristián }\end{array}$ & $\begin{array}{l}\text { Una comparación de metodologías para el modelado de aplicaciones Web. } \\
\text { (Villarroel Acevedo \& Rioseco Reinoso, 2011) }\end{array}$ & Cuba \\
\hline DOC2 & $\begin{array}{l}\text { Silva Dario Andrés; Mercerat } \\
\text { Bárbara. }\end{array}$ & $\begin{array}{l}\text { Construyendo aplicaciones Web con una metodología de diseño orientada a } \\
\text { objetos. (Silva \& Mercerat, 2010) }\end{array}$ & $\begin{array}{l}\text { Buenos Aires, } \\
\text { Argentina }\end{array}$ \\
\hline DOC3 & $\begin{array}{l}\text { Rodríguez, Ana Nieves del } \\
\text { Valle. }\end{array}$ & $\begin{array}{l}\text { Propuesta para lograr especialización en tiae: metodologías de diseño usadas en } \\
\text { ingeniería Web, su vinculación con las ntics. (Del Valle Rodríguez, 2008) }\end{array}$ & $\begin{array}{l}\text { Buenos Aires, } \\
\text { Argentina }\end{array}$ \\
\hline DOC5 & $\begin{array}{l}\text { Tomas Isakowitz, Edward A. } \\
\text { Stohr, P. Balasubramanian }\end{array}$ & $\begin{array}{l}\text { RMM: A Methodology for Structured Hypermedia Design. (Isakowitz, Stohr, \& } \\
\text { Balasubramanian, 1995) }\end{array}$ & Estados Unidos \\
\hline DOC6 & Sevilla Anrrango, Eva Estefanía & $\begin{array}{l}\text { Aplicación Web para la enseñanza del lenguaje de señas, módulo básico para } \\
\text { niños del segundo año de educación básica de la unidad educativa de sordos del } \\
\text { gobierno provincial de Imbabura. (Sevilla, 2015) }\end{array}$ & Ibarra, Ecuador \\
\hline DOC8 & Craig Standing & $\begin{array}{l}\text { The requirements of methodologies for developing web applications (Standing } \\
\text { C. , 2005) }\end{array}$ & $\begin{array}{l}\text { Perth, } \\
\text { Australia }\end{array}$ \\
\hline DOC9 & $\begin{array}{l}\text { Loor Montesdeoca, Edison } \\
\text { David }\end{array}$ & $\begin{array}{l}\text { Implementación de un sitio Web con software libre para la publicación de una } \\
\text { revista digital de divulgación científico-tecnológica en el área de la informática y } \\
\text { ciencias de la computación, inscrita en el movimiento open Access. (Loor, 2012) }\end{array}$ & Quito, Ecuador \\
\hline DOC10 & $\begin{array}{l}\text { Geovana De Los Ángeles } \\
\text { Velarde, Paredes María Isabel } \\
\text { Pilco Quitiu }\end{array}$ & $\begin{array}{l}\text { Análisis comparativo de metodologías para el desarrollo de la aplicación Web del } \\
\text { control de las prácticas pre-profesionales de la EIS de la ESPOCH. (Velarde } \\
\text { Paredes \& Pilco Quitiu, 2014) }\end{array}$ & $\begin{array}{l}\text { Chimborazo } \\
\text {,Ecuador }\end{array}$ \\
\hline DoC11 & María Valeria de Castro & $\begin{array}{l}\text { Aproximación mda para el desarrollo orientado a servicios de sistemas de } \\
\text { información Web: del modelo de negocio al modelo de composición de servicios } \\
\text { Web. (de Castro, 2007) }\end{array}$ & $\begin{array}{l}\text { Madrid, } \\
\text { España }\end{array}$ \\
\hline
\end{tabular}

Fuente: autores.

\section{DISCUSIÓN}

La interrogante plateada en este documento partió de la necesidad de conocer una metodología propicia para el desarrollo de aplicaciones Web. Debido a esto se realizaron investigaciones de tipo bibliográficas para con ello responder a las incógnitas que se venían dando en el trascurso de este artículo.

La metodología OOHDM se ha evidenciado como una base primordial para la derivación de diversas metodologías, al poseer una captura en forma visual de los requisitos permite al desarrollador desempeñar mejor su labor en el desarrollo de software, al contrario de lo que ocurre con metodologías como la SOHDM y NDT que ofrecen de manera textual, usando técnicas similares en su desarrollo SOHDM y NDT (Escalona, 2002). En contraste Villarroel Acevedo \& Rioseco Reinoso (2011), explica que los requisitos tienen que mantener un estándar para su modelamiento refiriéndose a UML como la herramienta optima y que la metodología OOHDM se destaca entre las demás por poseer una notación propia en este ámbito. Esto supone por el al efecto positivo que presenta el UML donde la correcta utilización de diagramas mejora la funcionalidad del sistema, 
además de proporcionar la eficiencia y usabilidad necesarias en la creación de un producto de software. Así mismo, concuerda en su investigación (Velarde Paredes \& Pilco Quitiu, 2014) haciendo hincapié en los beneficios al usar la OOHDM, pues ésta otorga seguridad, además de facilidad y manejo de aprendizaje.

Por último, un aspecto destacable que se debe tomar en cuenta es la robustez (capacidad para que un programa haga lo que se le propone) que pueda manejar la metodología según Isakowitz, Stohr, \& Balasubramanian (1995), explicando que las aplicaciones Web que comprendan una sobrecarga de datos e información manipulada necesitan que el proceso se enfoque en dicho aspecto. Se orienta al uso de RMM como la base para el diseño y desarrollo de aplicaciones de hipermedias robustas, pero a diferencia de la OOHDM, ésta no usa nodos únicamente se basa en la concepción topológica de las aplicaciones.

Las opiniones y resultados obtenidos por los autores han llevado al análisis de distintos métodos de desarrollo de aplicaciones Web, siendo el más óptimo para el desarrollo de aplicaciones Web el método OOHDM, debido a que establece los niveles conceptuales, estructurales y visibles de una mejor manera y además son indispensables en una aplicación Web según Escalona (2002), además de ofrecer completitud, fiabilidad, facilidad de uso.

\section{CONCLUSIONES}

Con base a los resultados que fueron obtenidos a partir de la investigación realizada, se concluye que en la actualidad han surgido diversas metodologías orientadas al desarrollo y modelado Web, las cuales contienen grandes similitudes entre sí, al buscar el desarrollo y mejorar el proceso repercutiendo en la calidad del producto Web. Es por ello que en muchas investigaciones se han realizado comparativas tomando en cuenta los procesos abarcados en el ciclo de vida, la calidad del proceso, el modelamiento, entre otras.

Entre las investigaciones analizadas se han podido identificar metodologías que contienen diversos enfoques de desarrollo, tal es el caso de la OOHDM que se enfoca en el desarrollo orientado a objetos, lo cual provee un punto fuerte en el modelado. Está en contraste con la metodología BDR, que es basada en el proceso de ciclo de vida del software y es enfocada en el análisis y obtención de requisitos.

A nivel global, para el desarrollo de aplicaciones Web, la metodología más utilizada es la metodología ágil, debido a que extiende la productividad, minoriza la sobrecarga de procesos y mejora la gestión de riesgos.

En las metodologías ágiles se observó que la OOHDM cumple como el método más óptimo en el desarrollo de aplicación Web debido a que facilita el trabajo dentro del equipo desarrollador y agiliza los procesos optimizando sus etapas, además de contemplar más etapas en el ciclo de vida de desarrollo y precisa el modelado de objetos. 


\section{REFERENCIAS BIBLIOGRÁFICAS}

1. Alor-Hernández, G. (2014). Frameworks, Methodologies, and Tools for Developing Rich Internet Applications. México: IGI Global.

2. Atzeni, P., Mecca, G., \& Merialdo, P. (2008). Design and Maintenance of Data-Intensive Web Sites. International Conference on Extending Database Technology, 436-450.

3. Barranco de Areba, J. (2001). Metodología del análisis estructurado de sistemas. Madrid: COMILLAS.

4. Berzal, F., \& Cortijo, J. F. (2010). Desarrollo Profesional de Aplicaciones Web con ASP.NET. México: iKor Consulting.

5. Caivano, R. M., \& Villoria, L. N. (2009). Aplicaciones web 2.0. México: Eduvim.

6. Campbell, J. (2004). A Comparison Of The Relationship Management Methodology And The Extended Business Rules Diagram Method. Sidney: Edith Cowan University.

7. Canos, J., Letelier, P., \& Panadés, C. (2003). Métodologías Ágiles en el Desarrollo de Software.

8. de Castro, M. V. (Marzo de 2007). Aproximación MDA para el desarrollo orientado a servicios de sistemas de información web: del modelo de negocio al modelo de composición de servicios web. Madrid: Universidad Rey Juan Carlos.

9. Del Valle Rodríguez, A. N. (2008). Metodologías de diseño usadas en ingeniería web, su vinculación con las ntics. Argentina: Universidad Nacional De La Plata .

10. Escalona Cuaresma, M. J. (2011). Metodologías para el desarrollo de sistemas de información global: análisis comparativo y propuesta. España: Universidad de Sevilla.

11. Escalona, M. J. (2002). Ingeniería de Requisitos en Aplicaciones para la Web-Un estudio comparativo. Journal of Web Engineering, 2(3), 193-212.

12. González, M., Abrahão, S., Fons, J., \& Pastor, O. (2002). Evaluando la Calidad de Métodos para el Diseño de Aplicaciones Web. I Simpósio Brasileiro de Qualidade de Software, II(18), 143-156.

13. Isakowitz, T., Stohr, E. A., \& Balasubramanian, P. (1995). RMM: A Methodology for Structured Hypermedia Design. CiteSeerX, 1-24.

14. Kaewkasi, C., \& Rivepiboon, W. (2002). WWM:APractical Methodology forWebApplication Modeling. Proceedings of the 26 th Annual International Computer Software and Applications Conference (COMPSAC'02) , I(1), 603-608.

15. Lange, D. B. (2005). An object-oriented design approach for developing hypermedia information systems. Journal of Organizational Computing and Electronic Commerce, 269293. doi:10.1080/10919399609540280

16. Londoño, O. L., Maldonado, L., \& Calderón, L. (2014). Guías para construir estados del arte. Bogotá: International Corporation of Networks of Knowledge.

17. Loor Montesdeoca, E. D. (Enero de 2012). Implementación de un sitio web con software libre para la publicación de una revista digital de divulgación científico - tecnológica en el área de la informática y ciencias de la computación, inscrita en el movimiento Open Access. Quito: Escuela Politécnica Nacional.

18. Luján Mora, S. (2002). Programación de aplicaciones web: historia, principios básicos y clientes web. España: Club Universitario.

19. Navarro, A., Fernandez, J., \& Morales, J. (2013). Revision de metodologias agiles para el desarrollo de software. Prospectiva, XI(2), 30-39.

20. Ortega Cantero, M., \& Bravo Rodríguez, J. (2001). Sistemas de interacción personacomputador. España: Universidad de Castilla-La Mancha. 
21. Preciado, J., Linaje, M., Sánchez, F., \& Comai, S. (2005). Necessity of methodologies to model Rich Internet Applications. Web Site Evolution, 2005. (WSE 2005). Seventh IEEE International Symposium on, I(1), 7-13.

22. Pressman, R. S. (2002). Ingeniería de Software: Un enfoque prático.

23. Retschitzegger, W., \& Schwinger, W. (2000). Towards Modeling of DataWeb Applications-A Requirement's Perspective. AMCIS 2000 Proceedings, 149-155.

24. Rodríguez, A. N. (2009). Métodologías de Diseño de aplicaciones Web. Argentina: Universidad Nacional de Plata.

25. Romani, C. C. (2004). Planeta web 2.0.

26. Rossi, G., Pastor, Ó., Schwabe, D., \& Olsina, L. (2007). Web Engineering: Modelling and Implementing Web Applications. Londres: Springer Science \& Business Media.

27. Santamarina, Á. (2010). Ingenieria web diriga por modelos.

28. Sevilla Anrrango, E. E. (2015). Aplicación Web para la enseñanza del Lenguaje de señas, Módulo Básico para Niños del segundo año de Educación Básica de la Unidad Educativa de Sordos del Gobierno Provincial de Imbabura. Universidad Técnica del Norte, 1-6.

29. Silva, D. A., \& Mercerat, B. (2001). Construyendo aplicaciones web con una metdología de diseño orientada a objetos. Revista Colombiana de Computación, II(2), 20.

30. Solís Pineda, C. (04 de 07 de 2008). Un Método de Desarrollo de Hipermedia Dirigido por Modelos. Valencia: Universidad Politecnica de Valencia.

31. Standing, C. (2005). The requirements of methodologies for developing web applications. Web Engineering, 261-265.

32. Valencia, A. M. (2014). Modelo de navegación Web para dispositivos móviles "WAE FOR MOBILE DEVICES". Santiago de Cali: Universidad del Valle.

33. van Bommel, P. (2003). Information Modeling for Internet Applications. United States: Idea Group Inc (IGI).

34. Velarde Paredes, G. d., \& Pilco Quitiu, M. I. (2014). Análisis comparativo de metodologías para el desarrollo de la aplicación Web del control de las prácticas pre-profesionales de la EIS de la ESPOCH. . Riobamba: Escuela Superior Politécnica de Chimborazo.

35. Vilariño de Almeida, J. C. (2010). Modelo Para la selección de la metodología de desarrollo web de una aplicación según sus características funcionales. Caracas: Universidad Católica Andrés Bello.

36. Villarroel Acevedo, R., \& Rioseco Reinoso, C. (2011). Una comparación de metodologías para el modelado de aplicaciones web. Revista Cubana de Ciencias Informáticas, V(2), 1-9. 


\section{CONSEJO EDITORIAL}

\begin{tabular}{|ll|}
\hline \multicolumn{2}{|c|}{ COMPONENTES } \\
\hline Director & Víctor Gisbert Soler \\
\hline \multirow{2}{*}{ Editores adjuntos } & $\begin{array}{l}\text { María J. Vilaplana Aparicio } \\
\text { Inés Poveda Pastor } \\
\text { Vicente Sánchis Rico }\end{array}$ \\
\hline \multirow{2}{*}{ Editores asociados } & $\begin{array}{l}\text { David Juárez Varón } \\
\text { F. Javier Cárcel Carrasco }\end{array}$ \\
\hline
\end{tabular}

\section{COMITÉ CIENTÍFICO TÉCNICO}

\begin{tabular}{|l|l|}
\hline ÁREA TEXTIL & $\begin{array}{l}\text { Prof. Dr. Josep Valldeperas Morell } \\
\text { Universidad Politécnica de Cataluña } \\
\text { España }\end{array}$ \\
\hline ÁREA FINANCIERA & $\begin{array}{l}\text { Prof. Dr. Juan Ángel Lafuente Luengo } \\
\text { Universidad Jaume I; Castellón de la Plana } \\
\text { España }\end{array}$ \\
\hline \multirow{2}{*}{ ORGANIZACIÓN DE EMPRESAS Y RRHH } & $\begin{array}{l}\text { Prof. Dr. Francisco Llopis Vañó } \\
\text { Universidad de Alicante } \\
\text { España }\end{array}$ \\
\hline \multirow{2}{*}{ ESTADÍSTICA; INVESTIGACIÓN OPERATIVA } & $\begin{array}{l}\text { Prof. Dra. Elena Pérez Bernabéu } \\
\text { Universidad Politécnica de Valencia } \\
\text { España }\end{array}$ \\
\hline DERECHO & $\begin{array}{l}\text { Prof. Dra. María del Carmen Pastor Sempere } \\
\text { Universidad de Alicante } \\
\text { España }\end{array}$ \\
\hline INGENIERÍA Y TECNOLOGÍA & $\begin{array}{l}\text { Prof. Dr. David Juárez Varón } \\
\text { Universidad Politécnica de Valencia } \\
\text { España }\end{array}$ \\
\hline $\begin{array}{l}\text { TECNOLOGÍA DE LA INFORMACIÓN Y LA } \\
\text { COMUNICACIÓN }\end{array}$ & $\begin{array}{l}\text { Prof. Dr. Manuel Llorca Alcón } \\
\text { Universidad Politécnica de Valencia } \\
\text { España }\end{array}$ \\
\hline
\end{tabular}

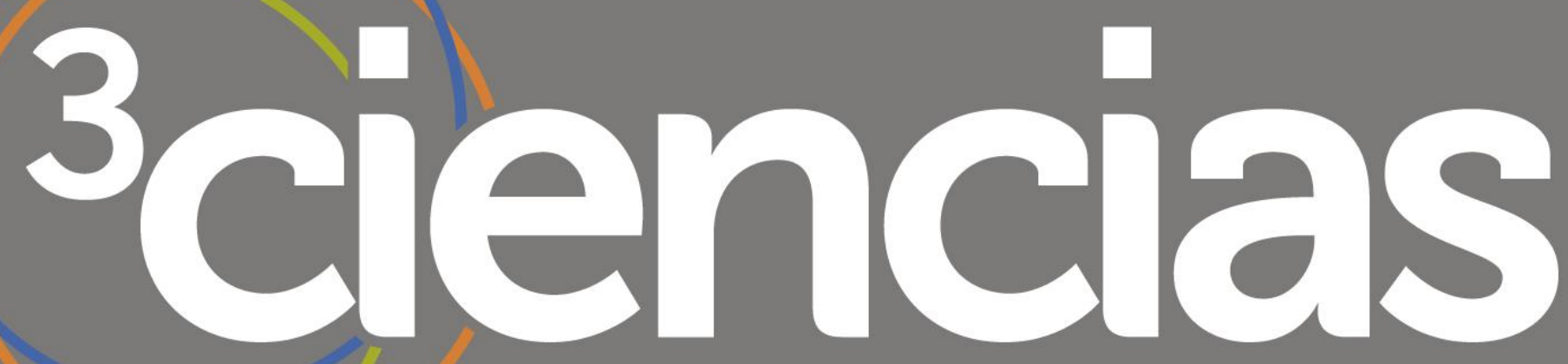




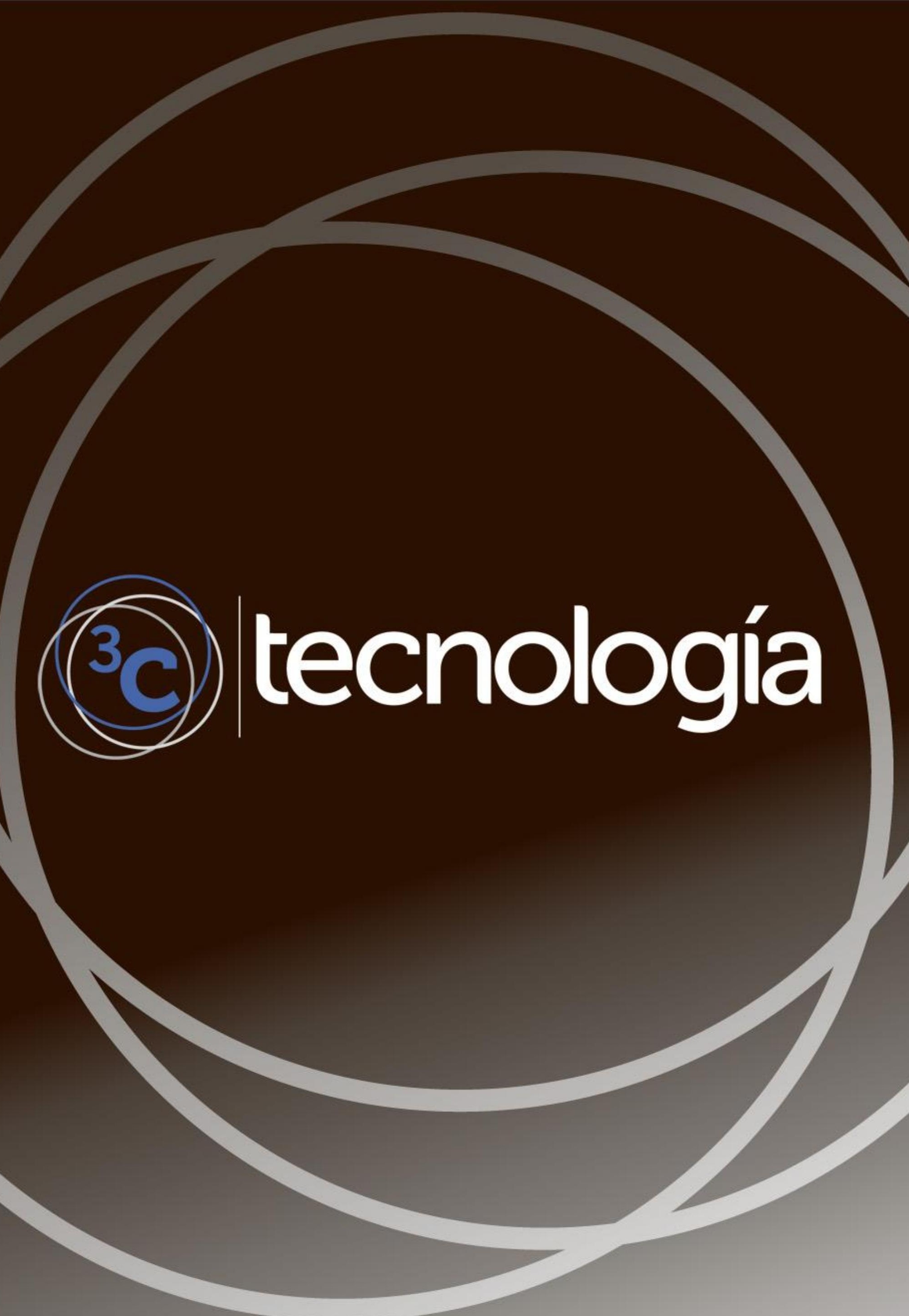

